\title{
CEsifo \\ WORKING

\section{Let their Knowledge Flow: The Effect of Returning Refugees on Export Performance in the Former Yugoslavia}

Dany Bahar, Andreas Hauptmann, Cem Özgüzel, Hillel Rapoport 


\section{Impressum:}

CESifo Working Papers

ISSN 2364-1428 (electronic version)

Publisher and distributor: Munich Society for the Promotion of Economic Research - CESifo $\mathrm{GmbH}$

The international platform of Ludwigs-Maximilians University's Center for Economic Studies and the ifo Institute

Poschingerstr. 5, 81679 Munich, Germany

Telephone +49 (o)89 2180-2740, Telefax +49 (o)89 2180-17845, email office@cesifo.de

Editors: Clemens Fuest, Oliver Falck, Jasmin Gröschl

www.cesifo-group.org/wp

An electronic version of the paper may be downloaded

- from the SSRN website: $\quad$ www.SSRN.com

- from the RePEc website: $\quad$ www.RePEc.org

- from the CESifo website: www.CESifo-group.org/wp 


\title{
Let their Knowledge Flow: The Effect of Returning Refugees on Export Performance in the Former Yugoslavia
}

\begin{abstract}
During the early 1990s Germany received over half a million Yugoslavian refugees fleeing war. By 2000, many of these refugees, who were under temporary protection, had been repatriated. We exploit this historical episode to provide causal evidence on the role that migrants play explaining export performance in global markets after returning to their home country. We find that the elasticity of exports to return migration is between 0.1 to 0.24 in industries where migrants were employed during their stay in Germany. In order to deal with endogeneity we use historic exogenous rules of allocation of asylum seekers across different German states to construct an instrumental variable for the treatment. The results are mostly driven by knowledge-intensive industries, and by workers in occupations intensive in analytical and managerial skills.
\end{abstract}

JEL-Codes: F140, F220, F620, O330, D830.

Keywords: migration, refugees, knowledge diffusion, management, exports, productivity.

Dany Bahar*

The Brookings Institution

USA - Washington DC 20001

db21@post-harvard.edu

Cem Özgüzel

Paris School of Economics

Université Paris 1 Panthéon-Sorbonne

Paris / France

Cem.Ozguzel@psemail.eu
Andreas Hauptmann

German Institute for Employment Research

(IAB) / Nuremberg / Germany

andreas.hauptmann@iab.de

Hillel Rapoport

Paris School of Economics

Université Paris 1 Panthéon-Sorbonne

Paris / France

Hillel.Rapoport@psemail.eu

*corresponding author

Latest Update: November 26, 2018

This paper benefited from helpful comments at various stages from Ran Abramitzky, Abhijit Banerjee, Sam Bazzi, Simone Bertoli, Clement De Chaisemartin, Michael Clemens, Wolfgang Dauth, Esther Duflo, Peter Egger, Albrecht Glitz, Simon Goerlach, Florian Lehmer, Ofer Malamud, Britta Matthes, Anna Maria Mayda, Thierry Mayer, Nathan Nunn, Ariell Reshef, David Yanagizawa-Drott and participants from different conferences and seminars where this paper was presented, such as the 36th BREAD/CEPR/STICERD/TCD Conference on Development Economics, 10th International Conference on Migration and Development, NBER Productivity Lunch, Boston University, ETH Zurich, Paris School of Economics, Tel Aviv University, University of Milan, George Mason University, and American University, among others. All errors are our own. 


\section{Introduction}

What do the emergence of the textile sector in Prussia, of the IT sectors in India and in Israel, of the garment industry in Bangladesh, and of the car-parts industry in Bosnia have in common? One particular aspect stands out: the circumstances of their birth and success can be traced back to a migration episode of some sort, and in all cases, the available evidence - be it anecdotal or empirical - points to migration-driven ideas, knowledge and technology transfers as the driving force behind it. ${ }^{1}$ For the most part, the economic debate on immigration has followed the political agenda and, as a result, has focused on the short-term labor market and fiscal effects of immigration. Perhaps because of this, less attention has been given to the long-run economic opportunities linked to migration. Nevertheless, there is a robust and growing literature documenting many aspects through which migration contributes to long-run growth, such as through innovation (e.g, Kerr, 2008; Choudhury, 2016; Kerr, 2018), through skill-complementarities arising from diversity (e.g., Ortega and Peri, 2014; Alesina et al., 2016; Docquier et al., 2018), and through the reduction of bilateral transaction costs resulting in higher trade (e.g., Gould, 1994; Rauch, 1999; Rauch and Trindade, 2002; Cohen et al., 2017; Parsons and Vézina, 2018) and investment flows (e.g., Kugler and Rapoport, 2007; Buch et al., 2006; Docquier and Lodigiani, 2010; Javorcik et al., 2011; Foley and Kerr, 2013; Burchardi et al., 2017; Kugler et al., 2018) across borders. In this paper we explore a novel and additional angle: the role that migrants play in spreading ideas, technology and knowledge across countries and how is that reflected in long-term macroeconomic outcomes, such as export performance. ${ }^{2}$ In particular, in this paper we

\footnotetext{
${ }^{1}$ For the textile sector in Prussia see Hornung (2014); for the IT sector in India and in Israel see Khanna and Morales (2017) and Rosenberg (2018), respectively; for the garment industry in Bangladesh see Rhee and Belot (1990) and Easterly (2001).

${ }^{2}$ Other studies have looked at the role of foreign workers inducing productivity shifts withinplants and within-firms are Markusen and Trofimenko (2009) and Poole (2013), respectively, focusing on wages of the non-foreign workers as a main outcome in their analysis. In a previous
} 
exploit a natural experiment and document how return migrants -having spent time in a foreign country- explain the subsequent emergence and growth of the same export sectors in which they worked in while living abroad.

The context of our study is the early 1990s, when about 700 thousand citizens of the former Yugoslavia fled to Germany escaping war. Most of the Yugoslavian migrants in the first half of the 1990s were given a Duldung status (German for "toleration"), which was in fact a temporary protection status, or more specifically, a "suspended deportation" permit. After the Dayton peace agreements were signed in 1995, the protection status of temporary migrants was revoked, forcing them to leave the country. By 2000, the majority of these migrants had been repatriated back to their home country or to other territories of the dissolved Yugoslavia. In this paper we exploit the stay of these refugees in Germany and the subsequent massive inflow of return migrants -with experience in the German workforce- into the former Yugoslavian countries, to study sector-specific productivity shifts as reflected by export performance. ${ }^{3}$ To do so we rely on confidential administrative data from the German Institute for Employment Research (IAB), which we use to compute the number of Yugoslavian migrants working in a particular 4-digit industry who had arrived to Germany during the Balkan refugee crisis and returned home after the war. We link this information to standard disaggregated international trade data and employ a difference-in-difference methodology to estimate changes in export values from Yugoslavian countries to the rest of the world caused by return migration of workers who in Germany were employed in those same sectors. In order to address concerns of endogeneity due to, for example, self-selection of workers into certain industries with high potential back home, we instrument the actual

work, we study the link between migration and productivity in a macro-empirical study, using the emergence and growth of export sectors as main outcomes, but without being able to establish causality (Bahar and Rapoport, 2018).

${ }^{3}$ Following Bahar et al. (2014) and Bahar and Rapoport (2018) we use changes in exports for a particular product as a proxy for productivity improvements. 
number of returning workers per industry with their expected number given a spatial dispersal policy that exogenously allocated asylum seekers across the different regions of Germany upon arrival.

We find that, on average, products with a one percent increase in return migration experienced an increase in exports to the rest of the world of 0.1 to 0.24 percent between the pre and post-war periods. In fact, the estimated elasticity increases as more time passes after refugees have returned. We perform a number of tests to rule out some plausible alternative explanations. For instance, all of our specifications control for changes in the stock of foreign investment into Yugoslavia, ruling out the possibility that our results are purely driven by investment patterns. Our results cannot be explained either by an existing previous trend on exports, nor by scale effects or by post-war convergence patterns. They also are not explained by changes in the relative global demand of that industry or by a structural transformation processes in which the industries we see emerging in Yugoslavia are shrinking in Germany. We also rule out the possibility that our results are driven by the downward shift in bilateral transaction costs typically associated with migrants that result in more exports to Germany. Finally, we also perform a number of "placebo" tests to show that our results are particular to Yugoslavia, and not part of a wider pattern that we are unable to identify in our main specification.

We then go one step further and explore mechanisms behind the result. We find evidence consistent with the idea that migrant workers exposed to industries in Germany bring back knowhow, knowledge and technologies back home that translates into higher productivity in those same industries, which in turn is reflected in export performance. This is consistent with a burgeoning literature that looks at foreigners and migrant returnees as drivers of knowledge diffusion (e.g. Kerr, 2008; Markusen and Trofimenko, 2009; Poole, 2013; Choud- 
hury, 2016; Hausmann and Neffke, 2016; Malchow-Møller et al., 2017; Bahar and Rapoport, 2018; Kerr and Kerr, 2018), as the transmission of tacit or noncodifiable knowledge requires human interaction (Arrow, 1969; Polanyi, 1966). To further support this interpretation, we exploit variation in the characteristics of the different industries and occupations of the migrant workers, with the premise that certain types of workers and occupations are more suited for diffusing productivity-inducing knowhow across borders and that such knowledge transfers matter more in certain industries than in others. In particular, we find that our results are driven knowledge-intensive industries, and by workers with high educational attainment, that are in occupations intensive in analytical tasks -as opposed to manual ones- and occupations that can be classified as professional and/or skill-intensive. These characteristics common to managerial roles make our results consistent with the growing literature emphasizing the role of management as a crucial determinant of productivity (e.g., Bloom and Van Reenen, 2007; Bloom et al., 2012, 2013). Our results are consistent, too, with recent work by Bloom et al. (2018) who find that management has a positive effect on the capacity of firms to export, as well as with anecdotical evidence. ${ }^{4}$ Furthermore, we find that our results are stronger when looking at workers who, while abroad, experienced fast wage growth, and were employed by the top paying firms within each industry.

This paper contributes to the literature in international economics and economic development in several ways. First, to the best of our knowledge, it is the first study that uses a natural experiment as a source of identification to causally

\footnotetext{
${ }^{4}$ For example, the story of Suad Bešlić. Bešlić was a soldier in the Bosnian forces during the Balkan wars in the early 1990s who arrived to Germany heavily wounded in 1994. After his long and painful recovery (which allowed him to extend his stay), he followed studies in Germany in car design. After graduation, he started working as a designer in Lenthmer, a leading manufacturer specialized in firefighting and rescue vehicles. Over the years, he became one of the top designers of the company. Upon his return to Bosnia, Beslic set up his company which produces and exports parts used in modern fire trucks. All of his workers go through training both in-house and in Germany. For other examples see Online Appendix Section A.
} 
estimate changes in country-wide and sector-specific export performance, and more broadly, productivity shifts. Thus, our findings suggest that migrants play a role in the development of nations by bringing in knowledge gained in other countries, and are thus a powerful driver for the international diffusion of productivity-enhancing knowledge. ${ }^{5}$ Second, we contribute to the economic development literature by linking the role of migrants in the diversification of countries' export baskets, which is evidenced to correlate with economic stability and growth (e.g., Imbs and Wacziarg, 2003; Hausmann et al., 2006; Hidalgo et al., 2007; Koren and Tenreyro, 2007; Krishna and Levchenko, 2009; Cadot et al., 2011).

The rest of the paper is divided as follows. Section 2 provides a historical summary of the Yugoslavian refugee crisis. Section 3 details the data sources. Section 4 explains the setting and the empirical strategy. Section 5 present the main results and performs a series of robustness tests. Section 6 explores differential results based on types of migrant workers' characteristics and their occupations. Section 7 concludes. ${ }^{6}$

\section{Historical context}

In June 1991 the Socialist Federal Republic of Yugoslavia started to disintegrate following several armed conflicts and ethnic civil wars. Fighting began with the "Ten-Day War" in the summer of 1991 after Slovenia declared its independence. Soon thereafter the conflict spread to Croatia and later on, in 1992, to Bosnia

\footnotetext{
${ }^{5}$ An extreme case of human-driven technological knowledge diffusion is the case of industrial espionage. For example, Glitz and Meyersson (2017) show that industrial espionage was a channel for knowledge diffusion between West and East Germany (the GDR) during the Cold War. The sectoral information provided by informants working across West German industries, helped East Germany increase its sectoral productivity and narrow West-to-East TFP gaps. They further show that the effects were particularly strong if the information originated from sectors that were closest to the West German technological frontier.

${ }^{6}$ The paper is accompanied by an Online Appendix, which is referred to throughout the text.
} 
and Herzegovina. It was only in December of 1995, upon the signing of the Dayton Peace Accord involving President Clinton, that the armed conflict officially ended. ${ }^{7}$

During the armed conflict, around 3.7 million people (roughly 16 percent of the Yugoslavian population) were displaced and fled from their homes, making this episode the largest migration flow in Europe since the end of the Second World War (Radovic, 2005). While many affected by the war became internally displaced, about 800 thousand people resettled outside of the boundaries of the former Yugoslavia, hoping to find refuge in foreign countries (Lederer, 1997). ${ }^{8}$ Among these countries, Germany was one of the most suited options to receive these refugees thanks to the the already significant Yugoslavian community residing there and to Germany's ability and willingness to provide protection to those fleeing the war. ${ }^{9}$ The flow of refugees into Germany responded to the dynamics of the conflict: in the early stages of the war, involving mostly Croatians, about one hundred thousand of them arrived to Germany; later on, when the war spread to Bosnia, acts of systematic violence triggered massive outflows from those areas and Germany hosted some 350,000 Bosnian refugees. Simultaneously, Germany also received another 250,000 Yugoslavians mainly from Serbia and from Kosovo. Thus, overall during the first half of the 1990s, Germany received roughly 700,000 migrants from Yugoslavia, making it by far the largest recipient foreign country (see Lederer (1997) for a detailed account

\footnotetext{
${ }^{7}$ From 1998 to 1999 the region was affected by yet another armed conflict: the Kosovo War. Our focus, however, is mostly on the conflicts that occurred prior to that and which resulted in massive population displacements.

${ }^{8}$ See Angrist and Kugler (2003) for a summary of migration of Yugoslavian nationals to different European destinations (in the context of a study on the impact they had on local labor markets).

${ }^{9}$ Throughout the paper, we refer to all those people escaping the Yugoslavian civil war as "refugees". This is a much broader use than the legal definition of refugee, which implies having being recognized by a receiving country, on a case-by-case basis, as a refugee (which is the same as having an asylum request approved) according to the definitions agreed upon and stated in the Geneva Convention on Refugees of 1951 and the Protocol Relating to the Status of Refugees of 1967 (among other country or region-specific definitions).
} 
of these flows).

Yugoslavian refugees that arrived to Germany were given the option of acquiring a temporary protection status, known as Duldung -a status created by the German authorities at the time ${ }^{10}$ - which can be translated to English as "toleration". The temporary character of the Duldung status did not constitute a permanent residence permit, but rather it was a "suspended deportation" status. In other words, a Duldung holder was allowed to remain in Germany until the Duldung's expiration, after which its holder was obliged to leave the country immediately. While the Duldung duration upon issuance was set to six months, the authorities had the option to renew it for another six months period as long as it was not safe for the refugee to return home (Dimova, 2006). De facto, the Duldung status was renewed for all holders as long as the war was still going on. Duldung holders were allowed to work in Germany shortly following their arrival, and had full mobility rights within the country.

Another less popular option for Yugoslavians fleeing the war and arriving to Germany was to formalize their refugee status, or in other words, to request and then receive formal asylum. According to Article 16(a) of the German Basic Law (Grundgesetz), an individual is eligible to seek asylum if he or she faces individual persecution and is able prove so. If granted asylum, the individual enters a path towards permanent residency (Hailbronner, 2003). Asylum recognition rates, however, were very low for citizens from the former Yugoslavia. ${ }^{11}$ This is because most of them could not prove to the German authorities they were facing individual persecution at home following the standards set by the

\footnotetext{
${ }^{10}$ In the early 1990s, as a response to the legal difficulties faced by the hundred of thousands of refugees seeking protection, -and knowing that most of these people were not eligible for asylum- the German government created the Duldung status. Duldung was granted relatively quickly to all those arriving because of the war in Yugoslavia, making it possible for Germany to process large numbers of arrivals. Compared to other European countries this was a considerable humanitarian gesture on the side of the German government.

${ }^{11}$ Between 1992 and 1995 only 1 percent of Bosnian applicants were granted asylum (Lederer, 1997).
} 
German authorities at the time (Dimova, 2006). Importantly enough, however, asylum seekers whose asylum request was denied were eligible to receive the Duldung status, and most of them did.

\subsection{Labor market conditions and mobility of refugees}

A large number of Yugoslavian refugees managed to integrate into the German labor force upon arrival. ${ }^{12}$ Overall, both Duldung holders and asylum seekers (e.g., those waiting for their asylum application to be approved or denied) had free access to the local labor market shortly after their arrival, with some important differences. Duldung holders were entitled to receive a work permit, and were allowed to work in Germany without any geographical nor sectoral limit. Asylum seekers who arrived prior to $1997^{13}$ were also allowed to work three months after their arrival date and while their application was being considered (if the application was eventually accepted, they naturally kept their right to work). Yet, an important difference between the two statuses concerned the mobility of the workers: Duldung holders could live and work with no withincountry geographical limitation whatsoever. Asylum seekers, on the other hand, were subjected to mandatory residency (Residenzpflicht) while their application was considered. They were obliged to stay within the region in which their application was processed. ${ }^{14}$ The decision on which region would process the application was made by the authorities based on pre-established quotas. This limitation on geographic mobility for asylum seekers is an important part of our

\footnotetext{
${ }^{12}$ The number of employed Yugoslavians rose by 60,000 people in 1992, equivalent to a $15.3 \%$ increase, as compared to 1991 (Deutscher-Bundestag, 1994).

${ }^{13}$ Labor market access conditions for asylum seekers changed a few times. Until 1991, immediate access to labor market was possible. Between 1991-1997, a waiting period of three months was enacted. Modifications in the law in 1997 banned asylum seekers from the labor market. This changed in 2001 when 1-year waiting time was introduced. For more details see Liedtke (2002).

${ }^{14}$ The rules on mobility while the application was being processed were defined by local governments. Some states restricted movement of the asylum seeker to a district, while others allowed free mobility within the state.
} 
identification strategy, which we detail in Section 4.1.1.

\subsection{End of the war and deportation}

The signature of the Dayton Peace Accord in December 1995 officially marked the end of the war that started in 1991 (in particular, by putting an end to the Bosnia war). After that date, the German authorities had no reason to further renew the Duldung status of refugees and indeed enacted the imminent deportation of refugees back to the former Yugoslavia. ${ }^{15}$ In fact, only one day after the signing of the Dayton Accord, Germany formally announced a repatriation plan through which Duldung refugees were gradually forced to leave the country (Dimova, 2006), often simultaneously rolling out assisted repatriation programs (Bosswick, 2000). ${ }^{16}$

Repatriation was planned in two main phases. The first phase targeted single adults and childless couples as well as people with family back in their home country. The second phase targeted the rest of the refugees. By the summer of 1996 letters requesting deportation were sent out, and by the end of 1996 people started getting deported. Repatriation and deportations continued until 2000 , though most of them had happened by 1998. Figures by international organizations and independent academic research suggest that about 75 percent of Yugoslavians civil war refugees returned to their home country or to another former Yugoslavian nation, with an additional 15 percent settling in third countries and only about 10 percent remaining in Germany (UNHCR, 2005; Ruhl

\footnotetext{
${ }^{15}$ For the Croatians, however the deportations started following the signature of the ceasefire agreement known as the Vance Plan in January of 1992. By the end of 1994 almost all of the Croatian refugees had returned (Lederer, 1997).

${ }^{16}$ Voluntary returns were mainly realized as a part of the program of German Government through REAG (Program for Reintegration and Emigration for Claimants of Asylum in Germany) and GARP (Government Program of Assistance to Repatriation) which was implemented in cooperation with the International Organization for Migration (IOM) whose target was to support voluntary return. Both programs were completed in 2001 (Nenadic et al., 2005).
} 
and Lederer, 2001; Lederer, 1997). ${ }^{17}$ The figures from the data source we use, however, suggest that for those who were employed at some point as wage earners in the manufacturing sector, return rates were substantial but not as high for the average refugee, as documented later on.

Refugees found employment across diverse sectors and relied on different channels to secure their jobs. Some were able to utilize their network of friends and family relatives, some relied on local employment agencies and some found work by themselves (e.g., Walker, 2010; Ruben et al., 2009). Ruben et al. (2009) note that those who worked during their time in Germany were also more likely to be employed upon return to the former Yugoslavia, with many finding jobs in industries in which they had worked before the war, others being employed in related sectors and some in totally new activities. There is plenty of anecdotal evidence, however, suggesting that after returning to their home countries refugees subsequently worked (or founded companies) in the very same sector they had worked at in Germany (or other countries such as Sweden or Austria). In Online Appendix Section A we give four examples of anecdotal stories presenting such professional itineraries. As these stories show, refugees benefited from their experiences in Germany in many ways. In addition to acquiring knowledge and skills in new industries, they learned about different production methods, and established networks which they later put into use to create trade links and attract foreign investment when establishing their own

\footnotetext{
${ }^{17}$ These numbers are confirmed when looking at the return rates with respect to the different nationalities and ethnicities involved in the conflict. For example, when it comes to Bosnian refugees, Rühl and Lederer (2001, p.50) describe: "[t/he number of Bosnian war refugees fell from 345,000 to approximately 28,000 by December 2000, more than 260,000 of which went voluntarily to Bosnia-Herzegovina. About 51,000 have migrated on to other countries (to the USA, Canada and Australia). The proportion of forced repatriations is well below 2\% (approximately 5,500 cases)." With respect to Croatian refugees, Lederer (1997, p.310) explains: "During the Croatian-Serbian War (1991 to 1993) numerous Croatians were also admitted to the Federal Republic of Germany. According to information from the Federal Ministry of the Interior of 9 October 1996, most of the original 100,000 Croatian refugees should have returned to their homeland within the framework of the repatriation process that began in 1994. However, the Federal Ministry of the Interior notes that there is no precise information on this from the federal states."
} 
companies. Once back home, most of them continued working in the same sectors where they had been employed during their stay in Germany. Although some found jobs as regular workers, many chose to set up their own companies.

\section{Data and sample}

We link a number of datasets together for our study. First, we use data on exports for the period 1984-2014 which comes from bilateral trade data compiled by Feenstra et al. (2005) with extensions and corrections suggested by Hausmann et al. (2014) (the original source of the trade data is UN Comtrade). In most cases our dependent variable is exports by product from each country to the rest of the world excluding Germany. We do this so that our results are not confounded with an increase in trade driven by lower transaction costs caused by migrant networks (e.g., Rauch and Trindade, 2002; Parsons and Vézina, 2018).

Products are defined using the 4-digit Standard Industry Trade Classification (SITC) revision 2, and include 786 different varieties. ${ }^{18}$ This product classification provides a disaggregation level that enables a meaningful discussion about export diversification patterns. Some examples of products in this level of disaggregation are, for example, "Knitted/Crocheted Fabrics Elastic or Rubberized" (SITC 6553), or "Electrical Measuring, Checking, Analyzing Instruments" (SITC 8748). Following Hausmann et al. (2014), we exclude countries below 1 million citizens and total trade below USD $\$ 1$ billion in 2010. Other variables created using trade data are explained as they are introduced into the analysis.

The data on migrant workers in Germany are based on records from the German social security system and comprise all persons employed subject to social security contributions, with the exception of self-employed and civil ser-

\footnotetext{
${ }^{18}$ The words product, good, sector and industry interchangeably refer to the same notion throughout the paper.
} 
vants. ${ }^{19}$ The records indicate the industry where the workers are employed. Our sample is restricted to $40 \%$ random draws of foreign nationals observed on June 30 of each year from 1975 to 2014 augmented by the employment history of each individual for our sampling period. This amounts to about 2.4 million workers per year on average, which is a large enough amount for the random draws to form a representative sample. ${ }^{20}$ Moreover, since we can observe the full employment history, we can determine whether an individual was employed before or after any given year in Germany, which we exploit to construct our treatment. Beyond individual information such as age, nationality, and educational attainment, the data include detailed occupational codes categorized in more than 300 different occupations. ${ }^{21}$

We also collected information on direct investments of German firms in former Yugoslavia sent to us by the German Central Bank (Deutsche Bundesbank) upon request. We use these data to compute German FDI stocks in former Yugoslavian countries at 2-digit SITC level between the years 1990-2010, to serve as a control. Second, in order to construct an instrument to deal with endogeneity issues, we used data on asylum applications in Germany, which comes from the German Federal Office for Migration and Refugees (Bundesamt für Migration und Flüchtlinge, BAMF) sent to us upon request. We also use inflow quotas mandated by the government that define the regional distribution of asylum seekers (Königsteiner Schlüssel). These quotas are determined yearly

\footnotetext{
${ }^{19}$ These records have been assembled by the Institute of Employment Research (IAB) into the Employment History $(\mathrm{BeH})$ data file (IAB, 2015). The data or variants of it have been widely used to study a variety of labor market aspects (e.g., Card et al., 2013; Dustmann and Glitz, 2015; Dustmann et al., 2017).

${ }^{20}$ For privacy issues, the sample utilized in this paper is an anonymized version of the original database. In order to comply with data privacy rules, sensitive values -industry-year observations with less than 20 workers- have been replaced with different moments of the distribution of the number of migrant workers from the same region in that same industry and year. The number of cells affected depends of course on the level of disaggregation of worker characteristics such as education, occupation, skill etc. More details on this procedure can be provided upon request. The results presented herein, however, are robust to using the non-anonymized version instead.

${ }^{21}$ See more details on this dataset in Online Appendix Section B.
} 
by the Joint Science Conference (Gemeinsame Wissenschaftskonferenz, GWK). The yearly data between 1990 and 2016 have been sent to us by the GWK upon request.

With these datasets we are able to match the exports of Yugoslavia to the rest of the world with the number of Yugoslavian workers in Germany working in the same product category. ${ }^{22}$

\section{Natural Experiment: Yugoslavian Refugees}

As pointed out in Section 2, around 700,000 migrants from the former Yugoslavia arrived to Germany in the first half of the 1990s. Figure (1) summarizes these numbers. In 1980 there were already about 600,000 Yugoslavians residing in Germany. This stock remained steady until the late 1980s when the net inflow of Yugoslavian migrants started to grow at a rate of 25,000 per year, until the year 1990. This rate skyrocketed to $168,000,250,000$ and 165,000 during 1991 , 1992 and 1993, respectively. The sharp increase in the net inflow of migrants was fueled by refugees escaping war. We also see an sharp increase in asylum requests from Yugoslavian citizens during the same years.

[Figure 1 about here.]

The number of Yugoslavians in Germany sharply declines starting in 1996, after the Dayton treaty was signed. By 2000 close to 350 thousand Yugoslavians had left the country. While some of them left to a third country, it has been

\footnotetext{
${ }^{22}$ Using our employment sample we compute the number of workers in Germany by nationality, product and year for all tradable industries. We use the nationality of the worker based on the passport recorded at his or her first appearance in the database. We rely on the work by Dauth et al. (2014) to match German 3-digit WZ industry codes to 4-digit SITC products. Our results are robust to cluster our standard errors using the German 3-digit WZ industry codes. Reconstructing our dependent variable using those industry codes, however, significantly decreases the number of observations, thus reducing the statistical power in our exercise. Further details on the employment sample, variable descriptions and auxiliary data are provided in Online Appendix Section B.
} 
estimated that the majority of them returned to countries of the (by then) former Yugoslavia (UNHCR, 2005; Ruhl and Lederer, 2001; Lederer, 1997).

The natural experiment, however, uses data on Yugoslavian workers that joined the German labor force (in each tradable sector) between 1991 and 1995 and had dropped out of it by year 2000. These parameters allow us to identify, with high certainty, those Yugoslavians of working age who were Duldung holders and had been deported by year $2000 .^{23}$ In our data we see patterns consistent with the historical narrative described so far: both the inflow of Yugoslavian workers into the tradable sector labor force between the years 1991 and 1995 and their outflow by year 2000 is highly unusual as compared to foreign workers from other nationalities, as Figure 3 shows. The figure graphs the yearly share of Yugoslavian workers entering and exiting the labor force of Germany's tradable sector. The share is always computed using the total number of foreign workers (other than Yugoslavians) entering and exiting the labor force in those same years at the denominator. It becomes clear from looking at the figure that Yugoslavians entered the labor force in much higher proportion during the first half of the 1990s, as compared to the same proportion in years before 1990 and after 2000. We also see that Yugoslavian workers exited the German labor force in higher proportion during the later half of the 1990s, consistently with the historical events.

[Figure 2 about here.]

\footnotetext{
${ }^{23}$ Our data also show that about half of these Yugoslavian workers who arrived between 1991 and 1995 are still active in the German labor force by 2014. Presumably, these "stayers" were not Duldung holders (and therefore, were not subject to deportation) or, alternatively, they were Duldung holders but were allowed to stay for humanitarian reasons. Again, as we noted above, the overall statistics suggest that over 75 percent of Duldung holders returned to the newly established countries of the former Yugoslavia. These are the people our treatment aims to capture: our treatment counts those workers who arrive between 1991 and 1995 and drop out of the labor force by the year 2000, by industry. This means that we are in fact counting all those workers in each manufacturing industry that were, most likely, Duldung holders. The fact that some other Yugoslavians who stayed beyond 2000 for whatever reason is not a threat to our identification strategy, as long as these cases were not more or less frequent in some industries than in others. We expand on this in Section 4.1.2.
} 


\subsection{Empirical strategy}

Our objective is to study changes in product-level Yugoslavian exports to the rest of the world given different levels of return migration of Yugoslavian refugees who worked in Germany in the corresponding industry. We do this through a difference-in-differences estimation. Given that the German data do not allow us to distinguish which is the region of origin of the refugees within Yugoslavia (we only see that they entered the labor force with a Yugoslavian passport), our unit of analysis is the combined exports by product of all countries of the former Yugoslavia. That is, the trade data includes export by product of $\mathrm{Yu}-$ goslavia as a nation until 1991, and we complement this by simply adding up exports by product of all countries that formed Yugoslavia post 1992: Bosnia and Herzegovina, Croatia, FYR of Macedonia, Montenegro, Serbia and Slovenia. ${ }^{24}$ We end up having a balanced-panel of exports by product for the former Yugoslavia from 1984 until 2014, which is the main input required to construct our dependent variable.

The main independent variable -the treatment- is the number of Yugoslavian refugees by sector who were (i) newly arrived into the German labor force between 1991 and 1995, (ii) had not been recorded in our data in 1990 or before, and (iii) had not been recorded in our data in 2000 or after. ${ }^{25}$ We cannot distinguish whether these workers with Yugoslavian passport that left the labor force indeed returned back to the former Yugoslavia. Thus, in our calculation of return migration we are including workers who, for instance, stayed in Germany working in the informal sector or went to a third country. Yet, all these

\footnotetext{
${ }^{24}$ Very few people left Slovenia while almost none left the FYR of Macedonia as both countries obtained their independence with limited or no armed conflict. While Slovenia was the republic with highest GDP per capita and a much more diversified export basket than the rest of the countries to begin with, Macedonia was one of the poorest republics of the former Yugoslavia with little exports. Our results are robust to excluding both Slovenia and Macedonia from the exports data (see Online Appendix Section I).

${ }^{25}$ Finding no entry for a person in our data implies that this person was not employed in any job, industry, or occupation subject to social security contributions on June 30 of any given year.
} 
possibilities work against us in our estimation, implying that our estimates are, to some extent, understating the effect of return migration. Moreover, the historical context summarized above suggests that about 75 percent of those who were repatriated upon the expiration of their Duldung status returned to the former Yugoslavia. ${ }^{26}$

Figure 3 describes the treatment variable. It plots the number of Yugoslavian workers that entered the German workforce between the years 1991 and 1995 and that had left the labor force by 2000 (in the horizontal axis), by 4-digit SITC code, against the ones (the vertical axis simply sorts the SITC codes from low to high). The treatment, as can be seen, is quite heterogenous across industries. Some of the codes that stand out as having a large amount of workers returnees are 8219 (Furniture parts), 6911 (iron and steel structures), 5989 (chemical products), and 2482 (worked wood of coniferous).

[Figure 3 about here.]

Before we turn to the econometrics, we look at whether products associated with a larger reduction of the number of Yugoslavian workers in Germany experienced more exports growth, only using the raw data. Figure 4 visualizes the total value of exports of products linked to different levels of treatment, year after year. The figure shows that up until 1995 (the year where our "treatment" begins) products in the four different categories had parallel trends. However, after 1995, the third and fourth quartiles in terms of treatment diverge quite significantly from the first two quartiles. This visualization not only provides some descriptive evidence of the results holding with raw data, but also shows that the parallel trends assumption required for the difference-in-differences method-

\footnotetext{
${ }^{26}$ About $10 \%$ of the Yugoslavian workers we see entering the labor force between 1991 and 1995 were 18 years or younger at the year of entry. $75 \%$ of them, in contrast, were 20 or older and $50 \%$ were 25 or older. This rules out the possibility that the entry of Yugoslavian into the labor force is mostly driven by locals with Yugoslavian passports joining the labor force at a young age, rather than refugees arriving to Germany.
} 
ology is a reasonable one.

[Figure 4 about here.]

Moreover, a descriptive exercise visualized in Figure 5, comparing the exports of Yugoslavia and of Germany across time shows that their export baskets became more similar across the years during the period of study, as measured by the export similarity index by Bahar et al. (2014).

[Figure 5 about here.]

So far, of course, we have only described the data and some interesting correlations. Our goal, however, is to explore the relationship in detail with the goal of estimating a causal effect. To do so, we turn to explore this result using regression analysis and estimate the following difference-in-differences specification:

$$
\text { exports }_{p, t}=\beta^{D I D} \text { treat }_{p} \times \text { after }_{t}+\beta^{f d i} f d i_{p, t}+\eta_{p}+\alpha_{t}+\varepsilon_{p, t}
$$

Subscripts $p$ and $t$ represent product and year, respectively. The left-hand side variable $\left(\right.$ exports $\left._{p, t}\right)$ measures the value of exports from the former Yugoslavia to the rest of the world excluding Germany for product $p$ during year $t$.

We start by estimating this regression using two periods: "before", which corresponds to 1990, just before the war started, and "after", which corresponds to 2005, five years after most Yugoslavian refugees had returned. To avoid our results being driven by noise in the dependent variable for a particular year, we use average exports per product between 1988 and 1990 for the "before" period, and the average between 2005 to 2007 for the "after" period. ${ }^{27}$

\footnotetext{
${ }^{27}$ Our results, however, are robust to using only data for the actual years for which the "before" and "after" periods are defined: 1990 and 2005.
} 
The variable of interest treat $_{p}$ is the number of workers that joined the German labor force for product $p$ between 1991 and 1995 and dropped out of that same labor force by 2000, according to our definition earlier. We rescale the variable treat $_{p}$ using the inverse hyperbolic sine. The inverse hyperbolic sine is defined at zero and behaves similarly to a log-transformation. The interpretation of regression estimators in the form of the inverse hyperbolic sine is similar to the interpretation of a log-transformed variable (see MacKinnon and Magee, 1990). ${ }^{28}$ after $_{t}$ is a dummy variable which equals 1 for the observations corresponding to the "after" period.

Given that in the actual estimations both the dependent and the main independent variables are in a logarithmic-type form (details on this below), $\beta^{D I D}$ represents the elasticity of exports to returnee workers. That is, industries with a 1 percent larger pool of returnee workers experience an increase in export growth which is $\beta_{D I D}$ percent larger between the "before" and "after" periods compared to industries with no returnee workers. Bear in mind that since this is a difference-in-difference setting, our results reflect relative differences in levels across industries based on their exposure to the treatment.

As migrants could also reduce transaction costs and facilitate foreign direct investment (e.g., Javorcik et al., 2011; Kugler and Rapoport, 2007), we control for the stock of FDI from Germany (in million $€$ ) to the combined Yugoslavian countries in the specification. ${ }^{29}$ We do so in order to rule out the possibility that the increase in exports is driven by the inflow of FDI in the same industries the migrants worked at while in Germany. Why would we want to rule out this possibility? Actually, we don't necessarily want to rule it out, as FDI inflows are one potential mechanism through which migrants can induce a productivity shift

\footnotetext{
${ }^{28}$ The inverse hyperbolic sine $($ asinh $)$ is defined as $\log \left(y_{i}+\sqrt{\left(y_{i}^{2}+1\right)}\right)$. Except for small values of $y, \operatorname{asinh}\left(y_{i}\right)=\log (2)+\log \left(y_{i}\right)$.

${ }^{29}$ Our results are unchanged if we include instead a broader FDI figure from all countries (in million $€$ ), not only from Germany. See Online Appendix E for these results.
} 
in their industries back home. However, by including this control we simply rule out FDI as mechanism, and instead focus on the idea that migrants, regardless of their ability to bring in investment, can explain changes in the composition of the export basket of their home countries. ${ }^{30}$

As for the other terms: $\eta_{p}$ represents product fixed effects while $\alpha_{t}$ represents year fixed effects (which in the main estimation is equivalent to one dummy variable for the year 2005). The two fixed effects are perfectly multi collinear with the terms treat $_{p}$ and after $_{t}$ if added separately. $\varepsilon_{p, t}$ represents the error term. Our estimations cluster standard errors at the product level (Besley and Burgess, 2004; Bertrand et al., 2004).

Using this specification, claiming that our results are unbiased imply that the industry-specific entry to and exit from the German labor force of Yugoslavian workers are exogenous with respect to future dynamics of Yugoslavian exports. Can we say this is indeed the case?

Our identification relies on the exogeneity of arrival and exit of refugees into the German labor force with regards to export trends back in Yugoslavia at the industry level. There are two main endogeneity concerns in our specification. First, the possibility that refugees self-selected into particular tradable sectors with growth potential in Yugoslavia upon their arrival, based on private knowledge. Second, that the exit of refugees from the German labor force by year 2000 -even if it was enforced by across-the-board repatriation efforts by the German authorities- happened more or less frequently in particular industries in a way that is correlated with export dynamics in Yugoslavia. We deal with each of these concerns next.

\footnotetext{
${ }^{30}$ There is also the possibility that FDI is a "bad control", given that the expansion of the labor force with skills relevant to a particular industry, which is what our treatment measures, can also attract FDI into those same industries. However, in order to be conservative, we decide to use FDI as a control in our main specification, particularly because the exclusion of such control doesn't substantially change the resulting estimation of $\beta^{D I D}$.
} 


\subsubsection{Self-selection into industries upon arrival}

In order to deal with the possibility that migrants self-selected into particular industries in a way that correlates with future Yugoslavian exports, we construct an instrumental variable that computes expected worker stocks per industry by exploiting a spatial dispersal policy applied to Yugoslavian asylum seekers

While asylum requests were being processed, asylum seekers were sent to different parts of the country following the Königstein State Convention (Königsteiner Staatsabkommen) which was signed in 1949 by all German federal states and defined cost-sharing rules between states in jointly financed projects. Although initially this convention concerned financing of joint science projects, the system was later adopted -among other things- for the allocation of asylum seekers within States in Germany. The dispersal of asylum seekers is regulated at the federal level by the Asylum Procedure Act (Asylverfahrensgesetz), where each state is allocated a certain number of asylum seekers according to its "Königstein" quota (Königsteiner Schlüssel). The quota is based on the weighted sum of population $(1 / 3)$ and tax revenues $(2 / 3)$, and it is re-calculated annually. In the absence of substantial regional shocks, this quota does not vary much over time.

In particular, upon the arrival of an asylum seeker into the German territory, he or she is absorbed by a reception center in the Federal State of arrival if there is any remaining capacity to receive more people according to the quota described above, or alternatively, the person is allocated to the reception center in a Federal State with the most vacancies according to the quota. ${ }^{31}$ Our identification strategy is based upon the premise that this allocation was exogenous. ${ }^{32}$

\footnotetext{
${ }^{31}$ If more than one reception center fits these criteria, the geographically nearest one to the entrance location of the asylum seeker is appointed responsible. After the first period in reception facilities, which can last up to a maximum of six months, the asylum seeker is placed in a district within the state of first allocation. The residence obligation ends as soon as the Federal Office grants asylum status. The average duration of the application procedure was between six months and two years.

${ }^{32}$ Concerns might remain given that the geographic allocation of refugees is exogenous
} 
An illustration of the quota system can be seen in Figure 6, which shows the share of asylum seekers that each of the sixteen German states should have received using the quota system in year 1995. For example, Nordrhein-Westfalen is the state that should have received most of the asylum seekers in 1995, followed by Baden-Württemberg and Bayern, while states such as Bremen or Saarland received a very small share.

[Figure 6 about here.]

Thus, to construct the instrument we combine three pieces of data: (1) the yearly inflow of asylum seekers from Yugoslavia to Germany between 1991 to 1995, (2) the asylum quotas for each of the sixteen German states per year, and (3) the relative size of each industry in each state based on the baseline year of 1990 using employment of German citizens. ${ }^{33}$ The resulting variable estimates the number of Yugoslavian asylum seeking workers in Germany per industry. The following equation reflects the calculation:

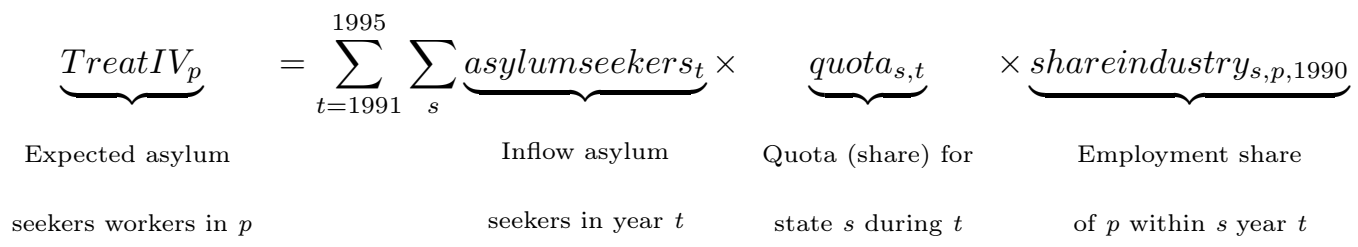

The instrumental variable is a feasible one under two conditions: first, if it correlates with the treatment, and second, if the exclusion restriction holds. In terms of the first condition, we expect a strong correlation between the treatment

conditional on the reception center at the port of arrival being at full capacity. In Online Appendix Section H1 we show that our results are robust when using an instrument that excludes the most common ports of arrivals in the calculation.

${ }^{33}$ We use only German employees to compute industry shares per state, and not foreigners, so that these shares won't reflect relative sizes in Yugoslavia based on the distribution of foreign workers in Germany. Furthermore, we use shares only for 1990 in order to avoid the instrument being affected by changes in relative sizes of industries which might also correlate with relative changes in the same industries in other countries. 
and the instrumental variable: as explained above, the exogenous geographic allocation for asylum seekers - even if they were a small share of all refugees (as seen in Figure 1) - is presumably a strong determinant of the final destination of all the Yugoslavian refugees (regardless of their actual status) within the country during that period. The reasoning is the following. First, the geographic allocation of asylum seekers is relevant for all refugees who request for asylum, even if the asylum turns out not to be approved. That is, if many of the refugees that eventually got a Duldung status originally requested for asylum, they also had to comply with this exogenous geographic allocation while their asylum status was being reviewed by the authorities. Second, the exogenous allocation of the share of Yugoslavians who actually requested asylum might as well be explanatory of the location choice of those who received Duldung even if they did not request for asylum to begin with. In fact, Figure 7 shows that such is the case, as it plots $\operatorname{Treat} I V_{p}$ in the horizontal axis against: (i) the actual number of Yugoslavian workers (regardless of the status with which they entered the country) in the labor force by industry in the left panel; and, (ii) the number of Yugoslavian workers that had left the labor force between 1995 and 2000 (our treatment) in the right panel. Each observation in the figure is a product, symbolized by its 4-digit SITC code. It can be seen in the figure that both the stock of actual Yugoslavian workers and the number of workers who left the labor force between 1995 and 2000 in each industry are strongly correlated with stocks that are predicted through the spatial dispersal policy.

[Figure 7 about here.]

Our main assumption regarding the second condition -the exclusion restriction- is that both the quota of asylum seekers per state and year defined by the German federal authorities, and the relative size of the German workforce of each industry in each state at the baseline year of 1990 are not correlated with 
future product-specific export trends of former Yugoslavian countries to the rest of the world. In fact, given that the quota per state is based on the state share of population and of tax revenues within Germany, and nothing else, we have no reason to think that our assumption is not a valid.

\subsubsection{Exogeneity of exit with respect to industries}

The other remaining concern is whether the exit of Yugoslavian Duldung holders from the German labor force was exogenous to the industry they were working in. For example, if workers left the labor force more massively in some industries more than others, in a way that is correlated to the future export potential in Yugoslavia, then this could invalidate our identification strategy.

This was not the case, as shown in Figure 8. The figure compares the proportion of Yugoslavians who arrived between 1991 and 1995 working in each 4-digit SITC product on the vertical axis, against the proportion of Yugoslavian who returned by 2000 (based on the definition of the treatment) working in each product on the horizontal axis. The dashed line represents the 45 degree line. If exit from the labor force by Yugoslavians was completely random, we would see a perfect alignment of those dots along the 45 degree line: the share of workers arriving into each industry must be the same as the share of workers leaving that industry. Barring some exceptions, the graph does approximate this scenario. In fact, the correlation between both shares is close to 0.9 .

Most dots, each one representing a 4-digit SITC code, are quite consistently aligned along the 45 degree line. Take the industry code 6991, for example, which represents the sector "Locksmith hardware". About 17\% of all Yugoslavian workers who arrived between 1991 and 1995 worked in that industry, according to the horizontal axis, and about $15 \%$ of those workers who left by the year 2000 dropped from that product's labor force. All in all, the evidence suggests that the exit from the labor force was exogenous across industries. Figure 
8 shows that there are a number of outliers (i.e., observations far from the 45 degree line) but these do not affect our results (see Online Appendix F).

[Figure 8 about here.]

\subsection{Summary statistics}

Table 1 presents the summary statistics. Our sample includes 786 products, and since we use two points in time for the differences-in-differences estimation, the initial empirical analysis will use up to 1572 observations. The table presents summary statistics for the main variables in the regression. The first four lines of the table present data for the average export value from former Yugoslavian countries to the rest of the world in years 1990 and 2005, all in million US dollars (note that we don't adjust these values for inflation, which is accounted for by our year fixed-effect). These two points in time are the ones used in the main specification, which correspond to years before and after the war. However, we also present results for a multi-period analysis as well that uses export data for all the years in between.

Given the fact that the left hand side is calculated in US dollars, we are required to use a monotonic transformation to deal with the fat-tailed distribution. All of our results are presented using three different transformations: $\log \left(\operatorname{export}_{p, t}\right), \log \left(\operatorname{export}_{p, t}+1\right)$ and $\operatorname{asinh}\left(\operatorname{export}_{p, t}\right)$. The first one is undefined for values where export $s_{p, t}=0$, and therefore, when using $\log \left(\right.$ export $\left._{p, t}\right)$ as the dependent variable the sample size is reduced. The two other transformations deal with the occasions where export $_{p, t}=0$ by either adding USD $\$ 1$ before the transformation or by computing instead the inverse hyperbolic sine $($ asinh $)$, respectively. ${ }^{34}$

\footnotetext{
${ }^{34}$ Since exports are aggregated across all destinations, the number of "zeroes" in the data is not as large as when using bilateral trade data. We explore this in detail in Online Appendix Section C.
} 
[Table 1 about here.]

Table 1 also summarizes the treatment. The third row in the Table presents statistics for the number of sampled workers with Yugoslavian passport that joined the German labor force at some point between 1991 and 1995. The average industry had 74 Yugoslavian workers that, arguably, arrived to Germany because of the war and joined the labor force. The next row is a subset of that group, and corresponds to our main treatment variable: the number of workers with Yugoslavian passport which had joined the German labor force sometime between 1991 and 1995 and had dropped from it by the year 2000. The value for this variable, averaged across all products, is 21.6. Our treatment exploits variation across industries, which we see in the table varies from 0 to $778 .{ }^{35}$ All in all, our treatment is based on roughly 20,000 Yugoslavian workers across all industries, representative of the actual distribution. ${ }^{36}$

Note that as mentioned above, our sample of working-age Yugoslavians employed in the tradable industry, shows that the rate of return was roughly 30 percent, substantially lower than the anecdotical 75 percent figure, which applies to the Yugoslavian refugee population as a whole (UNHCR, 2005; Ruhl and Lederer, 2001; Lederer, 1997). This discrepancy, however, poses no problem for our identification strategy as long as the rate of return is not biased towards certain industries, which we discussed above in Section 4.1.2.

Also note that despite presenting the summary statistics in nominal values, unless otherwise stated, all right hand side variables are rescaled using the inverse hyperbolic sine for estimation purposes.

\footnotetext{
${ }^{35}$ Non-integer number of workers in an industry is a result of the use of weights based on industry code concordances during the data construction stage. For more information see Online Appendix Section B.

${ }^{36} 210,000$ Yugoslavian workers appear the first time in our data between 1991 and 1995 . This seems very reasonable given the assumed that, if the total flow was of 700,000 people, it is reasonable to assume that half of that $-350,000$ - were of working age. Of those 210,000 , $35 \%$ (or 75,000 workers) had exited the sample before the year 2000. Of those roughly 75,000, only $22 \%$ (around 17,000 workers) had a job in tradable industries during the 1990s.
} 


\section{$5 \quad$ Main Results}

Results for specification (1) are presented in Table 2. For the "before" period it uses exports data averaged over 1988 to 1990, and for the "after" period it uses exports data averaged over 2005 to 2007. The treatment is defined as the number of workers of Yugoslavian origin that left the German labor force between 1995 and 2000, by product. ${ }^{37}$ The estimation includes product fixed effects, such that the results use only within-product variation, and year fixed effects, which in this case is equivalent to a dummy variable for the year 2005. The first three columns report results using an OLS estimation, while the last three columns report results using a 2SLS estimation, making use of the instrumental variable described in Section 4.1. The table reports results using $\log \left(\right.$ export $\left._{p, t}\right), \log \left(\right.$ exports $\left._{p, t}+1\right)$ and $\operatorname{asinh}\left(\right.$ export $\left._{p, t}\right)$ as dependent variables. Since the regressor treat $t_{p}$ is rescaled using the inverse hyperbolic sine transformation -which behaves similarly to a log transformation-we interpret $\beta^{D I D}$ as an elasticity. ${ }^{38}$

[Table 2 about here.]

In the first three columns, we find all estimates of $\beta^{D I D}$ to be positive and statistically different from zero for all different monotonic transformations of

\footnotetext{
${ }^{37}$ Online Appendix Table G1 replicates the results using different treatments: return migration between 1995 and 2005 and the stock of migrants in 1995. The results are robust to using these different treatments.

${ }^{38}$ The continuous character of our treatment implies, arguably, that our estimator can be characterized as a fuzzy differences-in-differences one (De Chaisemartin and D'Haultfoeuille, 2018). In our setting, the "control" group is stable over time (e.g., there are no control group "switchers"), which implies our estimation only relies on the common trends assumption. In other words, our setting allows us not to require the "stable treatment over time", nor the "homogenous treatment effect between groups" assumptions (assumptions 5 and 6 in De Chaisemartin and D'Haultfoeuille (2018)). While relaxing assumption 5 in our setting is straightforward, doing the same with assumption 6 might not be. Thus, as a robustness test, we compute the Wald DID estimator following De Chaisemartin and D'Haultfoeuille (2018), defining the treated units those above the 25th percentile in terms of the treatment. We find our results reassuring: the Wald DID point estimates are between 0.15 to 0.28 , depending on the monotonic transformation used, all statistically significant at the $10 \%$ level. The point estimates are slightly larger than the OLS ones reported in Table 2, but they all fall within the statistical margin of error of the estimators. We thank Clement De Chaisemartin for his guidance on exercise.
} 
the dependent variable. The standard errors are clustered at the product level, which is the level of disaggregation of the treatment.

Column 1 of Table 2 presents the estimates when using the natural logarithmic transformation for the dependent variable. The point estimate in the first column is around half the size of those in the other two columns. This is not surprising as the first column excludes zeros and therefore excludes instances in which products are more likely to grow faster if they have a non-zero value in the second period. ${ }^{39}$ Yet, this difference says something more: the fact that the point estimates in columns 2 and 3 are positive and significant -which include instances where a product was inexistent in the export basket of Yugoslavia by 1995-, and are larger than the point estimate in column 1, implies that the effect of return migration on comparative advantage is valid at the extensive margin (e.g., opening a new line of exports) as well as at the intensive margin (e.g., growth of already existing export lines), along the lines of the work by Bahar and Rapoport (2018). In either case, the results show that the elasticity of exports to return workers ranges from 0.1 to 0.15 , depending on the transformation of the left hand side variable used (and thus whether zeros are included or not).

Columns 4, 5 and 6 present the analogous 2SLS estimates. For those columns we also report the Kleibergen-Paap F statistics which measures the strength of the first stage. The Kleibergen-Paap F statistics is the right measure to look at when standard errors are not assumed to be i.i.d., as in our case. The high magnitude of the F statistics in all specifications imply that we can reject the possibility of weak instrumentation. The elasticities estimated through 2SLS are positive, statistically significant and qualitatively similar to the OLS results but the point estimates are larger in magnitude. Yet, the standard errors are

\footnotetext{
${ }^{39}$ In fact, Table G2 in the Online Appendix re-estimates columns (2), (3), (5) and (6) of Table 2 excluding observations with zero exports. In that case, the estimates are exactly the same as in columns (1) and (4) of Table 2.
} 
also larger, so that we cannot reject the hypothesis that the OLS and the 2SLS estimates are equal. Given the setting of the natural experiment, and the use of an instrumental variable, we interpret these results as causal. Thus, based on the 2SLS results, we find that Yugoslavian industries that received 10 percent more return migrants from Germany (that worked in those same industries), exhibited higher exports by 1.2 to 2.4 percent in 2005 as compared to 1990 .

Clearly, the point estimates resulting from the 2SLS estimation are larger than the OLS ones. This, naturally, requires an explanation. On the one hand, if self-selection is really happening in the OLS results, then we would have expected 2SLS estimates to be smaller, not larger. On the other hand, the 2SLS estimates represent the Local Average Treatment Effect (LATE) which relies on the variation of the asylum seekers allocation across German states. Thus, our 2SLS estimates use the variation of the treatment (i.e., return migration) that is biased towards Western Germany (due to the larger tax revenues from those states), where the most productive firms are located. Hence, a possible interpretation of these larger point estimates is that those migrants exposed to firms in more productive locations had more knowledge to gain - and therefore to transfer - upon their return. Under that scenario, it makes sense that our 2SLS estimates are larger, although as pointed out above, we cannot reject the hypothesis that our OLS and 2SLS point-estimates are the same.

Note that our estimations use as the dependent variable exports from former Yugoslavian countries to the rest of the world, excluding Germany. In that sense, we argue that our results are not explained by possible reductions of fixed costs of exporting to Germany caused by migrant networks. ${ }^{40}$ Also, in all specifications we control for the stock of German FDI in former Yugoslavian countries. By controlling for such FDI, we rule out the possibility that the

\footnotetext{
${ }^{40}$ Online Appendix Section D presents results for the main specification using as dependent variable exports to the rest of the world including Germany. As expected, the point estimates are (between 2 to 10 percent) larger.
} 
effect is driven by the ability of migrants to attract FDI into the same sectors they worked in during their stay in Germany. Yet, we find that variable to be negatively correlated with exports, which is puzzling. However, since the data for FDI stocks was originally at the 2-digit level (see Section 3), there is little variation left in it after the introduction of product fixed effects. ${ }^{41}$ Yet, it is worth noting that controlling for FDI aims to rule out a particular channel through which migrants can reshape the export basket of countries. However, even if part of the effect we are documenting is driven by migrants being able to attract capital (or invest their own) resulting in the emergence and growth of export industries, this also reflects the existence of inputs complementary to capital (e.g., the workers themselves and their skills) in the economy.

A plausible concern is whether our results are driven by other spurious correlations, such as post-war convergence effects, scale effects, global demand increases or structural transformation trends across countries, among others. In the following sections we perform a number of tests to rule out these possibilities. For instance, when it comes to post-war convergence, we look at pre-trends in the following subsection. In addition, as noticed above, our results are in part driven by the emergence of new export sectors, and not only by the growth of already existing ones. Concerns that our results are driven by scale effects - more workers returning resulting in larger export values - are possible; yet, we rule out this possibility by looking at differential effects between labor and capital intensive goods, showing that results are not driven by the former. In addition, we show below that our results are driven by workers in occupations intensive in managerial characteristics, which tend to be just a small share of all workers. When it comes to global demand, our results -as we show beloware robust to controlling for changes in the relative size of each export sector

\footnotetext{
${ }^{41}$ Online Appendix Section E2 estimates the correlation between Yugoslavian exports and FDI stocks using the same regression setting, and finds a positive coefficient when not including product fixed effects, which is the sign we would expect in such relationship.
} 
at a global scale. Finally, when it comes to other structural transformation trends, a possible concern is that industries shrinking in Germany (and thus shedding workers) emerge in other countries. While our identification strategy should account for that, we present a number of other results that rule out that possibility, too. For instance, we include controls for the relative size of each export sector in Germany; in addition, to address this concern we also perform a number of placebo tests in Section 5.2.2.

As an additional note, it is worth mentioning that when expanding this exercise to all countries - at the expense of weakening our identification strategy - we find our results to be externally valid (see Online Appendix Section L).

\subsection{Pre-trend and multi-period estimation}

Can our results be explained by a previous trend in exports? We explore this first by estimating the same specification but this time over the period 1985 to 1990, keeping the same treatment defined for years 1995 to 2000. Both OLS and 2SLS results are presented in Table 3, and in this case the estimates for $\beta^{D I D}$ are either non-significant or negative, except for the fourth column, in which it is significant and positive, but it is an outlier result, as it is not robust across specifications. This implies, for the most part, that if anything the products for which more migrants returned were in a negative growth trend before the war.

[Table 3 about here.]

Second, given the availability of exports data across several years, we turn to estimate the multi-period effect of return migration. To avoid noise in the estimation, we take 5-year averages for the dependent variable and estimate $\beta^{D I D}$ for 6 different periods, from 1985-1989 to 2011-2014 ${ }^{42}$. To do this, we simply re-estimate specification (1), this time substituting the dummy after

\footnotetext{
${ }^{42}$ For the last period we take a 4-year average due to lack of data for 2015.
} 
for several dummies, each one signaling a 5-year period, along the lines of Autor et al. (2003). In this multi-period setting, $\alpha_{t}$ are 5-year period fixed effects, and the product fixed effects $\eta_{p}$ are maintained, allowing for product-specific intercepts. Table 4 reports the 2 SLS estimation using the instrumental variable described above (notice we have in this setting four endogenous variables and four instrumental variables, which correspond to the treatment and the instrument multiplied by four different period dummies). All columns include FDI as a control, though it is not reported in the table. Naturally, the number of observations in this sample is much larger than before, as it includes 6 data points for each of the 786 products totaling up to 4716 observations (except for the first column where observations where exports $s_{p, t}=0$ are excluded).

\section{[Table 4 about here.]}

It is important to notice that across all different dependent variables, our instruments are relevant as reported by the KP F statistic. The estimation presented in Table 4 starts with the period 1985-1989, shows that the treatment is negative and barely statistically significant prior to the treatment, across the board. Period 1990-1994 is used as the base for the estimation and is thus excluded. The results indicate that the value of the elasticity are positive and statistically different from zero for every transformation of the dependent variable starting in the period 2000-2004. In the first column, the one using a $\log$ transformation, the elasticity is estimated to be 0.08 in the first period posttreatment. The same elasticity increases to 0.11 (an increase of $37.5 \%$ ) in period 2005-2009 before decreasing back to 0.06 in the last period. In the other two columns, between 2000 and 2004, the elasticity is estimated to be 0.16 , which is much larger than in Column 1. This strengthens our previous finding that the effect is stronger when we take into account the extensive margin. The elasticity grows up to 0.2 in the latest period along the lines of our results from Table 
2. These findings suggests one more important result: the marginal effect of return migration on the emergence of new exports becomes stronger over time, at least up to some point. These results are summarized in Figure 9, which shows in the upper panel the evolution of the expected value of exports (across our three different measures) by 5 -year periods for two groups of products: those for which the value of treat $_{p}$ equals 1 , and the second group is those for which treat $_{p}=0$. The figures in the lower panel show the difference between the two groups, and it can be seen how the effect becomes positive and statistically significant in the period 2000 to 2004. Note that, based on the standard errors (as measured by the whiskers representing 95 percent confidence intervals), we cannot reject the hypothesis that the trends for both groups in periods before 2000 are statistically the same.

[Figure 9 about here.]

\subsection{Robustness and placebo tests}

\subsubsection{Robustness tests}

We are also concerned that our results could be explained by confounding factors such as the global demand for certain goods or the possibility that the decline of certain industries in Germany and the rise of those same industries in transition countries such as Yugoslavia could be the two faces of the same coin. Let us address the first concern first: can increases in global demand for particular industries drive these results? This would be a concern if product-level global demand is also associated with the intensity of the treatment. We rule out this possibility in the results presented in Table 5, which replicates the main specification adding as a control the share of each product in global exports

(i.e., in the export basket of the world) for both 1990 and 2005. The results are robust to the inclusion of this control. 
[Table 5 about here.]

Another consideration is the following scenario: if transition countries - such as the former Yugoslavian countries - are gaining market shares from declining German industries, that would create a spurious correlation between the decline in the number of workers (including Yugoslavian workers) in Germany and the rise of the same sectors in the former Yugoslavia. We rule out this possibility by adding as a control to the main specification the export share of each product in the German export basket. Results are presented in Table 6. As can be seen, our results are robust to controlling for changes in the German export structure.

[Table 6 about here.]

Finally, we reestimate our specification this time using the country-product specific measure of productivity or comparative advantage for Yugoslavia, $\Phi_{p, t}$, estimated following Costinot et al. (2012) and the application by Leromain and Orefice (2014) ${ }^{43}$ Our alternative specification is then:

$$
\Phi_{p, t}=\beta^{D I D} \text { treat }_{p} \times \text { after }_{t}+\beta^{f d i} f d i_{p, t}+\eta_{p}+\alpha_{t}+\varepsilon_{p, t}
$$

Following the previous results, we use the same two different monotonic transformations for $\Phi_{p, t}$ (given that since there are no zero-values we skip the $\log \left(\Phi_{p, t}+1\right)$ transformation). Results are presented in Table 7. As can be seen, our results are robust to using this measure as the dependent variable in terms of sign and significance.

\footnotetext{
${ }^{43}$ According to Costinot et al. (2012),$\Phi_{p, t}=e^{\left(\phi_{p, t} / 6.53\right)}$, where the figure 6.53 is their estimation of the elasticity of (adjusted) bilateral exports with respect to observed productivity, and $\phi_{p, t}$ is estimated as the country-product specific productivity parameters for Yugoslavia using the following specification and using the complete matrix of bilateral trade (where $\mathrm{Yu}-$ goslavia is one of the $c$ countries in the dataset):

$$
\operatorname{asinh}\left(\exp _{c, c^{\prime}, p, t}\right)=\phi_{c, p, t}+\Omega_{c^{\prime}, p, t}+\Psi_{c, c^{\prime}, p}+\varepsilon_{c, c^{\prime}, p, t}
$$

In the specification $\exp _{c, c^{\prime}, p, t}$ is the export value from country $c$ to country $c^{\prime}$ of product $p$ in year $t, \phi_{c, p, t}$ is a exporter-product-year fixed effect, $\Omega_{c^{\prime}, p, t}$ is a importer-product-year fixed effect, $\Psi_{c, c^{\prime}, p}$ is a exporter-importer-product fixed effect and $\varepsilon_{c, c^{\prime}, p, t}$ is the error term.
} 
[Table 7 about here.]

\subsubsection{Placebo tests}

In this subsection we aim to show that our results cannot be explained by other economic processes occurring at the same time, which would also impact other countries or could be explained by other waves of migration. We do so by putting in place two "placebo" tests.

First, we check whether return migration to (the former) Yugoslavia can explain export changes in similar countries, which would hint that our original results are driven by some spurious correlation in the data. In particular, it could speak to a concern that the results are driven by policies undertaken by the former communist block countries around the same time resulting in productivity improvements in the same industries in which most Yugoslavian refugees worked during their stay in Germany. Thus, we look at countries that had a similar export structure to that of Yugoslavia in 1990, and focus on the top five such countries ranked by the Export Similarity Index by Bahar et al. (2014). The countries that fall into this list are, in order, Hungary, Romania, Poland, Austria and Bulgaria. Specifically, we estimate the same model but with two differences. First, the dependent variable is exports from each one of these five countries to the rest of the World except Germany (as opposed to exports from Yugoslavian countries); and second, we control for the stock of their respective migrant workers in Germany in 1995 for each SITC 4-digit industry, given that, naturally, their own emigrants could also explain changes in exports (as shown by Bahar and Rapoport, 2018).

We visualize our results (based on one regression per country) in Figure 10. The figure shows that the treatment is statistically insignificant for all countries across every specification. For comparison purposes, the figure also shows the original (OLS) results for Yugoslavia, which is positive and statistically signifi- 
cant.

[Figure 10 about here.]

The second placebo test we run is somehow the mirror image of the first one and, essentially, it addresses an alternative explanation. The placebo test aims to rule out that the changes we see in Yugoslavia are driven by the shrinkage of the same industries in Germany (shedding workers, migrants among them), as part of a global general equilibrium of structural transformation process. Thus, the test asks whether the number of Polish workers, for example, that were part of the German labor force in 1995 but not in 2000, explain changes in the Yugoslavian export basket. To do this we focus on the five countries other than Yugoslavia with the largest changes in the stock of migrant workers in the German labor force between 1995 and 2000. These countries are, in order, Turkey, Greece, France, Poland and Italy. Specifically, we estimate the same main model using Yugoslavian exports as the dependent variable, with two differences. First, the treatment is the number of migrant workers from these five countries that were in the sample in 1995 and left by 2000 by SITC 4-digit industry; and second, under the same logic as the previous placebo test, we control for the stock of Yugoslavian migrant workers in Germany in 1995 for each SITC 4-digit industry.

The results are visualized (based on one regression per country) in Figure 11. The figure shows that the treatment is statistically insignificant for all countries across every specification. For comparison purposes, again, the figure also shows the original (OLS) results for Yugoslavia, which is positive and statistically significant.

[Figure 11 about here.] 


\subsubsection{Effect by geographic regions}

Table 8 presents results for the estimation of $\beta^{D I D}$ according to specification 1 , where in each row the left hand side variable includes exports to a particular geographical region. Interestingly enough, this table suggests that our main results using $\log \left(\right.$ export $\left._{p, t}\right)$ (e.g., products that already existed in the Yugoslavian export basket) hold across all regions except the Middle East and North Africa (MENA) and Latin America and the Caribbean (LAC). For regions such as Western and Eastern Europe -traditional trade partners for Yugoslavian countries- the results imply that there was an increase in the intensive margin of exports. However, when including zero exports on the left-hand side (columns $2,3,5$ and 6 ) results are estimated as positive and significant for North America, MENA and LAC regions. And the number of new products exported to these regions are significant. When looking at Yugoslavian exports to LAC, for example, export values are zero for 421 products (out of 786) in 1990. That set of products with zero exports in 1990 is reduced to 224 in 2005 . The same figures for MENA are 199 (in 1990) and 118 (in 2005). Thus, this implies that part of the effect we are finding when limiting the sample to those regions is driven by new exports to these two destinations.

\section{[Table 8 about here.]}

We believe these results are particularly important, because they are consistent with the idea that following the return of these migrants back home, Yugoslavian countries started exporting new products to new destinations, implying that the effect we are finding reflects a structural change in the export activity of the country. Note that these results by sub-regions also mitigate concerns that our results could be driven by the effect of migration networks on transaction costs, as we discuss in more details in the next section. 


\subsubsection{Product heterogeneity analysis}

Our main interpretation for the above results is that Yugoslavian returning refugees were able to increase the productivity of industries they worked in while in Germany thanks to the knowhow and experience they acquired abroad. In this section we proceed to rule out alternative explanations and do so by reestimating specification (1), this time interacting the term treat $_{p} \times$ after $_{t}$ with three different product characteristics. First, we look at differentiated versus homogenous and reference-priced goods, using the definition of Rauch (1999) (i.e., a dummy variable). Second, we use the physical capital intensity level of each product,, as defined by Nunn (2007) using data from the NBER-CES Manufacturing Industry Database of Becker et al. (2013). Third, we use human capital intensity taken from Shirotori et al. (2010) to study whether there is a differential relationship between migrants and products with different knowledge intensities. These last two variables are continuous, and we standardize them to have zero mean and a standard deviation of one.

First, we address the possibility that the results are driven by the ability of migrants to lower trade transaction costs, making exports are more likely upon their return. This is what we check in the first three columns of Table 9, which interacts the treatment with a dummy indicating whether the product is differentiated as defined by Rauch (1999). At first, we should not worry much about this possibility, given that our dependent variable already excludes exports to Germany. However, a concern remains if some of these migrants instead of returning to Yugoslavia migrated to third countries, and the increases in exports we are catching are induced by the decrease in transaction costs between Yugoslavian countries and, say, Austria or Belgium. However, as can be seen in columns 1 to 3 , the effect for differentiated products (those that are more likely to react to changes in trade transaction costs) is not different 
than for homogenous products (except for column 1 where the interaction under consideration is statistically significant, but this is not robust across the different linear transformations in columns 2 and 3). Thus, we do not have enough evidence to support an interpretation based on decreasing trade transaction costs. Recall also that from the previous section, the results are partly driven by new exports to new regions such as LAC where there are virtually no immigrants from former Yugoslavian countries.

Second, according to some of the most traditional trade models based on capital and labor endowments, our results could be driven by the fact that an inflow of workers into the economy could result into the export basket shifting towards labor intensive goods (Rybczynski, 1955). Yet, the results are not different for goods at different levels in the scale of capital intensity, as seen in columns 4 to 6 of Table 9 .

Lastly, if this is a story of knowledge transmission, then we should expect some differential effects in terms of the knowledge intensity of the good. Interestingly, we find that return migrants explain more export growth in products that are higher in the scale of knowledge intensity (as measured by human capital intensity), as seen in columns 7-9 of Table 9. Naturally, this last set of results can also be interpreted as a Rybczynski effect in a model of trade that incorporates factor endowments such as human capital, knowledge-workers or certain skills.

[Table 9 about here.]

\subsection{What is behind these results?}

The idea that migrants can play a role in shaping the comparative advantage of countries is part of a growing literature that links migrants and their descendants to the diffusion of knowledge (e.g., Kerr, 2008; Choudhury, 2016; Hausmann 
and Neffke, 2016; Bahar and Rapoport, 2018; Kerr, 2018), and our results so far suggest this mechanisms could be a plausible one. If this were the case, we should be able to see stronger results when looking at migrant workers more suited to acquire and transfer knowledge. This is what we explore in the next section, where we study the role of different types of occupations in explaining changes in comparative advantage.

\section{Mechanisms: Heterogeneous effects by work- ers' characteristics}

An important question that has been looked at recently in the labor economics literature is whether certain occupations, especially those intensive in managerial skills, are essential in fostering productivity (e.g., Bloom and Van Reenen, 2007; Bloom et al., 2012, 2013). We contribute to this literature by looking at whether our results are better explained by workers' skill levels and occupational patterns.

In particular, we expand Specification (1) and rewrite it as:

$$
\text { exports }_{p, t}=\sum_{i} \beta_{i}^{D I D} \text { treat }_{p, i} \times \text { after }_{t}+\beta^{f d i} f d i_{p, t}+\eta_{p}+\alpha_{t}+\varepsilon_{p, t}
$$

Where each term treat $_{p, i}$ corresponds the total number of returning Yugoslavians in each category $i$ in terms of workers' characteristics. All other terms remain the same as in Specification (1).

We present results using characteristics grouped in six different categories. First, instead of counting the number of returnees, we weight them with their last seen salary while in Germany (wageKsm1) in thousand $€$ (euros). Higher salaries should not only reflect higher productivity, but the highest salaries 
within each industry is often believed to be a proxy for managerial tasks. ${ }^{44}$

Second, skilled vs. unskilled workers based on their education levels. As unskilled we define workers without post-secondary education (edulow), and skilled as workers with education beyond high school, including vocational training, college degree or more (eduhigh). Since education does not devalue, we simply use the highest educational information attached to each worker at any point during the period of observation. To improve consistency of our variable, we correct missing values by using past and future values as developed by Fitzenberger et al. (2006).

Third, we distinguish migrants with occupations intensive in manual tasks (taskmanual) vs. occupations intensive in analytical and cognitive tasks (taskanalytical), using the classification provided by Dengler et al. (2014), which formalizes German occupations into five task categories, similarly to Autor et al. (2003). ${ }^{45}$

Fourth, we classify occupations as low skilled (bf2lowskill) and high skilled (bf2highskill) based on Blossfeld (1987) classification of professions. For example, high skilled occupations include managerial ones as well as professionals (i.e., engineers, lawyers, technicians, accountants, lab technicians), and low skilled occupations include drivers, carpenters, textile processing operatives, etc.

Fifth, we distinguish workers by the supervisory intensity of their occupation based on the German Qualifications and Career Survey (BIBB/BAuA) of 1999. In particular we use the workers' responses regarding their supervisory status ${ }^{46}$ and assign to each occupation both the share of workers that self-report acting as supervisors (svct1) and the share of those that report the opposite (svct0). ${ }^{47}$

\footnotetext{
${ }^{44}$ Using arbitrary wage cutoffs to identify managers in each industry results in very noisy measures. Thus, we use a continuous one.

${ }^{45}$ Spitz-Oener (2006) first applied the task-based approach on German occupations based on survey data. The classification we use is based on year 2011 .

${ }^{46}$ Based on the answer to the question: "Do you have coworkers for whom you are the direct supervisor?".

${ }^{47}$ Online Appendix Section J summarizes the values of these characteristics for each one of the occupations in our dataset, along with the number of workers in our sample in each occupation.
} 
Sixth, we distinguish workers based on whether they worked in the top 25 percent paying firms within the industry in terms of average wages ( $f$ waget251), or in the bottom 75 percent paying firms ( $f$ waget 251 ). Typically, top paying firms are the most productive ones, by being able to attract the best workers and by innovating or adopting innovations that help workers be more productive.

Finally, we distinguish workers based on the average growth in their wage within an industry during their stay in Germany, as proxy for productivity improvements. We separate workers within each industry in two groups: workers with wage growth (based on the compound average growth rate, CAGR) below median in their industry (wgrcagramd0) and those with wage growth above the median (wgrcagramd1).

The summary of our results are presented in Table $10{ }^{48}$ Each column present results using a different monotonic transformation of the dependent variable, consistently with all previous results in the paper. Columns show the estimated value of $\beta_{i}^{D I D}$ for each of the constructed treatments belonging to each of the categories described above. We only present results using OLS, as we don't have instruments for more than one endogenous variable at a time.

[Table 10 about here.]

The first row replicates the main results using the total number of returnees per industry, for comparison purposes (migct1). Overall, based on the point estimates and statistical significance, our results show that our findings are stronger for workers with higher wage levels (row 2). They are also particularly driven by workers with higher educational attainment (rows 3 and 4), workers in occupations that are intensive in analytical tasks (as opposed to manual ones) and workers in skilled occupations (as opposed to unskilled ones). The

\footnotetext{
${ }^{48}$ See Online Appendix Section K for tables with all the estimations by group, including both univariate and multivariate regression. While there is multicollinearity, the relative size of the point-estimates remain consistent in univariate and multivariate regressions.
} 
results are also strongly driven by workers with occupations intensive in cognitive and analytical tasks, as opposed to manual ones (rows 5 and 6), as well as by workers in skilled occupations (rows 7 and 8). The results for workers in occupations intensive in supervision are consistent, though not statistically significant, probably due to lack of variance (rows 9 and 10).

We also find that the results are particularly driven by workers who worked in the top paying firms during their stay in Germany (rows 11 and 12). We also find that workers for whom wages grew faster during their stay in Germany correlate with a higher export performance, though with no statistical significance (rows 13 and 14).

Note that the point-estimates are to be interpreted in terms of percentages, and thus, ultimately, the marginal effect of one worker belonging to each of the categories driving the results is much larger in relative terms than what the point estimate suggests (or 1000 euros of salary, in the case of row 2). This is because the types of workers driving the results are a smaller share when looking at the within-industry composition of workers in the sample. Figure 12 estimates the marginal effect of one migrant worker on exports using asinh(exports $\left.s_{p, t}\right)$ as the dependent variable (results using $\log \left(\right.$ export $\left._{p, t}\right)$ and $\log \left(\right.$ exports $_{p, t}+$ 1) are qualitatively similar). The figure shows that, as compared to counting the number of workers (first bar), the marginal effect of each 1000 euros in salary for a worker is large and statistically significant. The figure also shows clearly that the marginal effect for workers with higher educational attainment is infinitely larger than for those with low educational attainment (given that the point estimate for the latter category is below zero). Similarly, workers in occupations intensive in analytical tasks are about 23 times more "effective" than those in occupations intensive in manual tasks. Workers in occupations that are considered skilled are about 35 times more effective than those in 
occupations considered unskilled. Workers in occupations for which supervision is more common are 25 times more effective than those in occupations where supervision is less common (though the difference is not statistically significant). Workers who were employed by the top 25 percent paying firms are, similarly to educational attainment category, infinitely more effective than those who worked in the bottom 75 percent. Similarly, a worker that experienced wage growth above the median value is much more effective than those with slower wage growth (though, again, not statistically significant). All in all, these results suggest that the size of the effect we document depends on who the workers are in terms of their skills, the characteristics of their occupations, as well as who did they work for and how successful in their jobs they were while abroad.

[Figure 12 about here.]

Our results for workers in occupations with managerial skills are consistent with the findings of Bloom et al. (2018), who find that management has a $\mathrm{n}$ effect on firms' exports. By way of comparison, baring the differences in the way management is measured across our study and Bloom et al. (2018), the order of magnitude of both estimators are comparable. In the case of Bloom et al. (2018), they find that a one-standard-deviation rise in the management z-score is associated with $23 \%$ to $37 \%$ larger export revenues (for firms in China and the US, respectively). Our study shows that at the industry level, the elasticity of exports to an inflow of workers with foreign experience in occupations intensive in managerial skills lies between 0.14 and 0.5 , depending on how we proxy for managerial skills.

The idea that a small number of workers can have such an important effect on exports of a whole industry in such little time might seems implausible at first, but some anecdotical evidence documented by others seems to strongly support that idea. For instance, Rhee and Belot (1990) and Easterly (2001), 
document the story of the success of the garment sector in Bangladesh. Between 1980 and 1986, the share of garments in Bangladesh's total exports rose from 0.5 to 28.3 percent. The unprecedented take-off of the garment export sector is often attributed to 130 Bangladeshi workers - only four of them in management positions- who spent eight months in 1979 working and being trained in Korea as part of an agreement between their company, Desh of Bangladesh, and the Korean firm Daewoo. The knowhow acquired by these workers seems to have been crucial in making Desh a highly successful exporter firm. Yet, perhaps more importantly, such knowhow eventually spilled over as workers moved to other firms or created new ones, contributing to the massive success of garment exports as one of Bangladesh's most significant export sectors.

In this context, we believe our findings pointing to productive knowledge and managerial knowhow as the main mechanisms driving the export dynamics we document, are aligned with other studies in the literature.

\section{Concluding Remarks}

In this paper we exploit a natural experiment and show that the return of Yugoslavian refugees following the Balkan wars in the nineties resulted in the growth of exports from the former Yugoslavian countries to the rest of the world in the same products where those refugees worked at during their stay in Germany. As productivity is an underlying determinant of exports, we interpret our results as migrants being drivers of knowhow and technologies between countries, which result in productivity increases reflected in export performance. This assertion is backed by the fact that our results are particularly driven by migrants in occupations that are skilled, intensive in analytical and cognitive tasks, and intensive in supervision of other workers, as well as stronger in knowledge intensive industries. In that sense, our results are consistent with 
the literature linking productivity shifts and exports to improved managerial practices (e.g, Bloom and Van Reenen, 2007; Bloom et al., 2012, 2013, 2018).

Our results contribute to a burgeoning literature that emphasizes that migrants can serve as drivers of technology and knowledge diffusion resulting in productivity shifts, possibly reflected in exports. The ability of a worker to become more productive has to do with his or her accumulated experience and his or her ability to learn from others while on-the-job. Migration, thus, is an important vehicle in the process of knowledge and technology transfer across locations. Better understanding this process and identifying channels through which these dynamics occur are important missing pieces in the literature, and an active part of our future research agenda.

\section{References}

Alesina, Alberto, Johann Harnoss, and Hillel Rapoport. "Birthplace diversity and economic prosperity." Journal of Economic Growth 21, 2: (2016) 101138. http://link. springer.com/10.1007/s10887-016-9127-6.

Angrist, Joshua D., and Adriana D. Kugler. "Protective or counter-productive? labour market institutions and the effect of immigration on EU natives." The Economic Journal 113, 488: (2003) F302-F331.

Arrow, Kenneth J. "Classificatory Notes on the Production and Transmission of Technologcal Knowledge." The American Economic Review 59, 2: (1969) $29-35$.

Autor, David H, Frank Levy, and Richard J Murnane. "The Skill Content of Recent Technological Change: An Empirical Exploration." The Quarterly Journal of Economics 118, 4: (2003) 1279-1333. 
Bahar, Dany, Ricardo Hausmann, and Cesar A. Hidalgo. "Neighbors and the evolution of the comparative advantage of nations: Evidence of international knowledge diffusion?" Journal of International Economics 92, 1: (2014) $111-123$.

Bahar, Dany, and Hillel Rapoport. "Migration, Knowledge Diffusion and the Comparative Advantage of Nations." Economic Journal 128, 612: (2018) F273-F375.

Becker, Randy A, Wayne B Gray, and Jordan Marvakov. "NBER-CES Manufacturing Industry Database: Technical Notes." Technical Report February, 2013.

Bertrand, Marianne, Esther Duflo, and Sendhil Mullainathan. "How Much Should We Trust Differences-In-Differences Estimates?" The Quarterly Journal of Economics 119, 1: (2004) 249-275.

Besley, T., and R. Burgess. "Can Labor Regulation Hinder Economic Performance? Evidence from India." The Quarterly Journal of Economics 119, 1: (2004) 91-134.

Bloom, Nicholas, Benn Eifert, Aprajit Mahajan, David McKenzie, and John Roberts. "Does managment matter? Evidence from India." The Quarterly Journal of Economics 128, 1: (2013) 1-51.

Bloom, Nicholas, Kalina Manova, John van Reenen, Stephen Teng Sun, and Zhihong Yu. "Managing trade: Evidence from China and the US." NBER Working Paper Series http://www.nber.org/papers/w24718.

Bloom, Nicholas, Raffaella Sadun, and John Van Reenen. "Americans do IT better: US multinationals and the productivity miracle." American Economic Review 102, 1: (2012) 167-201. 
Bloom, Nicholas, and John Van Reenen. "Measuring and Explaining Management Practices Across Frims and Countries." Quarterly Journal of Economics CXXII, November: (2007) 1351-1408.

Blossfeld, Hans-peter. "Labor-Market Entry and the Sexual Segregation of Careers in the Federal Republic of Germany." American Journal of Sociology 93, 1: (1987) 89-118.

Bosswick, Wolfgang. "Development of Asylum Policy in Germany." Journal of Refugee Studies 13, 1: (2000) 43-60.

Buch, Claudia M., Jörn Kleinert, and Farid Toubal. "Where enterprises lead, people follow? Links between migration and FDI in Germany." European Economic Review 50, 8: (2006) 2017-2036.

Burchardi, Konrad B., Thomas Chaney, and Tarek A. Hassan. "Migrants, Ancestors, and Foreign Investments." mimeo, Chicago Booth Research Paper , June.

Cadot, Olivier, Celine Carrere, and Vanessa Strauss-Kahn. "Export Diversification: What's behind the Hump?" Review of Economics and Statistics 93, 2: (2011) 590-605.

Card, David, Jörg Heining, and Patrick Kline. "Workplace Heterogeneity and the Rise of West German Wage Inequality*." The Quarterly Journal of Economics 128, 3: (2013) 967-1015.

Choudhury, Prithwiraj. "Return migration and geography of innovation in MNEs: A natural experiment of knowledge production by local workers reporting to return migrants." Journal of Economic Geography 16, 3: (2016) 585-610. 
Cohen, Lauren, Umit G. Gurun, and Christopher Malloy. "Resident Networks and Corporate Connections: Evidence from World War II Internment Camps." The Journal of Finance 72, 1: (2017) 207-248.

Costinot, Arnaud, Dave Donaldson, and Ivana Komunjer. "What Goods Do Countries Trade? A Quantitative Exploration of Ricardo's Ideas." Review of Economic Studies 79: (2012) 581-608.

Dauth, Wolfgang, Sebastian Findeisen, and Jens Suedekum. "The Rise Of The East And The Far East: German Labor Markets And Trade Integration." Journal of the European Economic Association 12, 6: (2014) 1643-1675.

De Chaisemartin, C., and X. D'Haultfoeuille. "Fuzzy differences-in-differences." Review of Economic Studies 85, 2: (2018) 999-1028.

Dengler, Katharina, Britta Matthes, and Wiebke Paulus. "Occupational Tasks in the German Labour Market : an alternative measurement on the basis of an expert database." Fdz methodenreport, Institut für Arbeitsmarkt- und Berufsforschung (IAB), Nürnberg, 2014.

Deutscher-Bundestag. "Bericht der Beauftragten der Bundesregierung für die Belange der Ausländer über die Lage der Ausländer in der Bundesrepublik Deutschland 1993. BT-Drs. 12/6960." http://dipbt.bundestag.de/doc/btd/12/069/１206960.pdf (22.09.2017), 1994.

Dimova, Rozita. "Max Planck Institute for Social Anthropology Working Papers. 87 From Protection To Ordeal: Duldung Status and Bosnian Refugees." Max Planck Institute for Social Anthropology Working Papers 49, 87: (2006) $0-12$. 
Docquier, Frédéric, and Elisabetta Lodigiani. "Skilled Migration and Business Networks." Open Economies Review 21, 4: (2010) 565-588.

Docquier, Frédéric, Riccardo Turati, Jerome Valette, and Chrysovalantis Vasilakis. "Birthplace Diversity and Economic Growth : Evidence from the US States in the Post-World War II Period." IZA Discussion Paper Series , 11802.

Dustmann, Christian, and Albrecht Glitz. "How Do Industries and Firms Respond to Changes in Local Labor Supply?" Journal of Labor Economics 33, 3: (2015) 711-750.

Dustmann, Christian, Uta Schönberg, and Jan Stuhler. "Labor Supply Shocks, Native Wages, and the Adjustment of Local Employment." The Quarterly Journal of Economics 132, 1: (2017) 435-483.

Easterly, W. The Elusive Quest for Growth. 2001.

Eberle, Johanna, Peter Jacobebbinghaus, and Julia Witter. "Generation of Time-Consistent Industry Codes in the Face of Classification Changes." FDZMethodenreport 05/2011, September.

Feenstra, Robert C., Robert E. Lipsey, Haiyan Deng, Alyson C. Ma, and Hengyong Mo. "World Trade Flows: 1962-2000.", 2005.

Fitzenberger, Bernd, Aderonke Osikominu, and Robert Völter. "Imputation Rules to Improve the Education Variable in the IAB Employment Subsample." Schmollers Jahrbuch : Journal of Applied Social Science Studies 126, 3: (2006) 405-436.

Foley, C. Fritz, and William R. Kerr. "Ethnic Innovation and U.S. Multinational Firm Activity." Management Science 59, 7: (2013) 1529-1544. 
Glitz, Albrecht, and Erik Meyersson. "Industrial Espionage and Productivity." CESifo Working Paper Series, 6525.

Gould, DM. "Immigrant links to the home country: empirical implications for US bilateral trade flows." The Review of Economics and Statistics 76, 2: (1994) 302-316.

Hailbronner, Kay. "National Report Germany." In Study on the Single Asylum Procedure One-stop-shop against the Background of the Common European Asylum System and the Goal of a Common Asylum Procedure, edited by Kay Hailbronner, Luxemburg, 2003, 221-244.

Hausmann, Ricardo, César A Hidalgo, Sebastián Bustos, Michele Coscia, Alexander Simoes, and Muhammed A. Yildirim. The Atlas of Economic Complexity: Mapping Paths to Prosperity. Cambridge, MA: MIT Press, 2014.

Hausmann, Ricardo, Jason Hwang, and Dani Rodrik. "What you export matters." Journal of Economic Growth 12, 1: (2006) 1-25.

Hausmann, Ricardo, and Frank Neffke. "The Workforce of Pioneer Plants.", 2016.

Hidalgo, César A, Bailey Klinger, AL Barabási, and Ricardo Hausmann. "The product space conditions the development of nations." Science 317, 5837: (2007) 482-7.

Hornung, Erik. "Immigration and the Diffusion of Technology : The Huguenot Diaspora in Prussia." American Economic Review 104, 1: (2014) 84-122.

IAB. "Employment History (BEH).", 2015.

Imbs, Jean, and Romain Wacziarg. "Stages of Diversification." American Economic Review 93, 1: (2003) 63-86. 
Javorcik, Beata S., Caglar Ozden, Mariana Spatareanu, and Cristina Neagu. "Migrant networks and foreign direct investment." Journal of Development Economics 94, 2: (2011) 231-241.

Kerr, Sari Pekkala, and William R. Kerr. "Global Collaborative Patents." Economic Journal 128: (2018) 235-272.

Kerr, William. The Gift of Global Talent: How Migration Shapes Business, Economy 83 Society. Stanford: Stanford University Press, 2018.

Kerr, William R. "Ethnic scientific communities and international technology diffusion." Review of Economics and Statistics 90, 3: (2008) 518-537.

Khanna, Gaurav, and Nicolas Morales. "The it Boom and Other Unintended Consequences of Chasing the American Dream.", 2017.

Koren, Miklos, and Silvana Tenreyro. "Volatility and Development." The Quarterly Journal of Economics 122, 1: (2007) 243-287.

Krishna, Pravin, and Andrei Levchenko. "Comparative Advantage, Complexity and Volatility." Technical report, National Bureau of Economic Research, Cambridge, MA, 2009.

Kugler, Maurice, Oren Levintal, and Hillel Rapoport. "Migration and CrossBorder Financial Flows." The World Bank Economic Review 32, 1: (2018) $148-162$.

Kugler, Maurice, and Hillel Rapoport. "International labor and capital flows: Complements or substitutes?" Economics Letters 94, 2: (2007) 155-162.

Lederer, Harald. Migration und Integration in Zahlen. Bonn, 1997, beauftragt edition. 
Leromain, Elsa, and Gianluca Orefice. "New revealed comparative advantage index: Dataset and empirical distribution." International Economics 139: (2014) 48-70.

Liedtke, Matthias. "National welfare and asylum in Germany." Critical Social Policy 22, 3: (2002) 479-497.

MacKinnon, JG, and Lonnie Magee. "Transforming the Dependent Variable in Regression Models." International Economic Review 31, 2: (1990) 315-339.

Malchow-Møller, Nikolaj, Jakob Roland Munch, and Jan Rose Skaksen. "Do Foreign Experts Increase the Productivity of Domestic Firms?" The Scandinavian Journal of Economics 12, 10: (2017) 3218-3221.

Markusen, James R., and Natalia Trofimenko. "Teaching locals new tricks: Foreign experts as a channel of knowledge transfers." Journal of Development Economics 88, 1: (2009) 120-131.

Nenadic, Mario, Nermina Dzepar-Ganibegovic, Medzid Lipjankic, Drago Borovcanin, Nada Spasojevic, Dragana Kovac, and Abela Pobrić. "Comparative Analysis on Access to Rights of Refugees and Displaced Persons." Ministry for Human Rights and Refugees Bosnia and Herzegovina, 2005.

Nunn, Nathan. "Relationship-Specificity, Incomplete Contracts, and the Pattern of Trade." The Quarterly Journal of Economics 122, 2: (2007) 569-600.

Ortega, Francesc, and Giovanni Peri. "Openness and income: The roles of trade and migration." Journal of International Economics 92, 2: (2014) 231-251. http://linkinghub.elsevier.com/retrieve/pii/S0022199613001268.

Parsons, Christopher, and Pierre-Louis Vézina. "Migrant Networks and Trade: The Vietnamese Boat People as a Natural Experiment." The Economic Journal 128, 612: (2018) F210-F234. 
Polanyi, M. The Tacit Dimension. Chicago; London: University of Chicago Press, 1966, 2009 edition.

Poole, Jennifer. "Knowledge Transfers from Multinational to Domestic Firms: Evidence from Worker Mobility." The Review of Economics and Statistics 95, 2: (2013) 393-406. http://econpapers.repec.org/RePEc:tpr:restat:v: $95: y: 2013: i: 2: p: 393-406$.

Radovic, B. "A Brief Retrospective on the Problem of Refugees in the Yugoslav Wars 1991-99." In Living in post-war communities, edited by G Opacic, I Vidakovic, and B Vujadinovic, Belgrade: International Aid Network, 2005, $11-26$.

Rauch, James E. "Networks versus markets in international trade." Journal of International Economics 48, 1: (1999) 7-35.

Rauch, James E., and Vitor Trindade. "Ethnic Chinese Networks in International Trade." Review of Economics and Statistics 84, 1: (2002) 116-130.

Rhee, Yung, and Therese Belot. "Export Catalysts in Low-Income Countries.", 1990.

Rosenberg, David. Israel's Technology Economy. Cham: Palgrave Macmillan, 2018.

Ruben, Ruerd, Marieke Van Houte, and Tine Davids. "What determines the embeddedness of forced-return migrants? Rethinking the role of pre- and post-return assistance." International Migration Review 43, 4: (2009) 908937.

Ruhl, Stefan, and Harald W Lederer. Migrationsbericht 2001 der Ausländerbeauftragten im Auftrag der Bundesregierung. Beauftragte der Bundesregierung für Ausländerfragen, 2001. 
Rybczynski, T. M. "Factor Endowment and Relative Commodity Prices." Economica 22, 88: (1955) 336-341.

Shirotori, M, B Tumurchudur, and O Cadot. "Revealed Factor Intensity Indices at the Product Level." Policy Issues in International Trade and Commodities 2010,44 .

Spitz-Oener, Alexandra. "Technical Change, Job Tasks, and Rising Educational Demands: Looking outside the Wage Structure." Journal of Labor Economics 24, 2: (2006) 235-270.

UNHCR. "After the war was over." Refugee magazine 3, 140: (2005) 1-32. http://www . unhcr.org/433bded34.pdf.

Walker, William S. German and Bosnian voices in a time of crisis: Bosnian refugees in Germany, 1992-2002. Indianapolis: Dog Ear Publishing, 2010. 
Figure 1: Migration from Yugoslavia into Germany

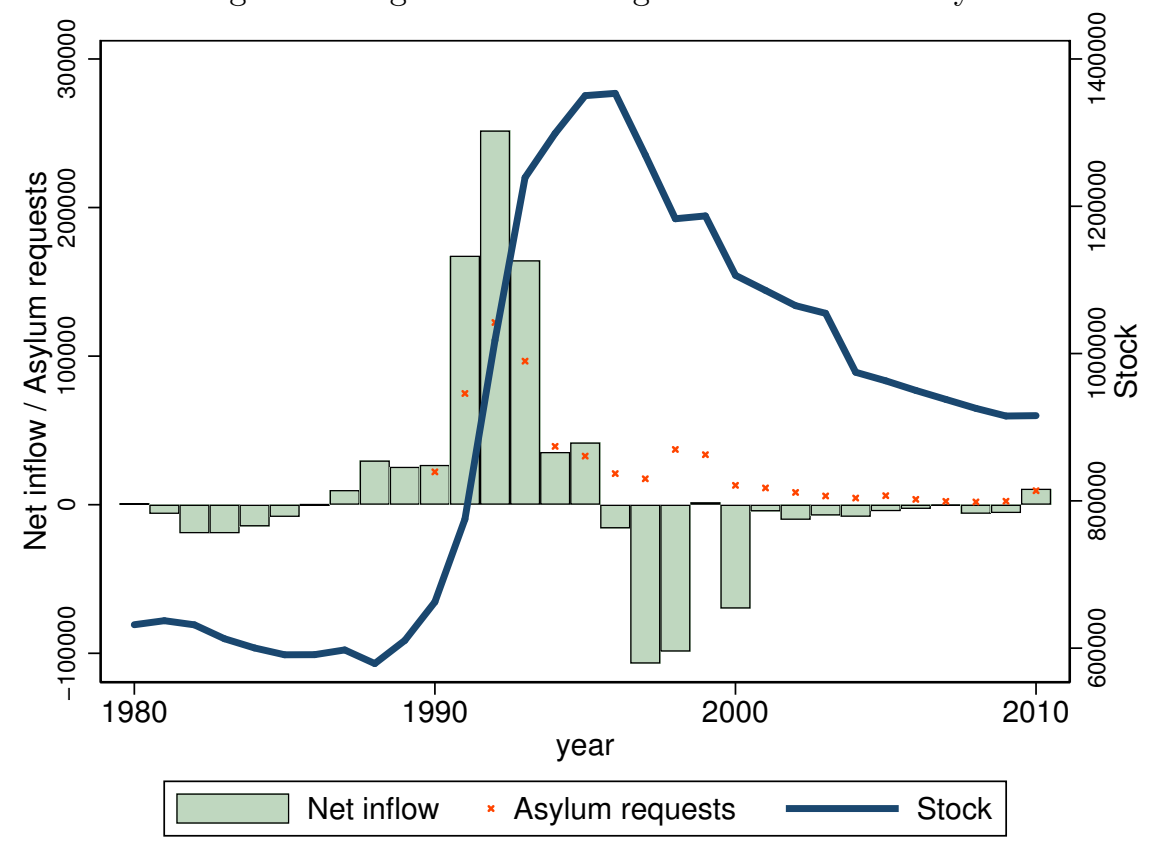

The figure shows the net inflow, stock and asylum requests of migrants from (former) Yugoslavia into Germany, from 1980 until 2010. The number of migrant stocks by nationality is based on the Central Register of Foreigners (Ausländerzentralregister, AZR). The data have been downloaded from the GENESIS-online data base of the German Federal Statistical Office (Statistisches Bundesamt), Table 12521-0002. Data on migration flows by nationality are from the migrations statistics (Wanderungsstatistik) of the German Federal Statistical Office (Statistisches Bundesamt) and sent to us upon request. 
Figure 2: Yugoslavian workers yearly entry to and exit from German's labor force

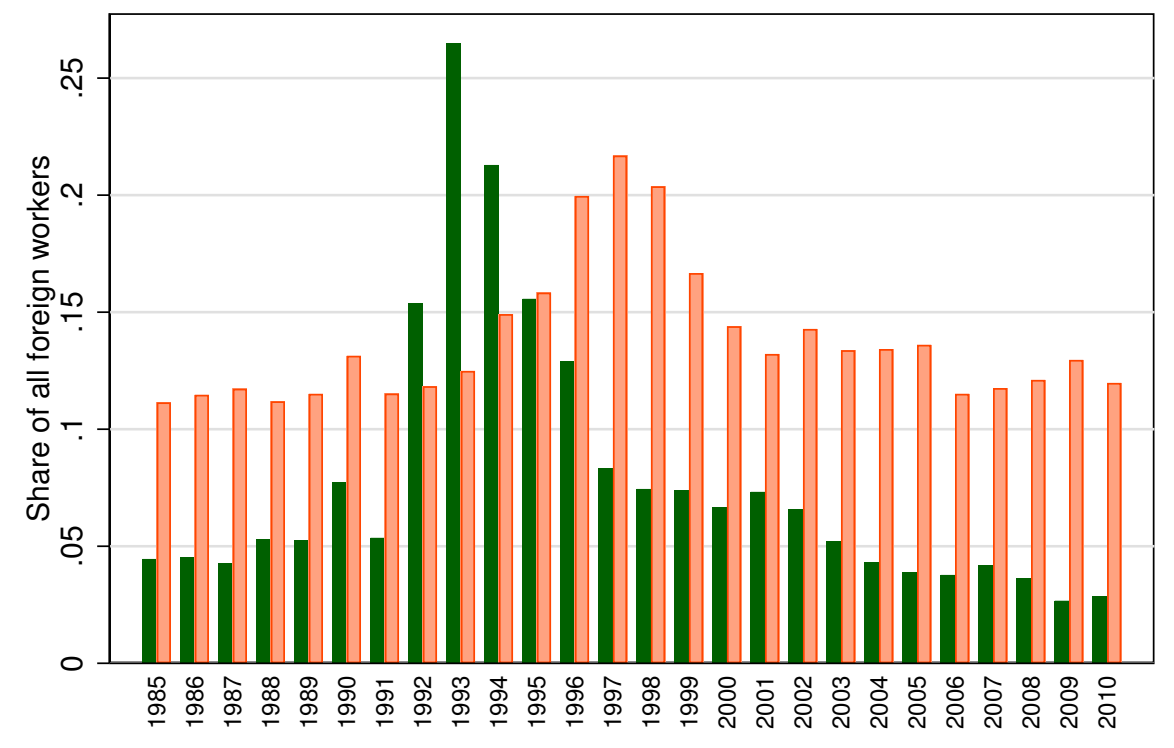

$\square$ Entry $\square$ Exit

The graph shows the yearly share (out of all foreign workers) of Yugoslavians entering and exiting the labor force of Germany's tradable sector. 
Figure 3: Yugoslavians in German workforce, by product

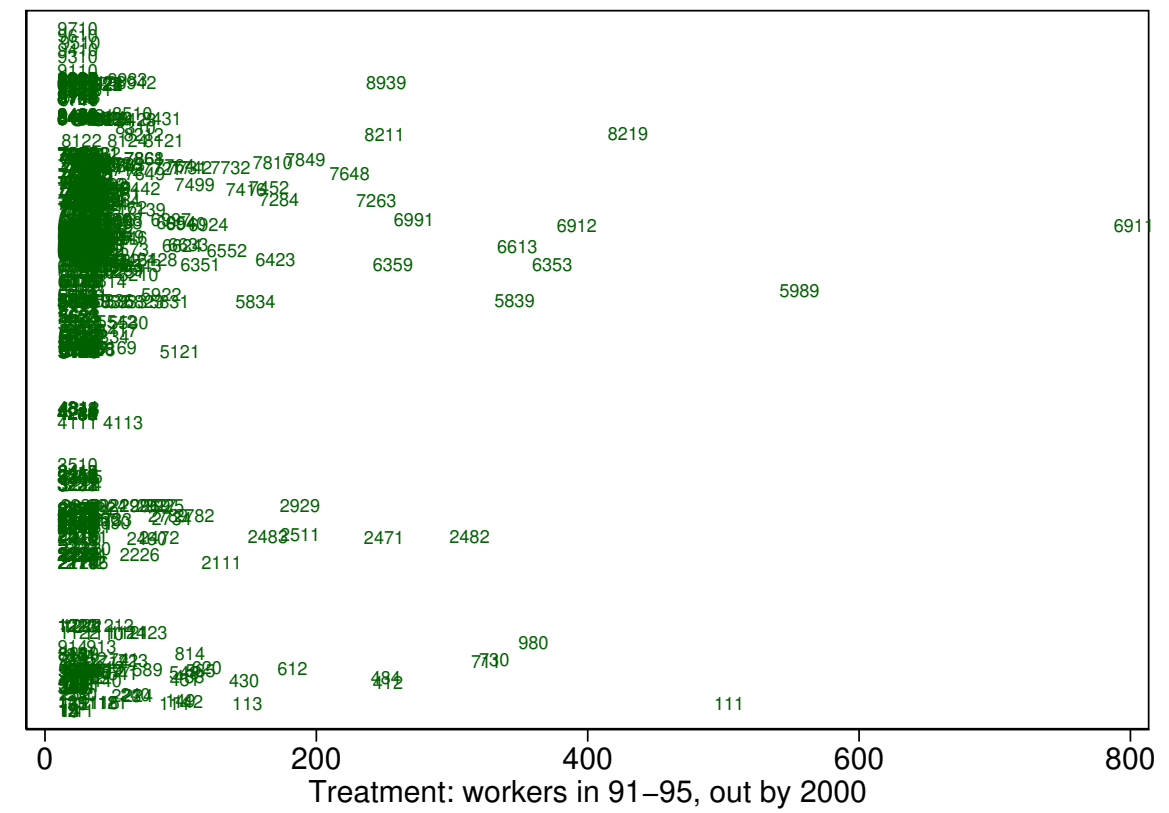

The figure shows the number of Yugoslavian workers in the German workforce that arrived between 1991 and 1995 agains those that remain in year 2000 and beyond, by 4-digit product. 
Figure 4: Exports for products with different levels of treatment

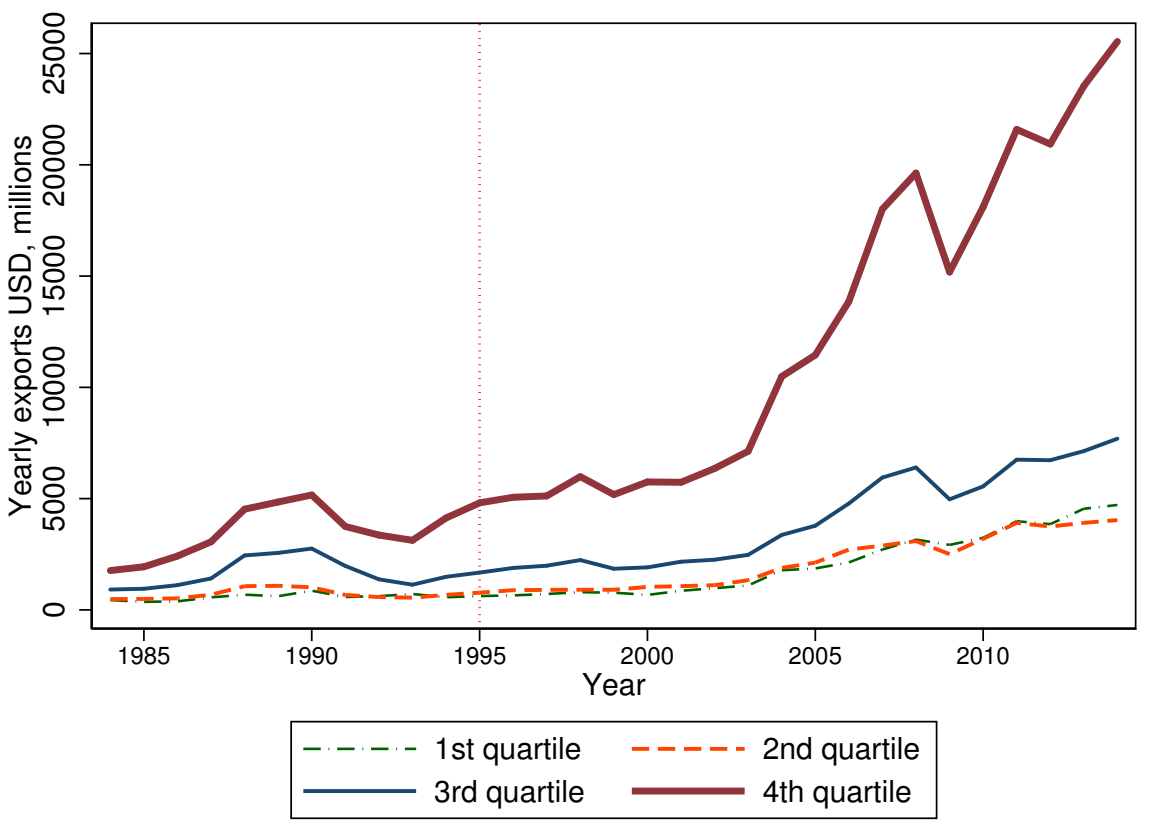

The figure plots the cumulative value of exports of the former Yugoslavia to the rest of the world (vertical axis) across years. Treatment is defined as the number of return migrants from Germany by 2000 . 
Figure 5: Export Similarity Index between Germany and Yugoslavia, by year

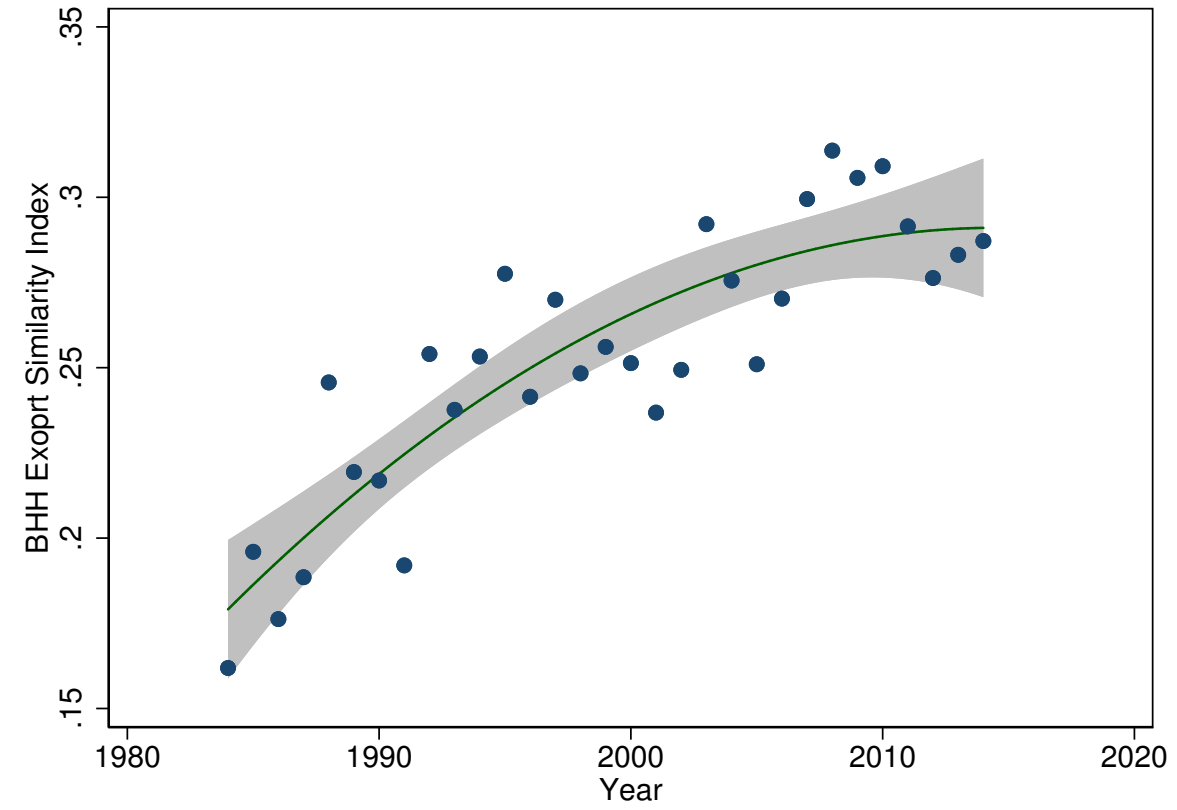

The figure plots the export similarity index (Bahar et al., 2014) between Germany and the former Yugoslavia across time. 
Figure 6: Distribution rule of asylum seekers in Germany 1995

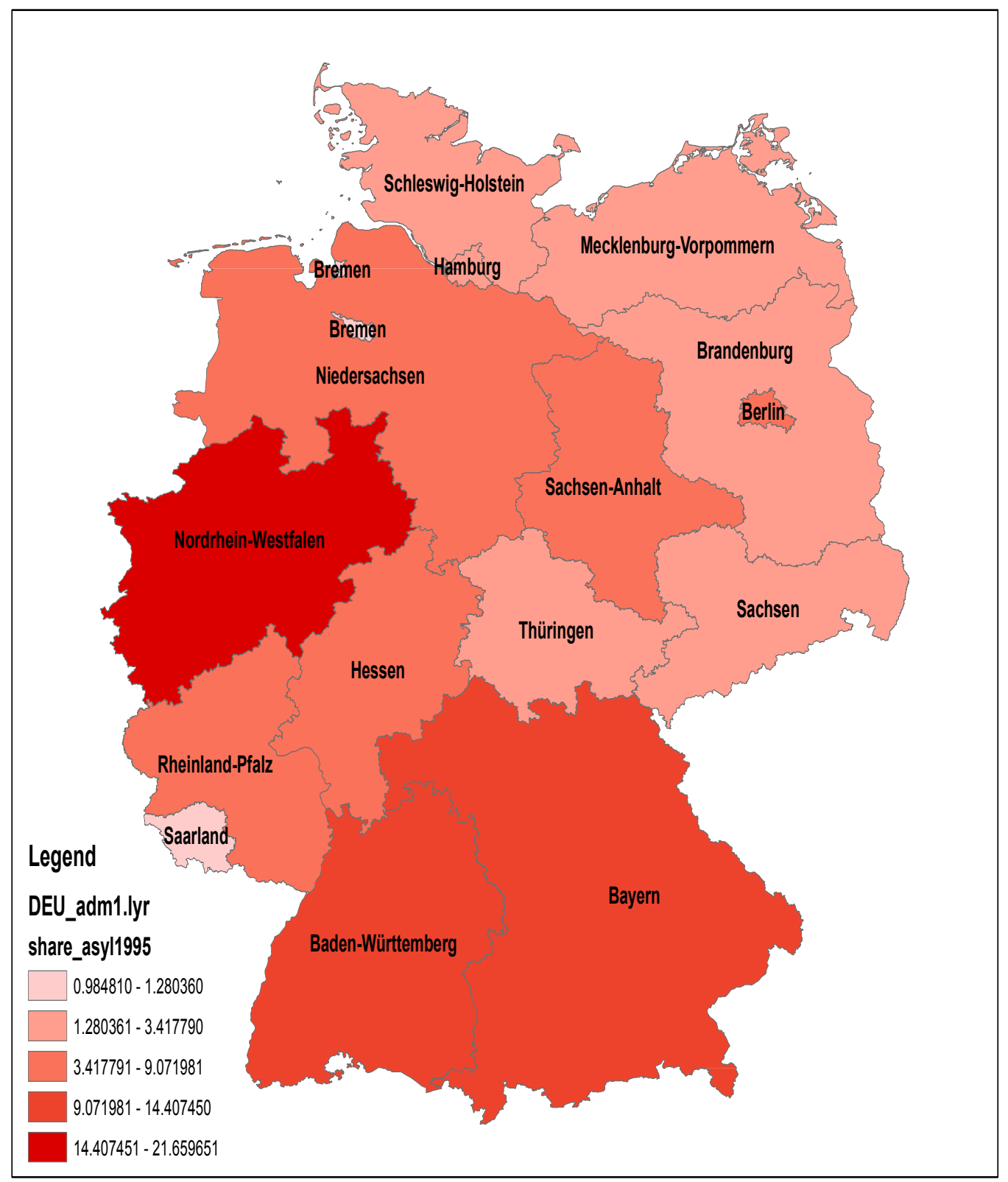

The figure maps the different German states with their shade representing the share of all asylum seekers in Germany they were mandated to receive by law in 1995, based on their population and tax revenues. 
Figure 7: Instrumental Variable Relevance

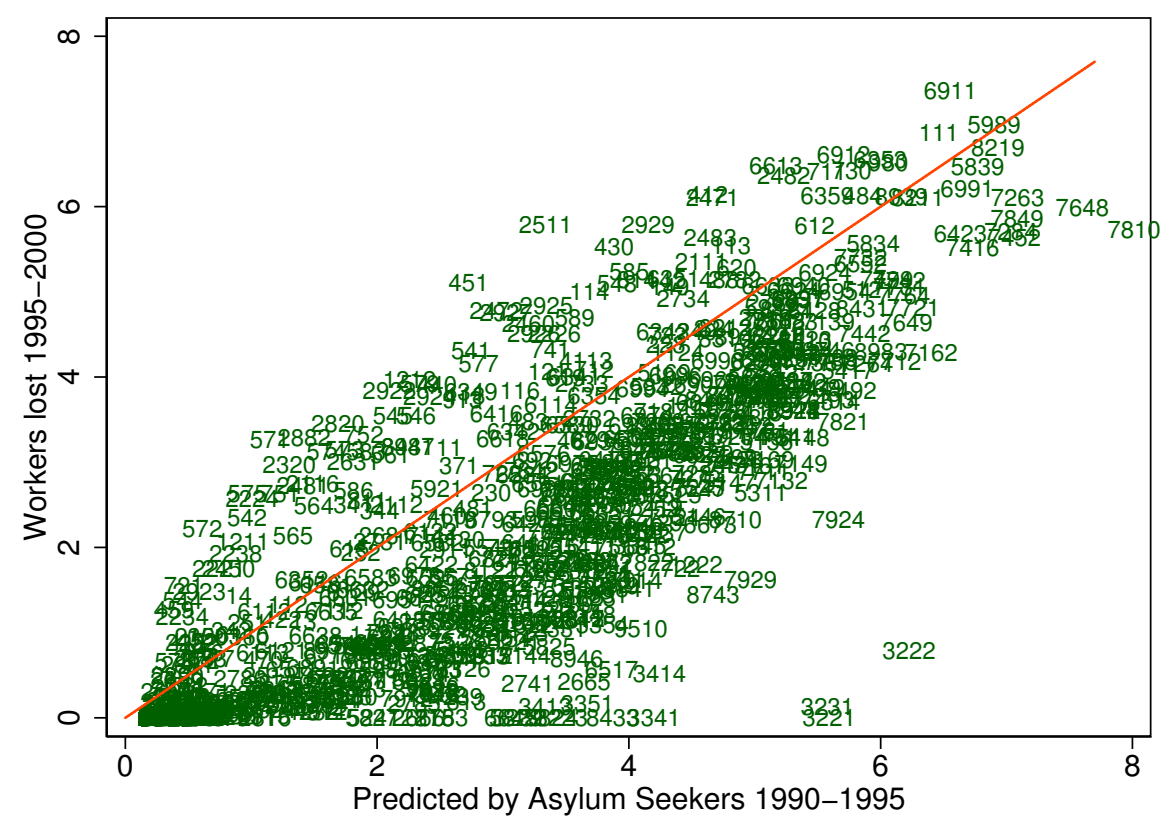

The figure plots the expected number of asylum seekers expected to work in each industry based on their geographic allocation in each state and the employment share of each 4-digit SITC code in that state using data from 1991 to 1995 in the horizontal axis (in logs) against the number of Yugoslavian workers who arrived between 1991 and 1995 and leave the German labor force between by 2000 (in logs), by each 4-digit SITC code. The figure represents a graphical visualization of the first stage of the two stages least squares. 
Figure 8: Share of arrival vs exit from the German labor force by product

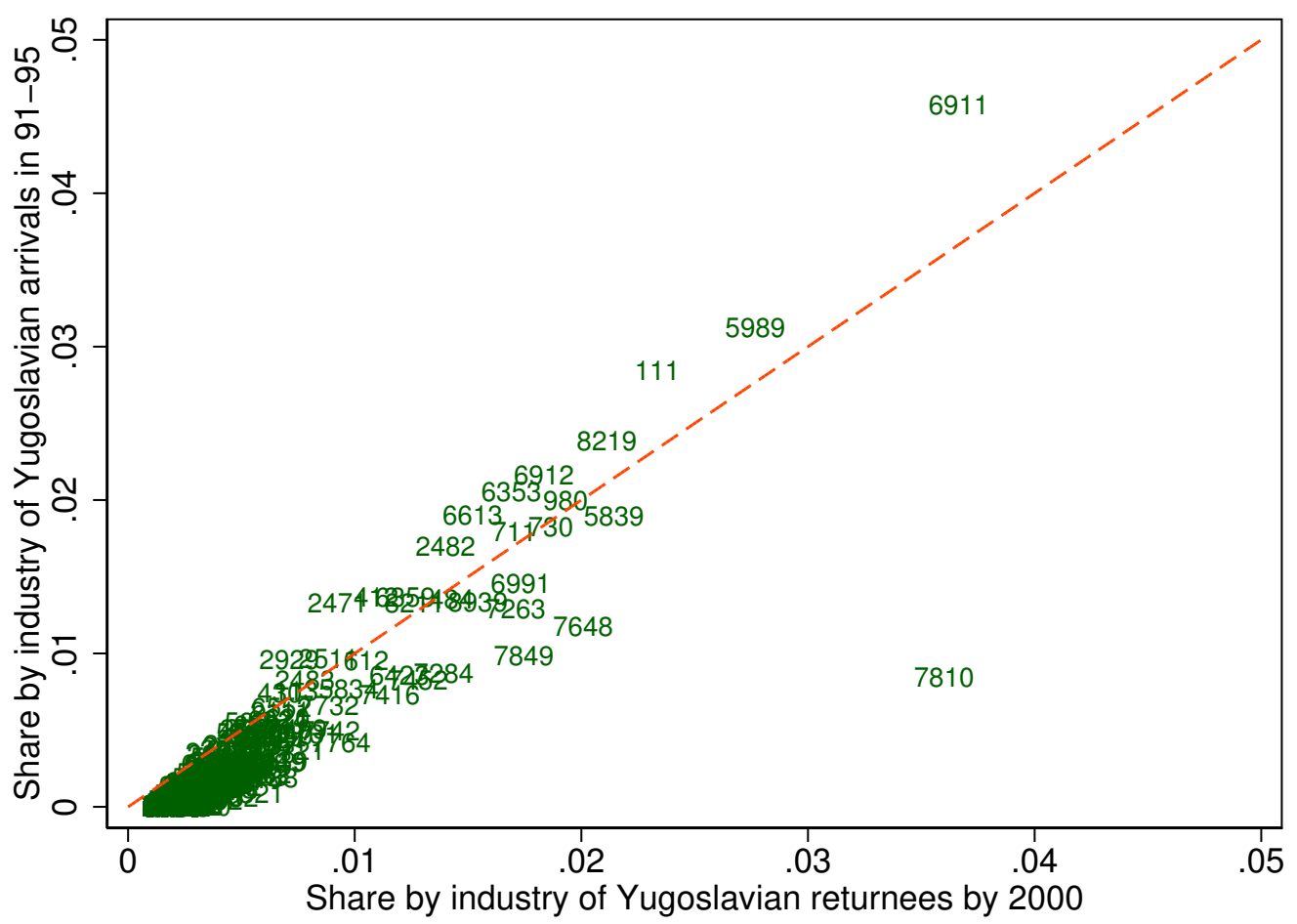

The figure plots the share of Yugoslavian workers in each industry out of the total that joined the labor force between 1991 to 1995 on the vertical axis against the share of Yugoslavian workers in each industry out of the total that dropped out of the labor force by 2000 (according to the way we define the treatment). 
Figure 9: Difference-in-difference, 5 year periods
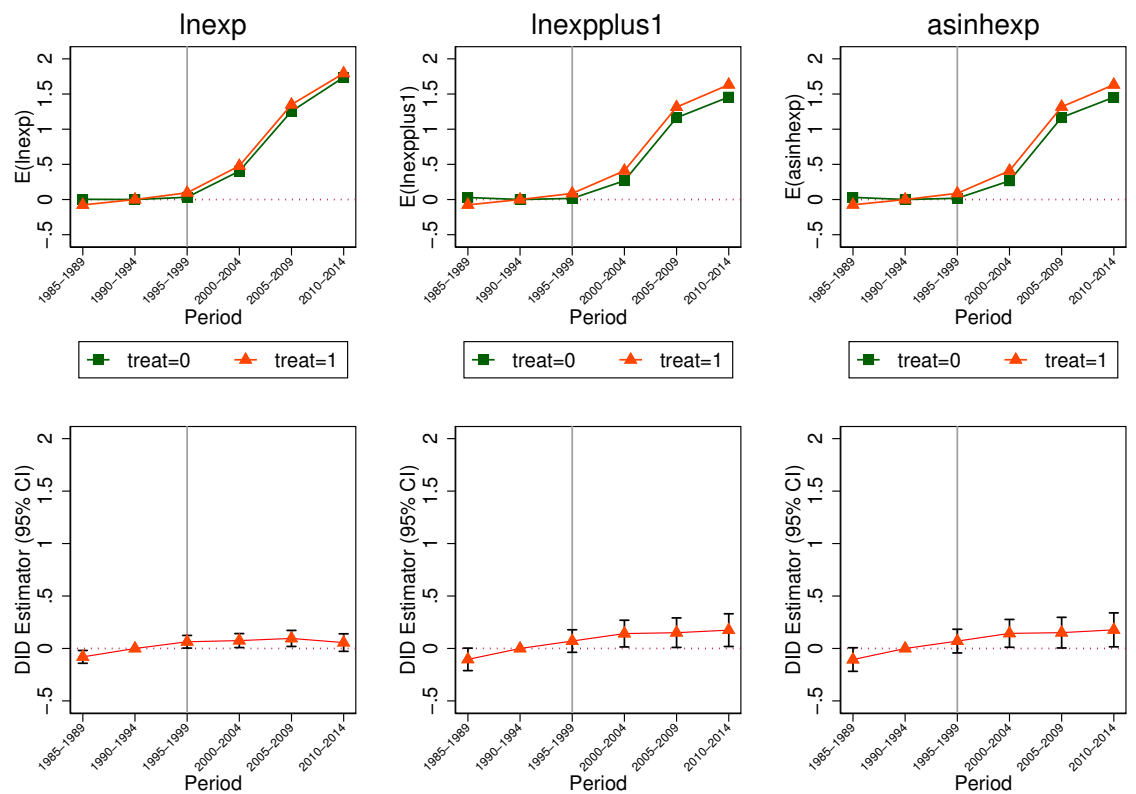

The figures above plot export growth over time for two groups: products for which treat $_{p}=$ 1 , and products for which treat $p=0$. The dependent variable is the 5-year average of exports (each column uses a different linear transformation and the period 1990-1994 is used as the base year). The figures below plot the difference between the difference between the two groups of industries. The results are estimated using 2SLS and control for FDI. 95\% confidence intervals for the estimation are represented by the whiskers. 
Figure 10: "Placebo" test using exports from similar countries
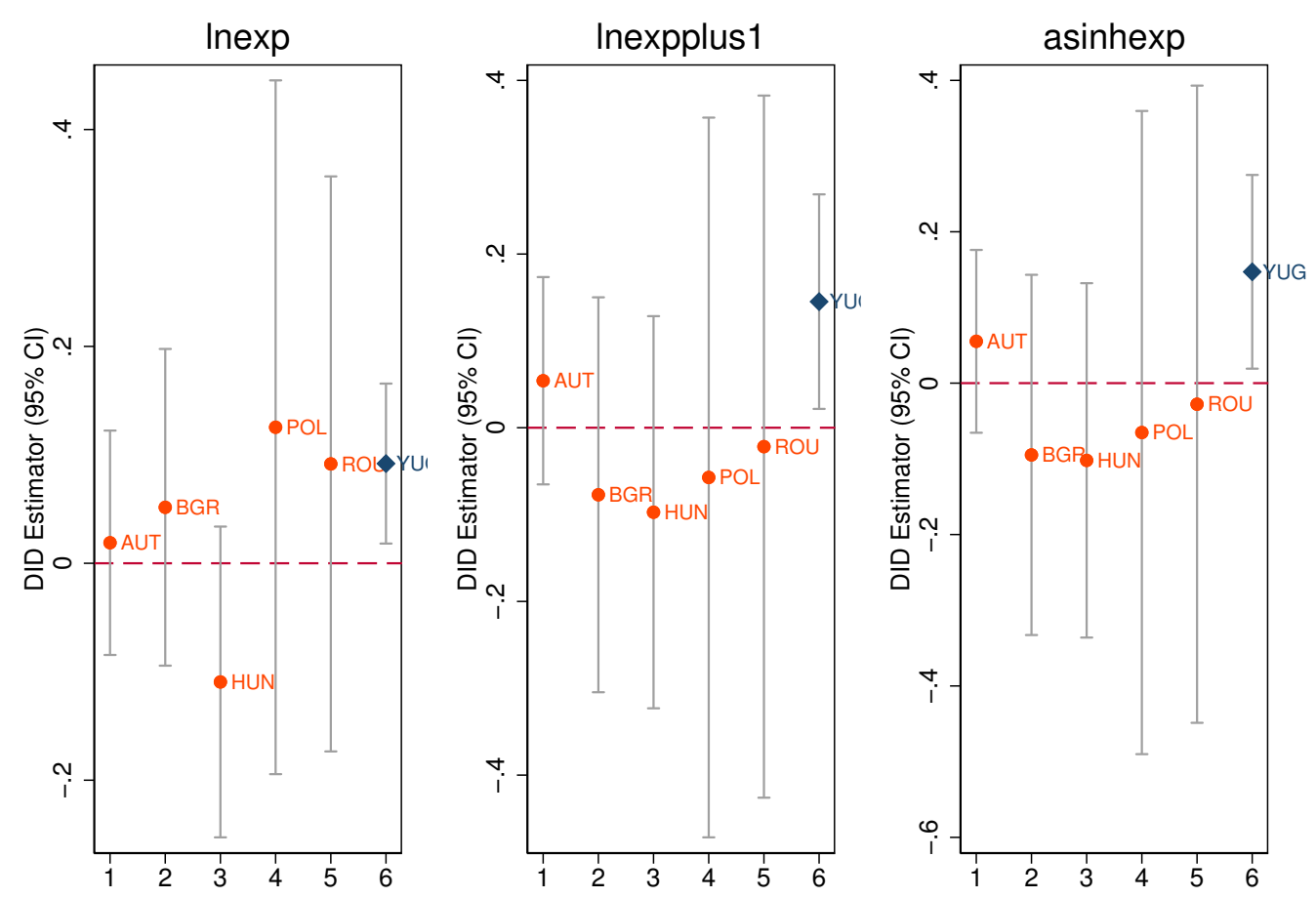

This figure plots coefficients of the estimation for specification 1 for each country, using different monotonic transformations. The estimation uses exports averaged over 1988 to 1990 for the initial year and exports averaged for 2005 to 2007 as the end year. The results are estimated using OLS, and controls for FDI and stock of workers from each respective country. $95 \%$ confidence intervals for the estimation are represented by the whiskers. 
Figure 11: "Placebo" test using return migrants to other countries
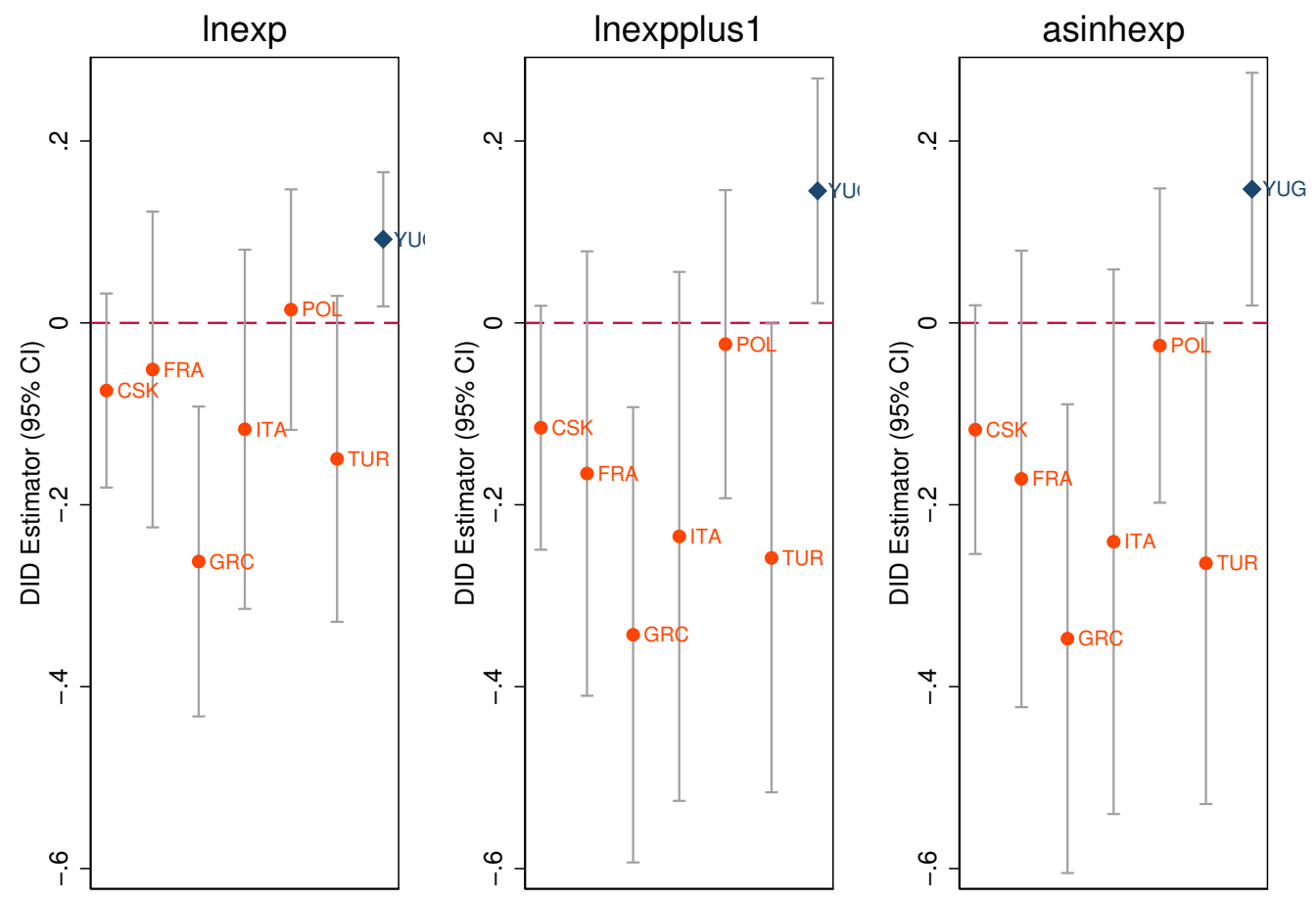

This figure plots coefficients of the estimation for specification 1 for each country, using different monotonic transformations. The estimation uses exports averaged over 1988 to 1990 for the initial year and exports averaged for 2005 to 2007 as the end year. The results are estimated using 2SLS, and controls for FDI and stock of workers from each respective country. $95 \%$ confidence intervals for the estimation are represented by the whiskers. 
Figure 12: Marginal effect by type of migrant

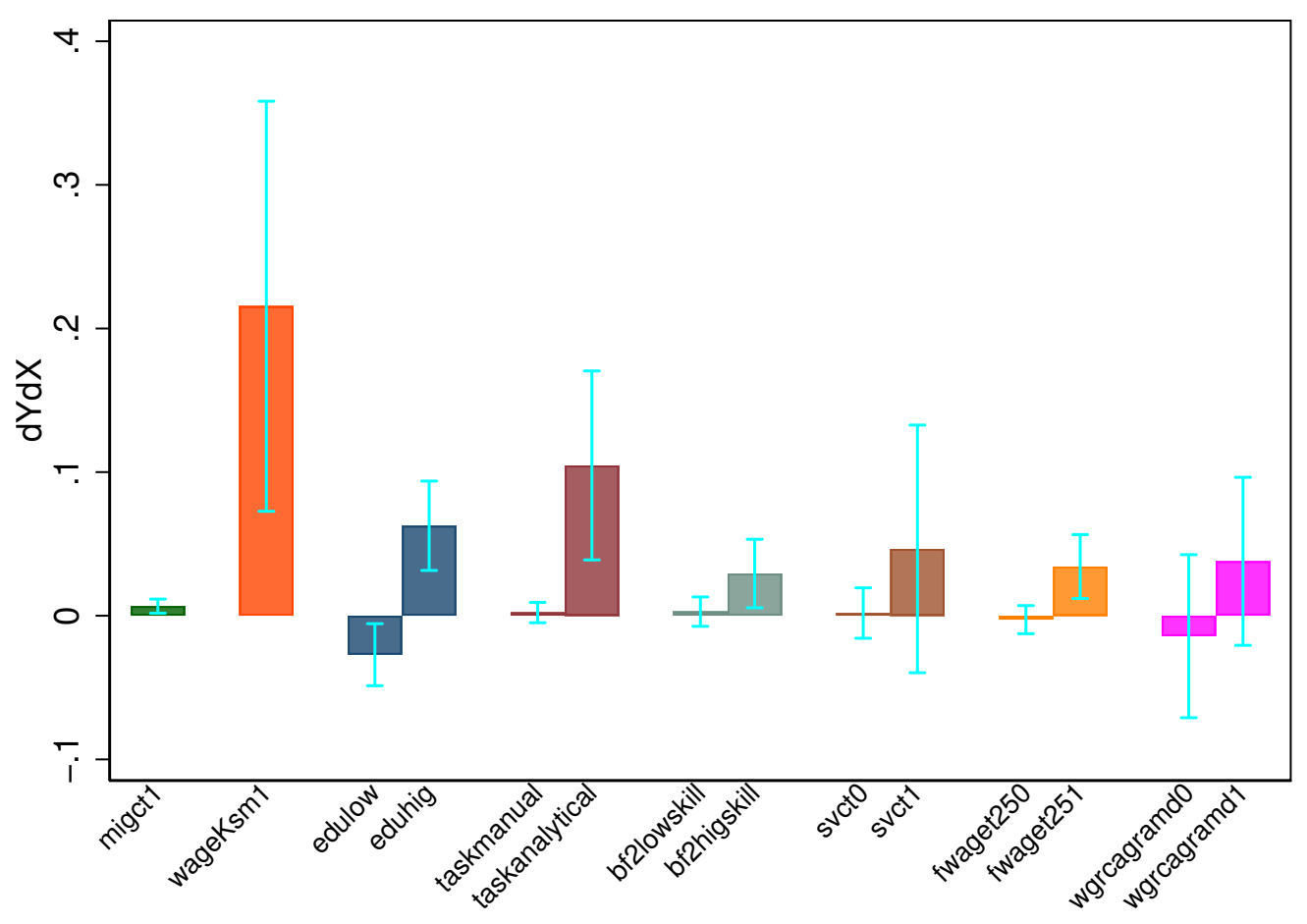

This figure plots the estimated marginal effect of 1 migrant returnee on exports from the home country based on the levels of migrants of each type in the sample. It uses $\operatorname{asinh}\left(\right.$ exports $\left._{p, t}\right)$ as the dependent variables. Whiskers represent 90 percent confidence intervals. 
Table 1: Summary Statistics Yugoslavian Refugees in Germany

\begin{tabular}{lccccc}
\hline \hline Variable & N & Mean & sd & Min & Max \\
\hline Exports YUG in 1990, million USD & 786 & 12.472 & 31.65 & 0.0 & 395.0 \\
Exports YUG in 2005, million USD & 786 & 24.458 & 71.62 & 0.0 & $1,090.0$ \\
YUG workers in 91-95 & 786 & 74.025 & 190.78 & 0.0 & $2,018.7$ \\
YUG workers in 91-95 \& out by 2000 & 786 & 21.641 & 60.61 & 0.0 & 778.5 \\
\hline
\end{tabular}

This table presents the sample summary statistics for the variables used to estimate specification (1). 
Table 2: Difference-in-difference estimation

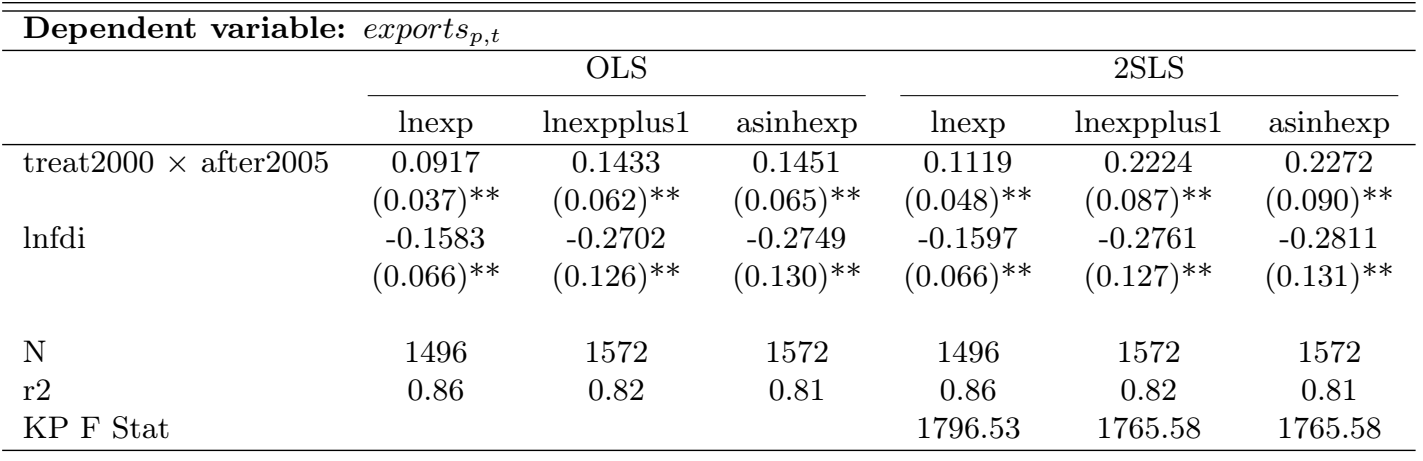

This table shows result of the estimation for specification (1) using different monotonic transformations for export $_{p}, t$ in each column. The estimation uses average exports for years 1988 to 1990 in the "before" period and average exports for years 2005 to 2007 in the "after" period. The first three columns report results from an OLS estimation, while the last three columns report results from a 2SLS estimation. All columns include product fixed effects and year fixed effects. Standard errors clustered at the product level presented in parenthesis.

${ }^{*} p<0.10,{ }^{* *} p<0.05,{ }^{* * *} p<0.01$ 
Table 3: Difference-in-difference estimation, previous trend

\begin{tabular}{|c|c|c|c|c|c|c|}
\hline \multirow[t]{3}{*}{ Dependent variable: } & \multicolumn{6}{|c|}{$\overline{\text { exports }} s_{p, t}$} \\
\hline & \multicolumn{3}{|c|}{ OLS } & \multicolumn{3}{|c|}{$2 \mathrm{SLS}$} \\
\hline & $\operatorname{lnexp}$ & lnexpplus1 & asinhexp & $\ln \exp$ & lnexpplus1 & asinhexp \\
\hline treat $2000 \times$ after 1990 & $\begin{array}{l}0.0382 \\
(0.032)\end{array}$ & $\begin{array}{c}-0.1234 \\
(0.071)^{*}\end{array}$ & $\begin{array}{c}-0.1358 \\
(0.075)^{*}\end{array}$ & $\begin{array}{c}0.0902 \\
(0.039)^{* *}\end{array}$ & $\begin{array}{c}-0.0314 \\
(0.096)\end{array}$ & $\begin{array}{l}-0.0427 \\
(0.101)\end{array}$ \\
\hline $\mathrm{N}$ & 1352 & 1572 & 1572 & 1352 & 1572 & 1572 \\
\hline $\mathrm{r} 2$ & 0.90 & 0.83 & 0.82 & 0.90 & 0.82 & 0.82 \\
\hline KP F Stat & & & & 2409.37 & 2165.02 & 2165.02 \\
\hline
\end{tabular}

This table shows result of the estimation for specification (1) using different monotonic transformations for export $_{p}, t$ in each column. The estimation uses years 1985 and 1990. All columns include product fixed effects and year fixed effects. Standard errors clustered at the product level presented in parenthesis. ${ }^{*} p<0.10,{ }^{* *} p<0.05,{ }^{* * *} p<0.01$ 
Table 4: Difference-in-difference (2SLS) 5 year periods

\begin{tabular}{|c|c|c|c|}
\hline \multicolumn{4}{|c|}{ Dependent variable: export $_{p, t}$} \\
\hline & $\ln \exp$ & lnexpplus1 & asinhexp \\
\hline \multirow[t]{2}{*}{ treat2000 $\times$ Period 1985-1989 } & -0.0810 & -0.1068 & -0.1085 \\
\hline & $(0.031)^{* *}$ & $(0.055)^{*}$ & $(0.058)^{*}$ \\
\hline \multirow[t]{2}{*}{ treat2000 × Period 1995-1999 } & 0.0636 & 0.0711 & 0.0705 \\
\hline & $(0.031)^{* *}$ & $(0.056)$ & $(0.059)$ \\
\hline \multirow[t]{2}{*}{ treat2000 $\times$ Period $2000-2004$} & 0.0755 & 0.1450 & 0.1471 \\
\hline & $(0.034)^{* *}$ & $(0.066)^{* *}$ & $(0.069)^{* *}$ \\
\hline \multirow[t]{2}{*}{ treat2000 $\times$ Period 2005-2009 } & 0.0967 & 0.1544 & 0.1547 \\
\hline & $(0.039)^{* *}$ & $(0.073)^{* *}$ & $(0.076)^{* *}$ \\
\hline \multirow{2}{*}{ treat2000 $\times$ Period $2010-2014$} & 0.0566 & 0.1784 & 0.1814 \\
\hline & $(0.043)$ & $(0.081)^{* *}$ & $(0.084)^{* *}$ \\
\hline $\mathrm{N}$ & 4585 & 4716 & 4716 \\
\hline $\mathrm{r} 2$ & 0.85 & 0.80 & 0.79 \\
\hline KP F Stat & 402.85 & 431.28 & 431.28 \\
\hline
\end{tabular}

This table shows result of the estimation for specification (1) using different monotonic transformations for export $s_{p}, t$ in each column. It estimates the treatment across different 5-year periods. All columns include FDI as control, as well as product fixed effects and 5-year period fixed effects. Standard errors clustered at the product level presented in parenthesis.

${ }^{*} p<0.10,{ }^{* *} p<0.05,{ }^{* * *} p<0.01$ 


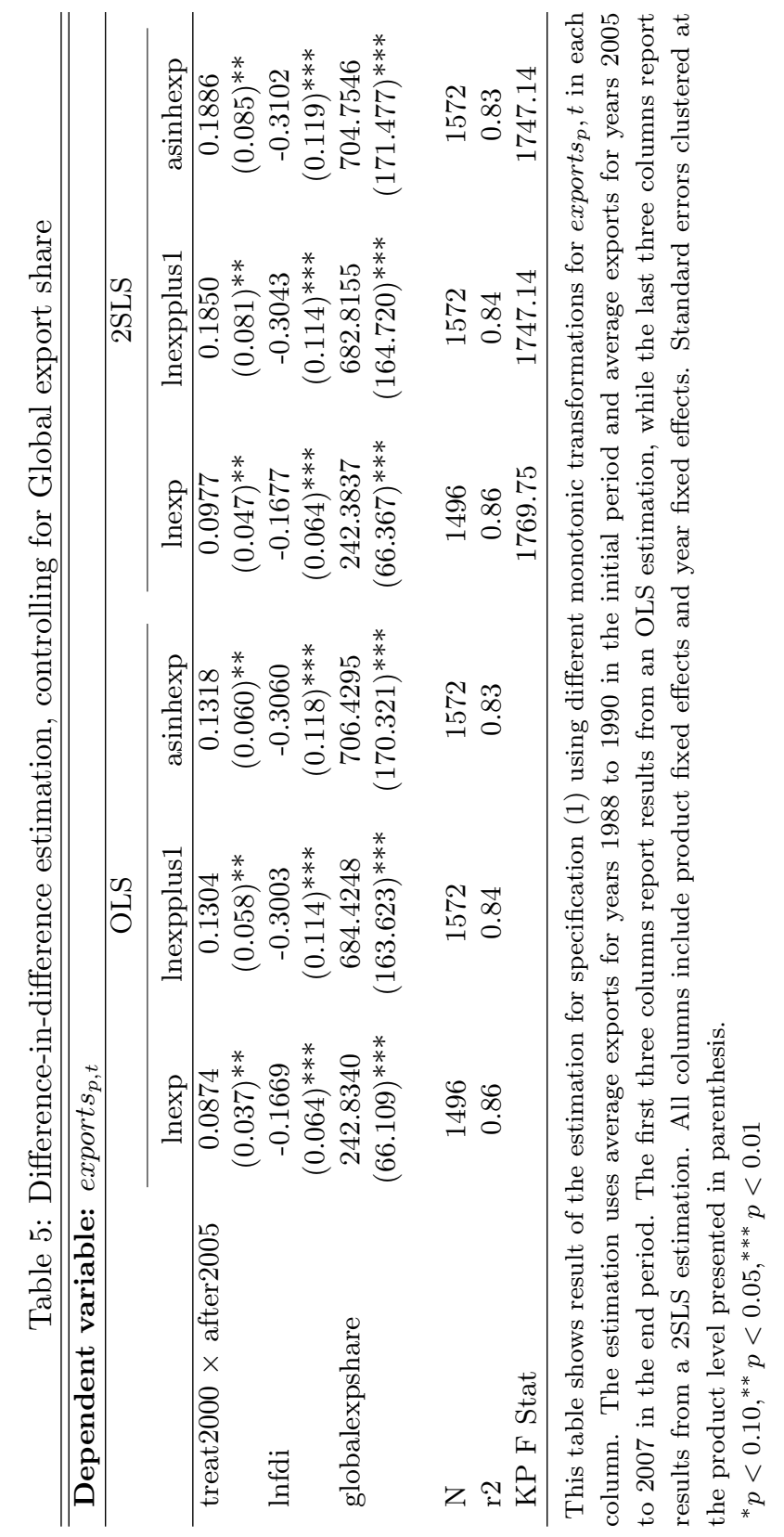




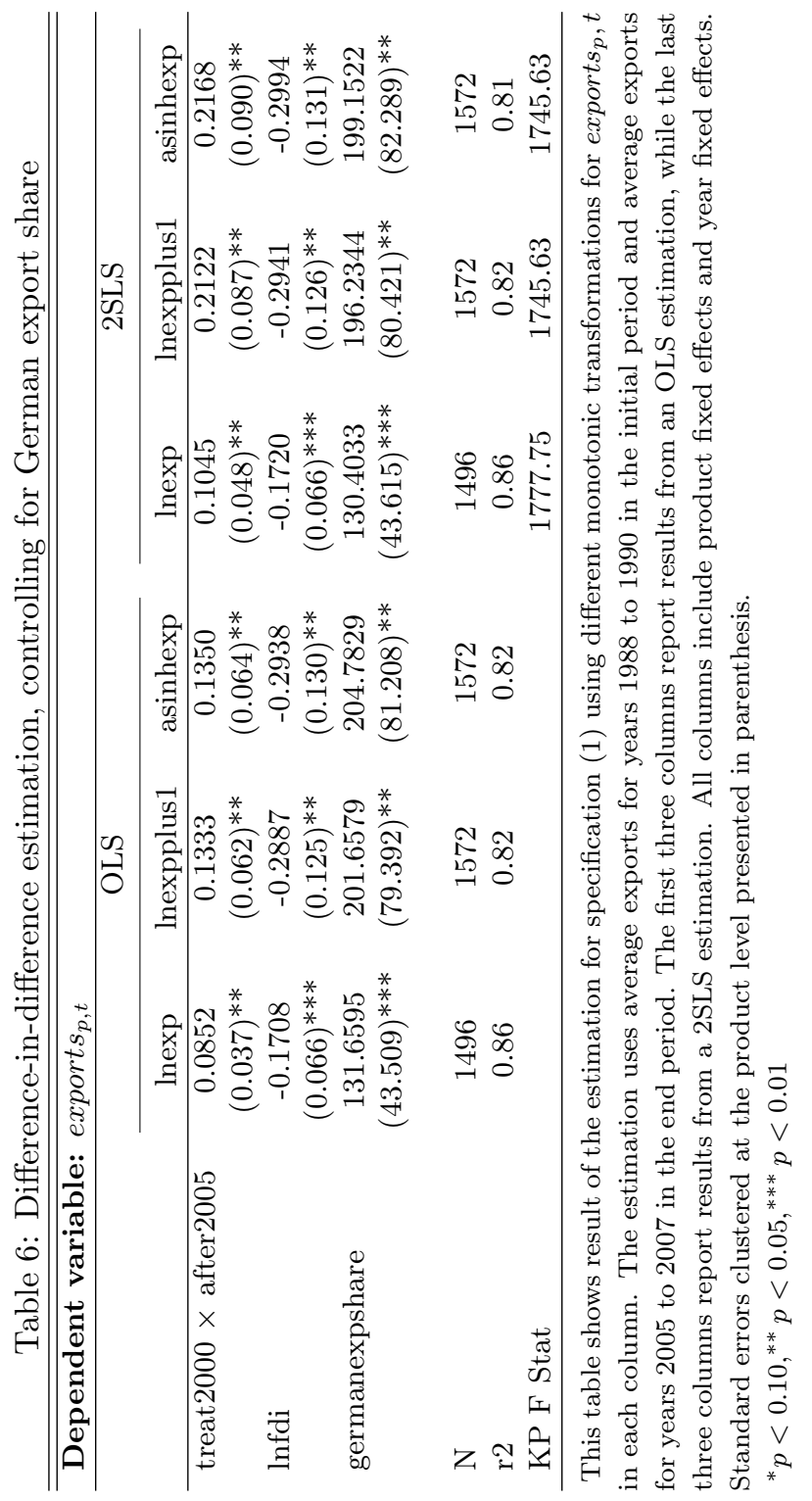


Table 7: Difference-in-difference estimation, using Costinot et al. (2012) measures in LHS

\begin{tabular}{|c|c|c|c|c|}
\hline \multicolumn{5}{|c|}{ Dependent variable: $\Phi_{p, t}$, based on Cosinot et al. (2012) } \\
\hline & \multicolumn{2}{|c|}{ OLS } & \multicolumn{2}{|c|}{$2 \mathrm{SLS}$} \\
\hline & $\operatorname{lnxp}$ & $\operatorname{asinhxp}$ & $\operatorname{lnxp}$ & asinhxp \\
\hline \multirow[t]{2}{*}{ treat $2000 \times$ after 2005} & 0.0232 & 0.0185 & 0.0290 & 0.0231 \\
\hline & $(0.002)^{* * *}$ & $(0.002)^{* * *}$ & $(0.002)^{* * *}$ & $(0.002)^{* * *}$ \\
\hline \multirow[t]{2}{*}{$\operatorname{lnfdi}$} & 0.0046 & 0.0040 & 0.0041 & 0.0037 \\
\hline & $(0.003)$ & $(0.002)^{*}$ & $(0.003)$ & $(0.002)$ \\
\hline $\mathrm{N}$ & 1572 & 1572 & 1572 & 1572 \\
\hline r2 & 0.90 & 0.90 & 0.90 & 0.90 \\
\hline KP F Stat & & & 1940.01 & 1940.01 \\
\hline
\end{tabular}

This table shows result of the estimation for specification (1) using different monotonic transformations for $\Phi_{p, t}$ in each column. $\Phi_{p, t}$ is a measure of comparative advantage estimated following Costinot et al. (2012). The first two columns report results from an OLS estimation, while the last two columns report results from a 2SLS estimation. All columns include product fixed effects and year fixed effects. All columns include product fixed effects and year fixed effects. Standard errors clustered at the product level presented in parenthesis.

${ }^{*} p<0.10,{ }^{* *} p<0.05,{ }^{* * *} p<0.01$ 
Table 8: Difference-in-differences, by region of destination

\begin{tabular}{l|lll|lll}
\hline \hline & \multicolumn{5}{|c}{ OLS } \\
\hline Exports to... & $\log (\exp )$ & $\log (\exp +1)$ & $\operatorname{asinh}(\exp )$ & $\log (\exp )$ & $\log (\exp +1)$ & $\operatorname{asinh}(\exp )$ \\
\hline weurope & $0.106^{* * *}$ & 0.108 & 0.105 & $0.135^{* * *}$ & 0.113 & 0.108 \\
eeurope & $0.306^{* * *}$ & -0.238 & -0.278 & $0.192^{* * *}$ & -0.422 & -0.474 \\
namerica & $0.172^{* * *}$ & $0.182^{*}$ & $0.178^{*}$ & $0.138^{*}$ & $0.235^{* *}$ & $0.232^{*}$ \\
easiapac & $0.217^{* * *}$ & 0.091 & 0.079 & $0.150^{* *}$ & 0.010 & -0.007 \\
meastnafr & 0.010 & $0.200^{* *}$ & $0.211^{* *}$ & 0.067 & $0.289^{* *}$ & $0.304^{* *}$ \\
lac & $0.204^{* * *}$ & $0.221^{* *}$ & $0.216^{* *}$ & 0.137 & $0.255^{* *}$ & $0.251^{*}$ \\
ssa & $0.188^{* * *}$ & $0.217^{* *}$ & $0.215^{* *}$ & $0.123^{*}$ & 0.150 & 0.146 \\
\hline
\end{tabular}

This table shows result of the estimation for $\beta^{D I D}$ from specification (1), where each rows limits the importing countries to the different geographic regions. The first three columns report results from an OLS estimation, while the last three columns report results from a 2SLS estimation. All columns include product fixed effects and year fixed effects. Each group of results uses different monotonic transformations for exports,$t$ in each column. All columns include FDI as control, as well as product fixed effects and year fixed effects. Standard errors clustered at the product level presented in parenthesis.

${ }^{*} p<0.10,{ }^{* *} p<0.05,{ }^{* * *} p<0.01$ 
Table 9: Difference-in-differences (2SLS), heterogeneity analysis

\begin{tabular}{|c|c|c|c|}
\hline \multicolumn{4}{|c|}{ Panel A: Differentiated vs. Homogenous } \\
\hline & $\ln \exp$ & lnexpplus1 & asinhexp \\
\hline \multirow[t]{2}{*}{ TreatmentXAfter } & 0.0163 & 0.1562 & 0.1627 \\
\hline & $(0.063)$ & $(0.113)$ & $(0.117)$ \\
\hline \multirow{2}{*}{ TreatmentXAfterXDiff } & 0.1284 & 0.1083 & 0.1070 \\
\hline & $(0.048)^{* * *}$ & $(0.074)$ & $(0.076)$ \\
\hline $\mathrm{N}$ & 1356 & 1408 & 1408 \\
\hline $\mathrm{r} 2$ & 0.86 & 0.80 & 0.80 \\
\hline KP F Stat & 701.94 & 484.63 & 484.63 \\
\hline \multicolumn{4}{|c|}{ Panel B: Physical Capital Intensity } \\
\hline & $\operatorname{lnexp}$ & lnexpplus1 & asinhexp \\
\hline \multirow[t]{2}{*}{ TreatmentXAfter } & 0.1473 & 0.1614 & 0.1603 \\
\hline & $(0.052)^{* * *}$ & $(0.090)^{*}$ & $(0.093)^{*}$ \\
\hline \multirow[t]{2}{*}{ TreatmentXAfterXKI } & -0.0135 & -0.0280 & -0.0289 \\
\hline & $(0.022)$ & $(0.030)$ & $(0.031)$ \\
\hline $\mathrm{N}$ & 1328 & 1364 & 1364 \\
\hline $\mathrm{r} 2$ & 0.86 & 0.82 & 0.82 \\
\hline KP F Stat & 466.82 & 464.19 & 464.19 \\
\hline \multicolumn{4}{|c|}{ Panel C: Human Capital Intensity } \\
\hline & $\ln \exp$ & lnexpplus1 & asinhexp \\
\hline \multirow[t]{2}{*}{ TreatmentXAfter } & 0.0761 & 0.1593 & 0.1627 \\
\hline & $(0.047)$ & $(0.082)^{*}$ & $(0.086)^{*}$ \\
\hline \multirow[t]{2}{*}{ TreatmentXAfterXHCI } & 0.0749 & 0.1070 & 0.1086 \\
\hline & $(0.024)^{* * *}$ & $(0.039)^{* * *}$ & $(0.040)^{* * *}$ \\
\hline $\mathrm{N}$ & 1488 & 1562 & 1562 \\
\hline $\mathrm{r} 2$ & 0.86 & 0.82 & 0.82 \\
\hline KP F Stat & 931.54 & 957.06 & 957.06 \\
\hline
\end{tabular}

This table shows result of the estimation for specification (1), interacting the term treat $_{p} \times$ after $_{t}$ with three variables indicating product characteristics: differentiated vs. homogeneous goods (top panel), capital intensity (middle panel) and human capital intensity (bottom panel). Each group of results uses different monotonic transformations for exports $s_{p}, t$ in each column. All columns include FDI as control, as well as product fixed effects and year fixed effects. Standard errors clustered at the product level presented in parenthesis.

${ }^{*} p<0.10,{ }^{* *} p<0.05,{ }^{* * *} p<0.01$ 
Table 10: Difference-in-differences (OLS), workers' education and occupations

\begin{tabular}{l|lll}
\hline \hline$\beta_{D I D}$ & $\log (\exp )$ & $\log (\exp +1)$ & $\operatorname{asinh}(\exp )$ \\
\hline migct1 & $0.092^{* *}$ & $0.143^{* *}$ & $0.145^{* *}$ \\
\hline wageKsm1 & $0.165^{* *}$ & $0.250^{* *}$ & $0.253^{* *}$ \\
\hline edulow & -0.357 & -0.309 & -0.307 \\
eduhig & $0.502^{* * *}$ & $0.509^{* * *}$ & $0.509^{* * *}$ \\
\hline taskmanual & 0.001 & 0.037 & 0.038 \\
taskanalytical & $0.184^{* *}$ & $0.218^{* * *}$ & $0.219^{* * *}$ \\
\hline bf2lowskill & -0.003 & 0.043 & 0.044 \\
bf2higskill & $0.146^{* *}$ & $0.160^{* *}$ & $0.161^{* *}$ \\
\hline svct0 & -0.049 & 0.030 & 0.032 \\
svct1 & 0.218 & 0.179 & 0.178 \\
\hline fwaget250 & -0.077 & -0.041 & -0.039 \\
fwaget251 & $0.216^{* * *}$ & $0.242^{* * *}$ & $0.242^{* *}$ \\
\hline wgrcagramd0 & -0.087 & -0.096 & -0.096 \\
wgrcagramd1 & 0.187 & 0.252 & 0.254 \\
\hline \hline
\end{tabular}

This table shows result of the estimation for specification (1) using treatments constructed by aggregating workers by groups based on their skills and/or occupations. The table presents OLS estimations. Each group of results uses different monotonic transformations for exports $s_{p, t}$ in different columns column. All columns include FDI as control, as well as product fixed effects and year fixed effects. Standard errors clustered at the product level presented in parenthesis.

${ }^{*} p<0.10,{ }^{* *} p<0.05,{ }^{* * *} p<0.01$ 


\section{Online Appendix for \\ Let their knowledge flow: The effect of returning \\ refugees on export performance in the former \\ Yugoslavia}

Dany Bahar, Andreas Hauptmann, Cem Özgüzel and Hillel Rapoport

November 26, 2018

\section{A Anecdotal evidence: Four individual stories}

In 1999, only four years after having returned from Wolfsburg in Germany, Volkswagen's home town, Nijaz Hastor founded the Prevent group, currently one of Bosnia's largest companies. Prevent began manufacturing seat covers in the city of Visoko in Bosnia with a staff of 50, and has since diversified into yacht interiors, protective clothing, brake disks and fashion textiles. By 2016, the Prevent Group employed over 6,500 people and operated from about 15 different sites in Bosnia, exporting its products to a large number of different destinations across Europe and beyond. Hastor started his career working for a local firm supplying car parts in Sarajevo, but it is likely that the knowhow he acquired while working as an immigrant for the auto industry in Germany helped him build a world-class company able to manufacture high-end auto parts with high efficiency.

Almir Gvožđar is another example of a refugee who used his newly acquired skills and contacts to create his own company in a new industry. In 1996, following his return from Germany, Gvožđar invested all of his savings in a 
second-hand CNC machine tool and founded GAT Ltd in his family garage. Working alone, Gvožđar started producing motorcycle parts and selling them to his former employer in Germany, ABM Fahrzeugtechnik GmbH, a leading manufacturer of high-performance parts for the motorcycle industry, where he had worked as a technician during the war. Over the years, as the number of clients increased, business expanded as well. Currently GAT employs 65 people, operates from a facility of $1100 \mathrm{~m}^{2}$ and exports motorcycle parts and medical instruments across Western Europe.

Refugees who were hosted in other countries also had similar experiences. For instance, Enes Kahrimanovic left $\mathrm{BiH}$ in 1991 and moved to Austria where he started working for the Plaspack Company, one of the largest manufacturers and distributors of nets, transparencies and advertising transparencies in the EU, a sector in which he had no previous experience. As Austria allowed its refugees to become permanent residents, Kahrimanovic continued working at the Plaspack following the peace treaty. While working at the Plaspack, Kahrimanovic realized that some of the intermediary products imported from rest of Europe can be produced in Bosnia. Over the years, Kahrimanovic worked on finding partners in Bosnia that could supply the imported pieces. As deals with local companies were struck, the Plaspack Company supplied more and more of its parts from Bosnia. Finally, Austrian owners of the Plaspack decided to start a production in Bosnia, and gave Kahrimanovic the full responsibility of both establishing and managing the company. In 2007, he founded Austronet in the city of Kozarac and with a staff of 5 and started manufacturing safety netting for tennis courts and protective netting for the construction industry. Today this company employs 72 people and exports $97 \%$ of its production.

Although individual initiative has been an important element for the transfer of knowhow, it was not indispensable as it can be seen in the case of the 
Kavat Shoe Factory workers. In the beginning of the 1990s shoemaking was a trade that was declining in Sweden and Kavat, a shoe manufacturer specialized in high-quality leather shoes was having difficulties finding skilled craftsmen. When Bosnian refugees from Travnik, a region specialized in the textile industry, arrived to Kumla where the Kavat factory is located, it didn't take long before they were recruited. By working for Kavat, Bosnians acquired skills in shoemaking and learned about modern equipment and technologies. Kavat was so satisfied with its Bosnian employees that when they returned to Travnik after the war it helped them establish a production facility and integrated it to its supply chain. Over the years, as the demand for Kavat shoes increased, the company felt the need to expand its production. The decision for location, as put by the company, came naturally. In 2009 Kavat opened a factory in Travnik and recruited its former employees. Today Kavat is an international company which manufacture about 400.000 pairs of shoes every year, out of which 350.000 are made in their factory located in Bosnia.

\section{B Details on data, sample construction and vari- able description}

The employment data in Germany are based on the universe of social security notifications of all employees subject to social security contributions for the years 1975-2014 (IAB, 2015). For data privacy reasons we were not allowed to work with the full BeH data file. The data was provided by the IT Services and Information Management (ITM) of the IAB. A $40 \%$ random sample of foreign nationals on June 30 of each year was drawn and matched with all related individual $\mathrm{BeH}$ accounts which enables us to follow workers back and forth in time. 
Then the variable on educational attainment was corrected by ITM using information on past and future values (see more below). We keep all spells subject to social security contributions without specific tokens. Specific tokens are given to e.g. apprentices, employees in partial retirement, marginal parttime workers, seamen, or artists liable to social security. We keep one spell for per person-firm combination and focus on spells in tradable industries only. The $\mathrm{BeH}$ contains information on the industry affiliation, but different classifications have been applied over time. Therefore, we use time-consistent industry codes developed for these data by Eberle et al. (2011). In particular we use the German classification WZ 93 which corresponds to the European classification of NACE Rev. 1. When matching German 3-digit industry codes to 4-digit SITC product codes we apply correspondence tables provided by the United Nation Statistical Office and Dauth et al. (2014). If the source category applies to more than one target category we distribute workers according to the shares of German exports of those categories for each year separately. ${ }^{49}$

\section{Zeroes in the data}

There are 38 products that Yugoslavia does not export in either the pre-treatment period (1988-1990) or the post-treatment period (2005-2007). These products are excluded from our model when we examine log exports, but included in two other specifications. Including these products has a large impact on the magnitude of our estimated treatment effect, doubling the size of the coefficient in our instrumental variable specification (see Table 2 in main text).

For this reason, we look more closely at the prevalence of zero export prod-

\footnotetext{
${ }^{49}$ Using this weighting scheme we use the implicit assumption that German export shares are a good proxy for employment of Yugoslavians across German at the product level (SITC 4 digits). This is something we cannot directly test for because our data on employment is at the industry level (WZ 93 3-digit). However, when looking at the correlation between German exports and employment share of Yugoslavian workers by industry (WZ 93 3-digit) we find it is reasonably high: for the years 1991 to 1995 is 0.72 and statistically significant.
} 
ucts in this appendix. If the zeros mostly occur in the pre-treatment period, we might conclude that returning migrants launched new industries in Yugoslavia, which would explain the increased size of the treatment effect. However, this is not the case. Between the pre- and post-periods, 12 product lines were opened and 16 product lines were closed, and the product lines that were closed are much larger than those that opened. Three of the closed product lines are especially large, with exports over $\$ 20$ million in the pre-period but nothing in the post period. All three of these products are liquid fuels. Our results are robust to the exclusion of these three fuels, and we find that those products alone do not cause the increase in the size of the estimated treatment effect.

Given that Yugoslavia does export 770 of 786 products in the pre-treatment period, we examine the total number of products exported by other countries in that period to ascertain whether Yugoslavia is unusual in having so many export lines. We find that it is in fact not uncommon for countries to export so many products, and several developing markets a comparable levels of GDP per capita have a greater number of exports. This is shown in Figure C1.

\section{[Figure $\mathrm{C} 1$ about here.]}

We also consider the possibility that, though Yugoslavia exports many products, most of these export lines are small and insignificant. If this were true, our use of product fixed effects means that our results could be produced by sectors that are largely unimportant to the former Yugoslavian economies today. We therefore ran our main results excluding products with fewer than $\$ 25,000$ in exports in the pre-treatment period. Our results hold using this sub-sample, and we see that just 81 of 786 products have exports of less than $\$ 25,000$. We therefore conclude that the change in our estimated treatment effect changes when we add products with zero exports does not reflect a larger pattern of zeros driving our results. 
Figure C1: Exploration of zeros in our data

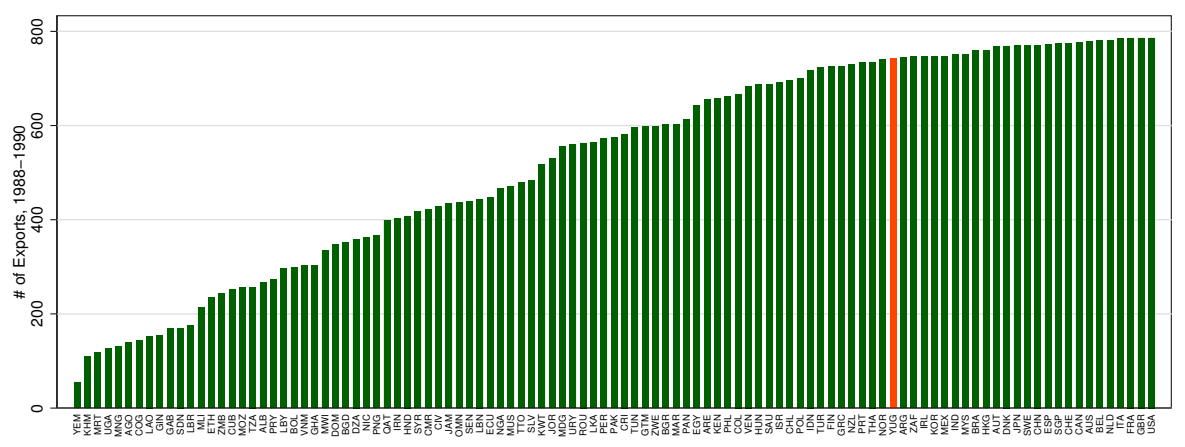

The figure compare the number of products exported to the rest of the world with reported export value above zero in the baseline period. The figure shows that Yugoslavia is no outlier in terms of the number of products exported (or, alternatively, the number of products with export value equal to zero). 


\section{Including exports to Germany}

Our main estimations purposely excludes exports to Germany from the dependent variable, to avoid our results being driven by a reduction of transaction costs following return migration. Table D1 presents results with total exports from Yugoslavian countries to the rest of the world, including to Germany. As expected, our point estimates are larger than in the main results.

[Table D1 about here.] 
Table D1: Difference-in-difference estimation, including exports to Germany Dependent variable: export $_{p, t}$

\begin{tabular}{|c|c|c|c|c|c|c|}
\hline & \multicolumn{3}{|c|}{ OLS } & \multicolumn{3}{|c|}{$2 \mathrm{SLS}$} \\
\hline & $\ln \exp$ & lnexpplus1 & asinhexp & $\ln \exp$ & lnexpplus1 & asinhexp \\
\hline \multirow[t]{2}{*}{ treat $2000 \times$ after 2005} & 0.1009 & 0.1504 & 0.1522 & 0.1194 & 0.2275 & 0.2324 \\
\hline & $(0.037)^{* * *}$ & $(0.063)^{* *}$ & $(0.065)^{* *}$ & $(0.048)^{* *}$ & $(0.087)^{* * *}$ & $(0.091)^{* *}$ \\
\hline \multirow[t]{2}{*}{$\operatorname{lnfdi}$} & -0.1500 & -0.2623 & -0.2671 & -0.1513 & -0.2681 & -0.2731 \\
\hline & $(0.066)^{* *}$ & $(0.126)^{* *}$ & $(0.131)^{* *}$ & $(0.066)^{* *}$ & $(0.127)^{* *}$ & $(0.132)^{* *}$ \\
\hline $\mathrm{N}$ & 1496 & 1572 & 1572 & 1496 & 1572 & 1572 \\
\hline r2 & 0.86 & 0.82 & 0.82 & 0.86 & 0.82 & 0.82 \\
\hline KP F Stat & & & & 1796.53 & 1765.58 & 1765.58 \\
\hline
\end{tabular}

This table shows result of the estimation for specification (1) using different monotonic transformations for export $_{p}, t$ in each column. The estimation uses average exports for years 1988 to 1990 in the initial period and average exports for years 2005 to 2007 in the end period. The dependent variable includes exports to Germany. The first three columns report results from an OLS estimation, while the last three columns report results from a 2SLS estimation. All columns include product fixed effects and year fixed effects. Standard errors clustered at the product level presented in parenthesis.

${ }^{*} p<0.10,{ }^{* *} p<0.05,{ }^{* * *} p<0.01$ 


\section{E Foreign Direct Investment}

Some endogeneity concerns might remain given the lack of use of a measure of FDI stocks in Yugoslavia which include not only Germany but most other countries. The reason for the concern is that the inflow of workers with skills relevant to a particular industry might trigger FDI into the country, from several sources, which can be the explanatory source of the rise of exports that we document. In order to deal with that, we gather data on aggregate FDI stocks in Yugoslavian countries by 2-digit SITC products in 2005. Given the lack of data of FDI stocks in Yugoslavia disaggregated by product before its dissolution, we assume the stock was zero in the "before" period of 1990. The data comes from The Vienna Institute for International Economic Studies (wiiw). Table E1 shows our main results are robust to the inclusion of the global FDI stock in Yugoslavia instead of the FDI from Germany only.

\section{[Table E1 about here.]}

In addition to this, the results presented in the paper raise some concerns regarding the negative sign of the estimates of the partial correlation of FDI stocks and export levels. If anything, we would expect this control to have a positive sign. To explore what is that drives this unexpected relationship we reestimate a variation of specification (1) that only includes the FDI variable on the right hand side. That is, we are analyzing the partial correlation between exports and FDI in our setting. The results are presented in Table E2. Columns 1-3 uses both product and year fixed effects, while columns 4-6 only uses year fixed effects. We can see that when excluding the product fixed effects the partial correlation between exports and FDI is estimated to be a positive one, as expected. This occurs, plausibly, because introducing the product fixed effects leave very little variation to be use in the estimation of the FDI coefficient, 
particularly because the FDI figures are defined at the 2 digit level, and the fixed effects at the 4-digit level. All in all, we find that when excluding the product fixed effects, products that have more FDI during that period explain larger export growth, as it is to be expected.

[Table E2 about here.] 
Table E1: Difference-in-difference estimation, using global FDI

\begin{tabular}{|c|c|c|c|c|c|c|}
\hline \multicolumn{7}{|c|}{ Dependent variable: exports $_{p, t}$} \\
\hline & \multicolumn{3}{|c|}{ OLS } & \multicolumn{3}{|c|}{ 2SLS } \\
\hline & $\ln \exp$ & lnexpplus1 & $\overline{\text { asinhexp }}$ & $\operatorname{lnexp}$ & lnexpplus1 & asinhexp \\
\hline \multirow[t]{2}{*}{ treat $2000 \times$ after 2005} & $\frac{1}{0.0788}$ & 0.1268 & 0.1284 & 0.1052 & 0.2082 & 0.2125 \\
\hline & $(0.037)^{* *}$ & $(0.062)^{* *}$ & $(0.065)^{* *}$ & $(0.046)^{* *}$ & $(0.082)^{* *}$ & $(0.085)^{* *}$ \\
\hline \multirow[t]{2}{*}{ lnglobalfdi } & -0.1044 & -0.1362 & -0.1372 & -0.1011 & -0.1282 & -0.1289 \\
\hline & $(0.050)^{* *}$ & $(0.084)$ & $(0.087)$ & $(0.050)^{* *}$ & $(0.084)$ & $(0.087)$ \\
\hline $\mathrm{N}$ & 1496 & 1572 & 1572 & 1496 & 1572 & 1572 \\
\hline $\mathrm{r} 2$ & 0.86 & 0.82 & 0.81 & 0.86 & 0.82 & 0.81 \\
\hline KP F Stat & & & & 2436.28 & 2441.33 & 2441.33 \\
\hline
\end{tabular}

This table shows result of the estimation for specification (1) using different monotonic transformations for exports $s_{p}, t$ in each column. The estimation uses average exports for years 1988 to 1990 in the initial period and average exports for years 2005 to 2007 in the end period. It includes as a control the global FDI stock in Yugoslavia by industry, as opposed to the Germany FDI stock only. The first three columns report results from an OLS estimation, while the last three columns report results from a 2SLS estimation. All columns include product fixed effects and year fixed effects. Standard errors clustered at the product level presented in parenthesis.

${ }^{*} p<0.10,{ }^{* *} p<0.05,{ }^{* * *} p<0.01$ 
Table E2: Exports vs. FDI

\begin{tabular}{|c|c|c|c|c|c|c|}
\hline \multicolumn{7}{|c|}{ Dependent variable: exports $s_{p, t}$} \\
\hline & $\ln \exp$ & lnexpplus1 & asinhexp & $\ln \exp$ & lnexpplus1 & asinhexp \\
\hline $\operatorname{lnfdi}$ & $\begin{array}{c}-0.1518 \\
(0.066)^{* *}\end{array}$ & $\begin{array}{c}-0.2594 \\
(0.125)^{* *}\end{array}$ & $\begin{array}{c}-0.2640 \\
(0.130)^{* *}\end{array}$ & $\begin{array}{c}0.1421 \\
(0.062)^{* *}\end{array}$ & $\begin{array}{c}0.2519 \\
(0.090)^{* * *}\end{array}$ & $\begin{array}{c}0.2573 \\
(0.092)^{* * *}\end{array}$ \\
\hline $\mathrm{N}$ & 1496 & 1572 & 1572 & 1524 & 1572 & 1572 \\
\hline r2 & 0.86 & 0.82 & 0.81 & 0.03 & 0.02 & 0.02 \\
\hline Product FE & $\mathrm{Y}$ & $\mathrm{Y}$ & $\mathrm{Y}$ & $\mathrm{N}$ & $\mathrm{N}$ & $\mathrm{N}$ \\
\hline
\end{tabular}

This table shows result of the estimation for specification (1) that only includes FDI stock as the right hand side variable, using different monotonic transformations for exports $s_{p}, t$ in each column. The first 3 columns include product fixed effects and the following 3 columns do not include those product fixed effects. All columns include year fixed effects. Standard errors clustered at the product level presented in parenthesis.

${ }^{*} p<0.10,{ }^{* *} p<0.05,{ }^{* * *} p<0.01$ 


\section{F Further tests on the exogeneity of exit from the labor force}

Figure 8 presents a very convincing picture in terms of the exogeneity of exit from the labor force. Yet, we still see some important outliers in that graph as measured by their distance to the 45 degree line.

This, and all the other smaller deviations, could happen in part because we know that not all of those entering the labor force between 1991 and 1995 are in fact Duldung holders given that some of them stayed on beyond the year 2000 . Yet, given this fact, the correlation between the two measures is quite high.

But yet again, the question is whether the exit from the labor force is exogenous with respect to the dynamics of exports at the product level back in Yugoslavia. In order to find whether the outliers are an issue to be concern about, we first compute a measure of the deviations from the 45 degree line which is the difference between the horizontal axis and the vertical axis. If this measure is above 0 for a given industry, for instance, it means the proportion of those Yugoslavians exiting from that industry was higher than the proportion of those who arrived to it.

We correlate this measure with the growth rate of Yugoslavian exports by industry between 1990 and 2005. Using three different measures of export growth that subtract the 1990 from the 2005 value after transforming export values in

both periods using $\log (x), \log (x+1)$ and $\operatorname{asinh}(x)$, the correlations result in $-0.0295,-0.0138,-0.0133$, respectively, all statistically insignificant.

\section{G Robustness Checks}

G1 reports 2SLS estimation for specification (1) using alternatives treatments. The first three columns use the difference in Yugoslavian workers per industry 
between 2005 and 1995, and the following three columns simply uses the baseline stock of Yugoslavian workers per industry in 1995.

[Table G1 about here.]

Table G2 reports 2SLS estimation for specification (1) using only observations with non-zero exports for the two monotonic transformations of the dependent variable $\log \left(\operatorname{export}_{c, p, t}+1\right)$ and $\operatorname{asinh}\left(\operatorname{export}_{c, p, t}\right)$.

[Table G2 about here.] 
Table G1: Difference-in-difference estimation, different treatments

\begin{tabular}{|c|c|c|c|c|c|c|}
\hline \multicolumn{7}{|c|}{ Dependent variable: exports $s_{p, t}$} \\
\hline & $\operatorname{lnexp}$ & $\operatorname{lnexp}$ & lnexpplus1 & lnexpplus1 & asinhexp & asinhexp \\
\hline treat $2005 \times$ after 2005 & $\begin{array}{c}0.0882 \\
(0.049)^{*}\end{array}$ & & $\begin{array}{c}0.2363 \\
(0.123)^{*}\end{array}$ & & $\begin{array}{c}0.2416 \\
(0.129)^{*}\end{array}$ & \\
\hline treat1995level $\times$ after 2005 & & $\begin{array}{c}0.0711 \\
(0.040)^{*}\end{array}$ & & $\begin{array}{c}0.1873 \\
(0.097)^{*}\end{array}$ & & $\begin{array}{c}0.1916 \\
(0.102)^{*}\end{array}$ \\
\hline $\operatorname{lnfdi}$ & $\begin{array}{c}-0.0707 \\
(0.068)\end{array}$ & $\begin{array}{r}-0.0756 \\
(0.068)\end{array}$ & $\begin{array}{c}-0.1856 \\
(0.149)\end{array}$ & $\begin{array}{c}-0.1976 \\
(0.151)\end{array}$ & $\begin{array}{c}-0.1901 \\
(0.155)\end{array}$ & $\begin{array}{c}-0.2024 \\
(0.157)\end{array}$ \\
\hline $\mathrm{N}$ & 1428 & 1428 & 1572 & 1572 & 1572 & 1572 \\
\hline $\mathrm{r} 2$ & 0.01 & 0.01 & 0.01 & 0.01 & 0.01 & 0.01 \\
\hline KP F Stat & 1448.35 & 3044.57 & 1736.97 & 3632.82 & 1736.97 & 3632.82 \\
\hline
\end{tabular}

This table shows result of the 2SLS estimation for specification (1) using different monotonic transformations for export $_{p}, t$ in each column. The estimation uses two other different definitions of treatment: (i) return migrants between 1995 and 2005, and (ii) the stock of migrant workers in 1995. The estimation uses exports between 1990 and 2005. All columns include product fixed effects and year fixed effects. Standard errors clustered at the product level presented in parenthesis.

${ }^{*} p<0.10,{ }^{* *} p<0.05,{ }^{* * *} p<0.01$ 
Table G2: Difference-in-difference estimation, no zeros

\begin{tabular}{|c|c|c|c|c|}
\hline \multicolumn{5}{|c|}{ Dependent variable: exports $s_{p, t}$} \\
\hline & \multicolumn{2}{|c|}{ OLS } & \multicolumn{2}{|c|}{2 SLS } \\
\hline & lnexpplus1 & asinhexp & lnexpplus1 & asinhexp \\
\hline \multirow[t]{2}{*}{ treat $2000 \times$ after 2005} & 0.0852 & 0.0852 & 0.0926 & 0.0926 \\
\hline & $(0.039)^{* *}$ & $(0.039)^{* *}$ & $(0.052)^{*}$ & $(0.052)^{*}$ \\
\hline \multirow[t]{2}{*}{$\operatorname{lnfdi}$} & -0.0691 & -0.0692 & -0.0696 & -0.0696 \\
\hline & $(0.067)$ & $(0.067)$ & $(0.068)$ & $(0.068)$ \\
\hline $\mathrm{N}$ & 1428 & 1428 & 1428 & 1428 \\
\hline $\mathrm{r} 2$ & 0.01 & 0.01 & 0.01 & 0.01 \\
\hline KP F Stat & & & 1284.71 & 1284.71 \\
\hline
\end{tabular}

This table shows result of the 2SLS estimation for specification (1) using different monotonic transformations for exports,$t$ in each column, excluding observations for which there were zero exports in either period. The estimation uses years 1990 and 2005. All columns include product fixed effects and year fixed effects. Standard errors clustered at the product level presented in parenthesis.

${ }^{*} p<0.10,{ }^{* *} p<0.05,{ }^{* * *} p<0.01$ 


\section{H Excluding most common ports of entry from the calculation of the instrumental variable}

Table H1 presents results where the instrumental variable is computed excluding

Bavaria and Baden-Wurttemberg (quotas are re-normalized to account for their exclusion), which were the most common port of entry of Yugoslavian refugees.

[Table H1 about here.] 
Table H1: Difference-in-difference estimation, IV without Bavaria and BadenWurttemberg

\begin{tabular}{|c|c|c|c|c|c|c|}
\hline \multicolumn{7}{|c|}{ Dependent variable: export $_{p, t}$} \\
\hline & \multicolumn{3}{|c|}{ OLS } & \multicolumn{3}{|c|}{$2 \mathrm{SLS}$} \\
\hline & $\ln \exp$ & lnexpplus1 & asinhexp & $\ln \exp$ & lnexpplus1 & asinhexp \\
\hline \multirow[t]{2}{*}{ treat $2000 \times$ after 2005} & 0.0917 & 0.1433 & 0.1451 & 0.1099 & 0.2250 & 0.2300 \\
\hline & $(0.037)^{* *}$ & $(0.062)^{* *}$ & $(0.065)^{* *}$ & $(0.048)^{* *}$ & $(0.087)^{* * *}$ & $(0.090)^{* *}$ \\
\hline \multirow[t]{2}{*}{$\operatorname{lnfdi}$} & -0.1583 & -0.2702 & -0.2749 & -0.1596 & -0.2763 & -0.2813 \\
\hline & $(0.066)^{* *}$ & $(0.126)^{* *}$ & $(0.130)^{* *}$ & $(0.066)^{* *}$ & $(0.127)^{* *}$ & $(0.131)^{* *}$ \\
\hline $\mathrm{N}$ & 1496 & 1572 & 1572 & 1496 & 1572 & 1572 \\
\hline $\mathrm{r} 2$ & 0.86 & 0.82 & 0.81 & 0.86 & 0.82 & 0.81 \\
\hline KP F Stat & & & & 1645.92 & 1592.03 & 1592.03 \\
\hline
\end{tabular}

This table shows result of the estimation for specification (1) using an instrument that excludes the states of Bavaria and Baden-Wurttemberg from the calculation, using different monotonic transformations for exports $s_{p}, t$ in each column. All columns include product and year fixed effects. Standard errors clustered at the product level presented in parenthesis.

${ }^{*} p<0.10,{ }^{* *} p<0.05,{ }^{* * *} p<0.01$ 


\section{Excluding Slovenia and Macedonia from the sample}

Table I1 replicates the results of Table 4 excluding Slovenia from the sample. Slovenia was the first Yugoslavian republic to secede and did not suffer from a

long war nor a massive exile of its inhabitants to other locations. Our results are robust to its exclusion from the left hand side variable.

[Table I1 about here.]

Table I2 repeats the same exercise and excludes Macedonia. Following Slovenia and Croatia, Macedonia held a referendum and declared its independence in late 1991. Unlike others, Macedonia managed to obtain its independence without going through an armed conflict. This is why, no war refugees from Macedonia went to Germany. Our results are robust to its exclusion from the left hand side variable.

[Table I2 about here.] 
Table I1: Difference-in-difference estimation, excl. Slovenia

\begin{tabular}{|c|c|c|c|c|c|c|}
\hline \multicolumn{7}{|c|}{ Dependent variable: exports $s_{p, t}$} \\
\hline & \multicolumn{3}{|c|}{ OLS } & \multicolumn{3}{|c|}{$2 \mathrm{SLS}$} \\
\hline & $\operatorname{lnexp}$ & lnexpplus1 & asinhexp & $\operatorname{lnexp}$ & lnexpplus1 & asinhexp \\
\hline \multirow[t]{2}{*}{ treat $2000 \times$ after 2005} & 0.0889 & 0.1366 & 0.1383 & 0.0997 & 0.2002 & 0.2046 \\
\hline & $(0.037)^{* *}$ & $(0.062)^{* *}$ & $(0.064)^{* *}$ & $(0.048)^{* *}$ & $(0.084)^{* *}$ & $(0.088)^{* *}$ \\
\hline \multirow[t]{2}{*}{$\operatorname{lnfdi}$} & -0.2018 & -0.3465 & -0.3526 & -0.2020 & -0.3471 & -0.3532 \\
\hline & $(0.073)^{* * *}$ & $(0.146)^{* *}$ & $(0.151)^{* *}$ & $(0.073)^{* * *}$ & $(0.146)^{* *}$ & $(0.151)^{* *}$ \\
\hline $\mathrm{N}$ & 1496 & 1572 & 1572 & 1496 & 1572 & 1572 \\
\hline $\mathrm{r} 2$ & 0.86 & 0.82 & 0.81 & 0.86 & 0.82 & 0.81 \\
\hline KP F Stat & & & & 2020.84 & 2030.42 & 2030.42 \\
\hline
\end{tabular}

This table shows result of the estimation for specification (1) using different monotonic transformations for export $s_{p}, t$ in each column, excluding exports from Slovenia as one of the former Yugoslavian republics post 1992. The estimation uses years 1995 and 2005. All columns include product fixed effects and year fixed effects. Standard errors clustered at the product level presented in parenthesis.

${ }^{*} p<0.10,{ }^{* *} p<0.05,{ }^{* * *} p<0.01$ 
Table I2: Difference-in-difference estimation, excl. Macedonia

\begin{tabular}{|c|c|c|c|c|c|c|}
\hline \multicolumn{7}{|c|}{ Dependent variable: exports $s_{p, t}$} \\
\hline & \multicolumn{3}{|c|}{ OLS } & \multicolumn{3}{|c|}{2 SLS } \\
\hline & $\ln \exp$ & lnexpplus1 & asinhexp & $\ln \exp$ & lnexpplus1 & asinhexp \\
\hline \multirow[t]{2}{*}{ treat2000 $\times$ after 2005} & 0.0917 & 0.1433 & 0.1451 & 0.1119 & 0.2224 & 0.2272 \\
\hline & $(0.037)^{* *}$ & $(0.062)^{* *}$ & $(0.065)^{* *}$ & $(0.048)^{* *}$ & $(0.087)^{* *}$ & $(0.090)^{* *}$ \\
\hline \multirow[t]{2}{*}{$\operatorname{lnfdi}$} & -0.1583 & -0.2702 & -0.2749 & -0.1597 & -0.2761 & -0.2811 \\
\hline & $(0.066)^{* *}$ & $(0.126)^{* *}$ & $(0.130)^{* *}$ & $(0.066) * *$ & $(0.127)^{* *}$ & $(0.131)^{* *}$ \\
\hline $\mathrm{N}$ & 1496 & 1572 & 1572 & 1496 & 1572 & 1572 \\
\hline $\mathrm{r} 2$ & 0.86 & 0.82 & 0.81 & 0.86 & 0.82 & 0.81 \\
\hline KP F Stat & & & & 1796.53 & 1765.58 & 1765.58 \\
\hline
\end{tabular}

This table shows result of the estimation for specification (1) using different monotonic transformations for export $s_{p}, t$ in each column, excluding exports from Macedonia as one of the former Yugoslavian republics post 1992. The estimation uses years 1995 and 2005. All columns include product fixed effects and year fixed effects. Standard errors clustered at the product level presented in parenthesis.

${ }^{*} p<0.10,{ }^{* *} p<0.05,{ }^{* * *} p<0.01$ 


\section{J Occupations by characteristics}

Table J1 presents the list of all the occupations in the dataset, with their respective frequency, and associated characteristics.

[Table J1 about here.]

[Table J2 about here.] 
Table J1: Occupations List

\begin{tabular}{|c|c|c|c|c|}
\hline Occupation & $\mathbf{N}$ & Tasks & Prof. skills & Share supervisor \\
\hline 323 Metal workers (no further specification) & 968 & 2 manual & 1 unskilled & .21722362 \\
\hline 51 Gardeners, garden workers & 858 & 2 manual & 1 unskilled & .18927162 \\
\hline 531 Assistants (no further specification) & 787 & & 1 unskilled & .11138389 \\
\hline 522 Packagers, goods receivers, despatchers & 719 & 2 manual & 1 unskilled & .09713266 \\
\hline 151 Plastics processors & 698 & 2 manual & 1 unskilled & .27068706 \\
\hline 181 Wood preparers & 602 & 2 manual & 1 unskilled & .09192798 \\
\hline 391 Bakery goods makers & 555 & 2 manual & 2 skilled & .36883311 \\
\hline 744 Stores, transport workers & 543 & 2 manual & 1 unskilled & .10129447 \\
\hline 501 Carpenters & 498 & 2 manual & 2 skilled & .23684861 \\
\hline 62 Forest workers, forest cultivators & 483 & 2 manual & 1 unskilled & .20126734 \\
\hline 402 Meat, sausage goods makers & 442 & 2 manual & 1 unskilled & 0 \\
\hline 271 Building fitters & 396 & 2 manual & 2 skilled & .15821244 \\
\hline 470 Building labourer, general & 386 & & & \\
\hline 933 Household cleaners & 376 & 2 manual & 1 unskilled & .07903877 \\
\hline 322 Other assemblers & 312 & 2 manual & 1 unskilled & .04823485 \\
\hline 411 Cooks & 266 & 2 manual & 2 skilled & .28007612 \\
\hline 682 Salespersons & 263 & 1 analytic & 1 unskilled & .1624328 \\
\hline 101 Stone preparers & 257 & 2 manual & 1 unskilled & .23494546 \\
\hline 141 Chemical plant operatives & 257 & 1 analytic & 1 unskilled & .28136134 \\
\hline 321 Electrical appliance, electrical parts assemblers & 250 & 2 manual & 1 unskilled & .14907955 \\
\hline 275 Steel structure fitters, metal shipbuilders & 250 & 2 manual & 2 skilled & .19518355 \\
\hline 112 Shaped brick, concrete block makers & 244 & 2 manual & 1 unskilled & .22286043 \\
\hline 401 Butchers & 239 & 2 manual & 2 skilled & .29524547 \\
\hline 442 Concrete workers & 232 & 2 manual & 1 unskilled & .41252334 \\
\hline 163 Book binding occupations & 210 & 2 manual & 2 skilled & .13312343 \\
\hline 273 Engine fitters & 186 & 1 analytic & 2 skilled & .2418478 \\
\hline 521 Goods examiners, sorters, n.e.c. & 183 & 1 analytic & 1 unskilled & .17720443 \\
\hline 241 Welders, oxy-acetylene cutters & 173 & 2 manual & 1 unskilled & .16681339 \\
\hline 412 Ready-to-serve meals, fruit, vegetable preparers & 169 & 2 manual & 1 unskilled & 0 \\
\hline 714 Motor vehicle drivers & 168 & 2 manual & 1 unskilled & .07980934 \\
\hline 311 Electrical fitters, mechanics & 151 & 1 analytic & 2 skilled & .31535207 \\
\hline 741 Warehouse managers, warehousemen & 146 & 1 analytic & 1 unskilled & .36790809 \\
\hline 352 Clothing sewers & 141 & 2 manual & 1 unskilled & 0 \\
\hline 392 Confectioners (pastry) & 136 & 2 manual & 2 skilled & .23874688 \\
\hline 41 Land workers & 135 & 2 manual & 1 unskilled & .03541072 \\
\hline 431 Milk, fat processing operatives & 119 & 2 manual & 1 unskilled & .18633992 \\
\hline 211 Sheet metal pressers, drawers, stampers & 111 & 2 manual & 1 unskilled & 0 \\
\hline 270 Locksmiths, not specified & 108 & 2 manual & 2 skilled & .27546819 \\
\hline 433 Sugar, sweets, ice-cream makers & 107 & 2 manual & 1 unskilled & .55506282 \\
\hline 441 Bricklayers & 105 & 2 manual & 2 skilled & .39556132 \\
\hline 177 Printer's assistants & 102 & 2 manual & 1 unskilled & .19699555 \\
\hline 432 Flour, food processors & 98 & 2 manual & 1 unskilled & .27100673 \\
\hline 143 Rubber makers, processors & 95 & 2 manual & 1 unskilled & .24792283 \\
\hline 482 Insulators, proofers & 85 & 2 manual & 1 unskilled & .35678298 \\
\hline 221 Turners & 84 & 1 analytic & 2 skilled & .23881324 \\
\hline 512 Goods painters, lacquerers & 83 & 2 manual & 1 unskilled & .25905095 \\
\hline 164 Other paper products makers & 79 & 2 manual & 1 unskilled & 0 \\
\hline 261 Sheet metal workers & 79 & 2 manual & 2 skilled & .34136059 \\
\hline 451 Carpenters & 76 & 2 manual & 2 skilled & .32004301 \\
\hline
\end{tabular}

This table presents the first part of the list of all the occupations in the dataset, with their respective frequency and associated characteristics. 
Table J2: Occupations List (cont.)

\begin{tabular}{|c|c|c|c|c|}
\hline Occupation & $\mathbf{N}$ & Tasks & Prof. skills & Share supervisor \\
\hline 111 Stoneware, earthenware makers & 74 & & 1 unskilled & 0 \\
\hline 212 Wire moulders, processors & 72 & 2 manual & 1 unskilled & .3442623 \\
\hline 303 Dental technicians & 71 & 2 manual & 2 skilled & .19073161 \\
\hline 272 Sheet metal, plastics fitters & 68 & & 2 skilled & 0 \\
\hline 472 Other building labourers, building assistants, n.e.c. & 66 & 2 manual & 1 unskilled & .12660338 \\
\hline 742 Transportation equipment drivers & 66 & 2 manual & 1 unskilled & .0789034 \\
\hline 781 Office specialists & 66 & 1 analytic & 2 skilled & .26168916 \\
\hline 162 Packaging makers & 60 & 2 manual & 1 unskilled & .04646367 \\
\hline 135 Glass processors, glass finishers & 60 & 2 manual & 1 unskilled & .14649977 \\
\hline 121 Ceramics workers & 59 & 2 manual & 1 unskilled & .05361638 \\
\hline 274 Plant fitters, maintenance fitters & 57 & 2 manual & 2 skilled & .23151613 \\
\hline 161 Paper, cellulose makers & 54 & 2 manual & 1 unskilled & .49392581 \\
\hline 71 Miners & 53 & 2 manual & 1 unskilled & .1553002 \\
\hline 251 Steel smiths & 50 & 2 manual & 2 skilled & .04485785 \\
\hline 263 Pipe, tubing fitters & 49 & 2 manual & 1 unskilled & .3949083 \\
\hline 262 Plumbers & 49 & 2 manual & 2 skilled & .26210474 \\
\hline 356 Sewers, n.e.c. & 48 & 2 manual & 1 unskilled & .04908014 \\
\hline 492 Upholsterers, mattress makers & 48 & 2 manual & 2 skilled & .12503124 \\
\hline 923 Other housekeeping attendants & 47 & 2 manual & 1 unskilled & .08383468 \\
\hline 376 Leather clothing makers & 45 & 2 manual & 1 unskilled & \\
\hline 373 Footwear makers & 44 & 2 manual & 1 unskilled & 0 \\
\hline 937 Machinery, container cleaners and related occupations & 44 & 2 manual & 1 unskilled & .05061111 \\
\hline 81 Stone crushers & 43 & & 1 unskilled & 0 \\
\hline 313 Electric motor, transformer fitters & 39 & 1 analytic & 1 unskilled & .13471446 \\
\hline 485 Glaziers & 39 & 2 manual & 2 skilled & .1977815 \\
\hline 403 Fish processing operatives & 36 & 2 manual & 1 unskilled & .5 \\
\hline 371 Leather makers, catgut string makers & 35 & 2 manual & 1 unskilled & 0 \\
\hline 225 Metal grinders & 35 & 2 manual & 1 unskilled & .28720212 \\
\hline 284 Precision mechanics & 35 & 1 analytic & 2 skilled & .16234579 \\
\hline 285 Other mechanics & 34 & 2 manual & 2 skilled & .2512635 \\
\hline 462 Road makers & 33 & 2 manual & 1 unskilled & .26799082 \\
\hline 291 Toolmakers & 32 & 2 manual & 2 skilled & .21778998 \\
\hline 224 Borers & 31 & 2 manual & 1 unskilled & 0 \\
\hline 931 Laundry workers, pressers & 31 & 2 manual & 1 unskilled & .1339676 \\
\hline 222 Drillers & 30 & 1 analytic & 1 unskilled & .15145272 \\
\hline 82 Earth, gravel, sand quarriers & 29 & & 1 unskilled & \\
\hline 282 Agricultural machinery repairers & 29 & 2 manual & 2 skilled & .30161076 \\
\hline 466 Other civil engineering workers & 28 & 2 manual & 1 unskilled & .42729718 \\
\hline 314 Electrical appliance fitters & 28 & 1 analytic & 2 skilled & .26680461 \\
\hline 44 Animal keepers and related occupations & 25 & 2 manual & 1 unskilled & .35544285 \\
\hline 281 Motor vehicle repairers & 25 & 1 analytic & 2 skilled & .34470057 \\
\hline 234 Galvanisers, metal colourers & 24 & 2 manual & 1 unskilled & .14969613 \\
\hline 213 Other metal moulders (non-cutting deformation) & 24 & 2 manual & 1 unskilled & 0 \\
\hline 203 Semi-finished product fettlers occupations & 24 & 2 manual & 1 unskilled & .1735251 \\
\hline 331 Spinners, fibre preparers & 24 & 2 manual & 2 skilled & .48452174 \\
\hline 935 Street cleaners, refuse disposers & 22 & 2 manual & 1 unskilled & .30638207 \\
\hline 342 Weavers & 21 & 2 manual & 1 unskilled & 0 \\
\hline 353 Laundry cutters, sewers & 21 & 2 manual & 1 unskilled & 0 \\
\hline 344 Machined goods makers & 21 & 2 manual & 1 unskilled & 0 \\
\hline 423 Other beverage makers, tasters & 20 & 2 manual & 2 skilled & 64293598 \\
\hline 784 Office auxiliary workers & 20 & 1 analytic & 1 unskilled & .09301868 \\
\hline
\end{tabular}

This table presents the second part of the list of all the occupations in the dataset, with their respective frequency and associated characteristics. 


\section{K Estimations using treatments by educational attainment and occupations characteristics}

Table 10 in the main body of the paper summarized the results exploiting heterogeneity of the treatment in terms of the skills and occupation characteristics of the workers. Tables K1 to K6 below present results for each estimation separately.

[Table K1 about here.]

[Table K2 about here.]

[Table K3 about here.]

[Table K4 about here.]

[Table K5 about here.]

[Table K6 about here.] 


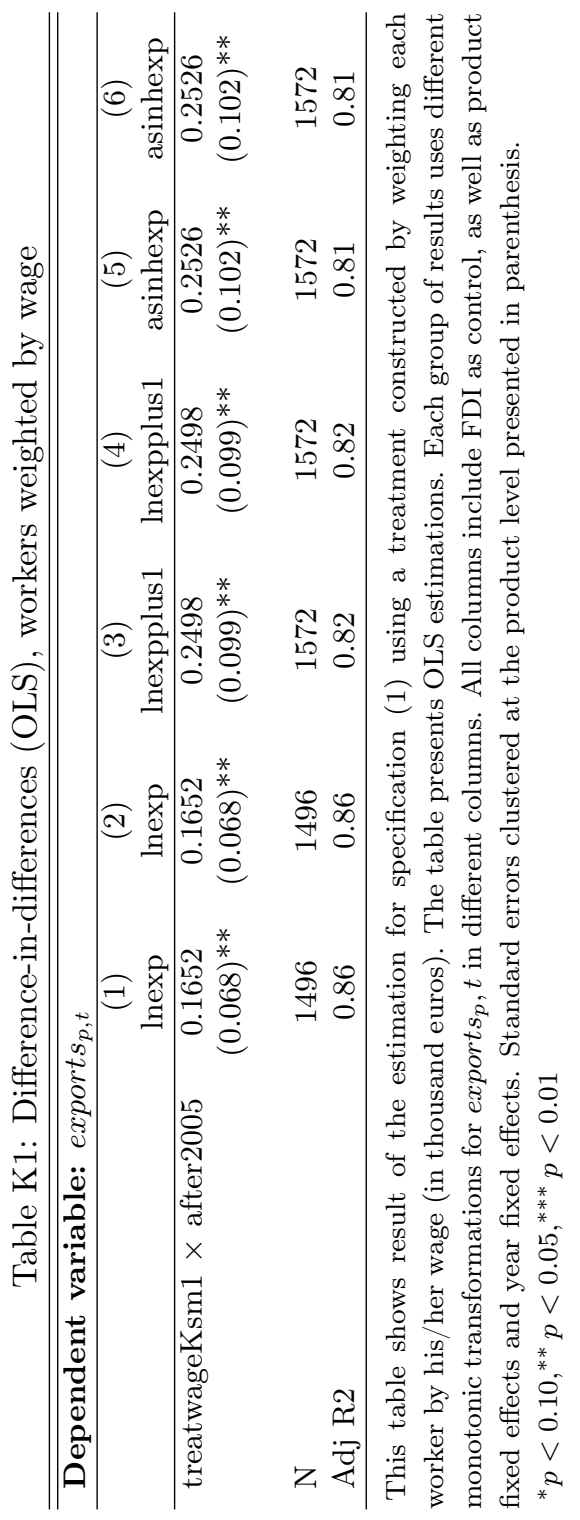




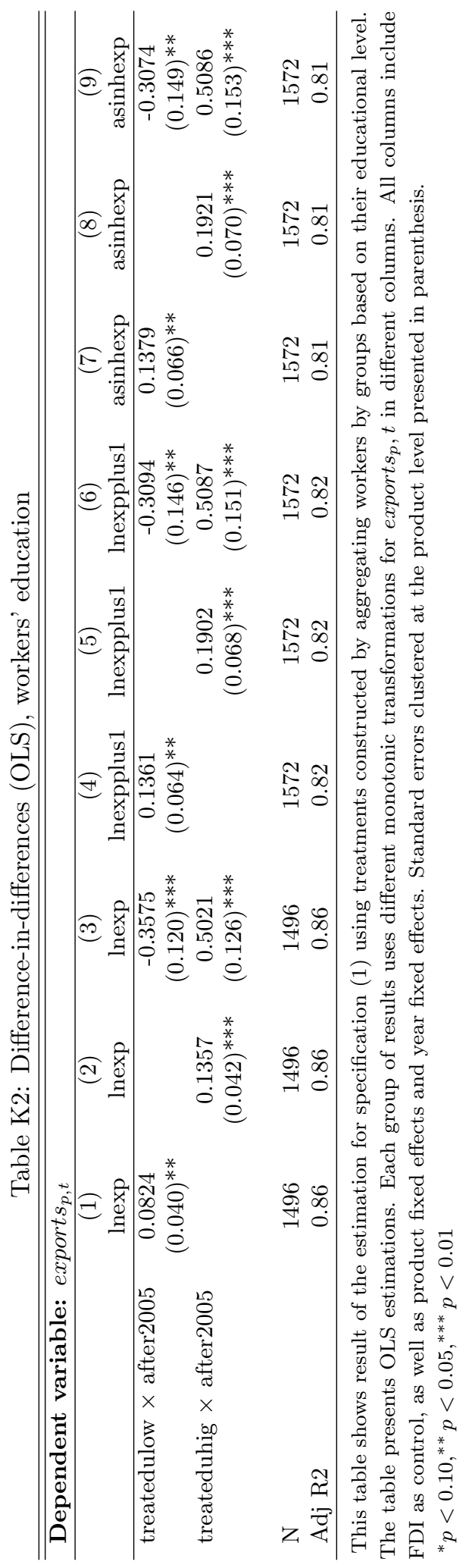




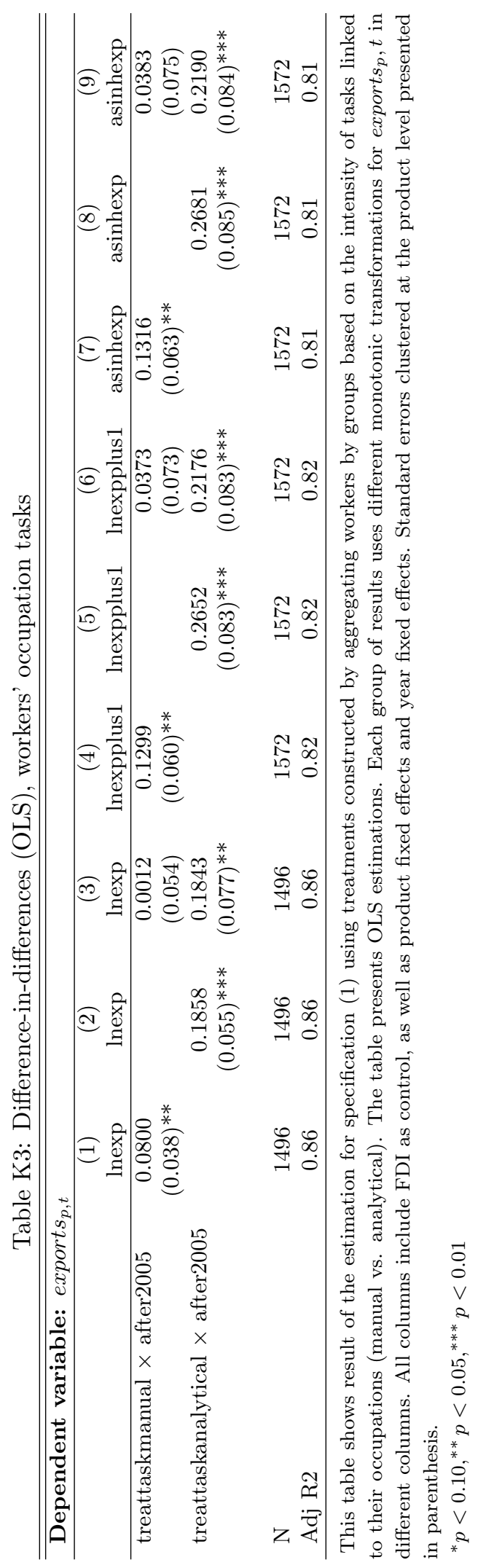




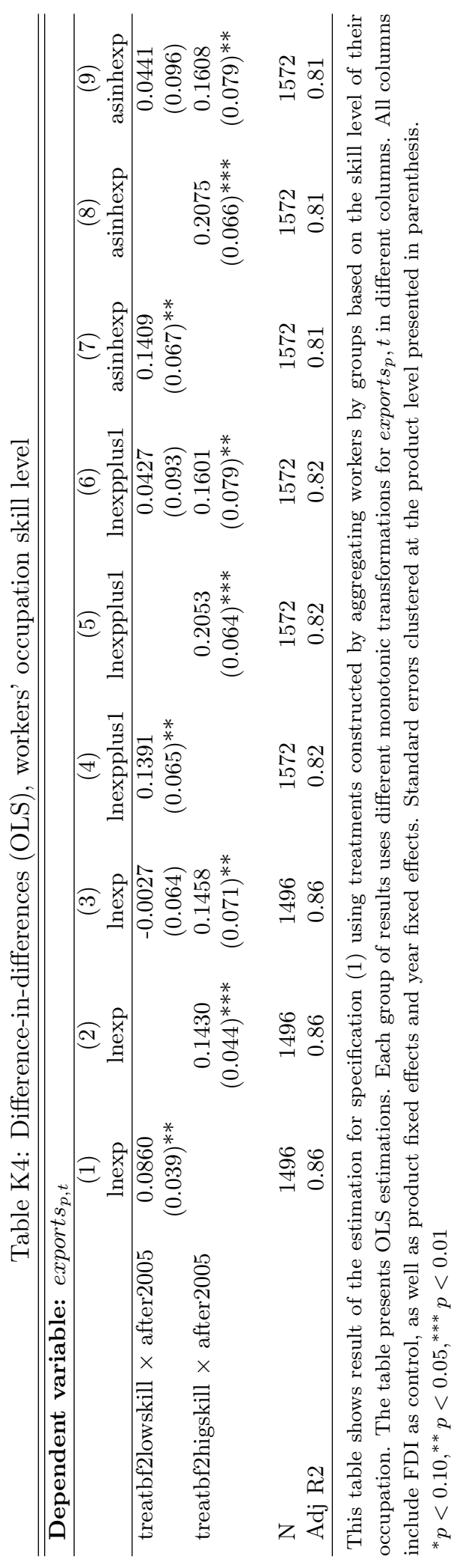




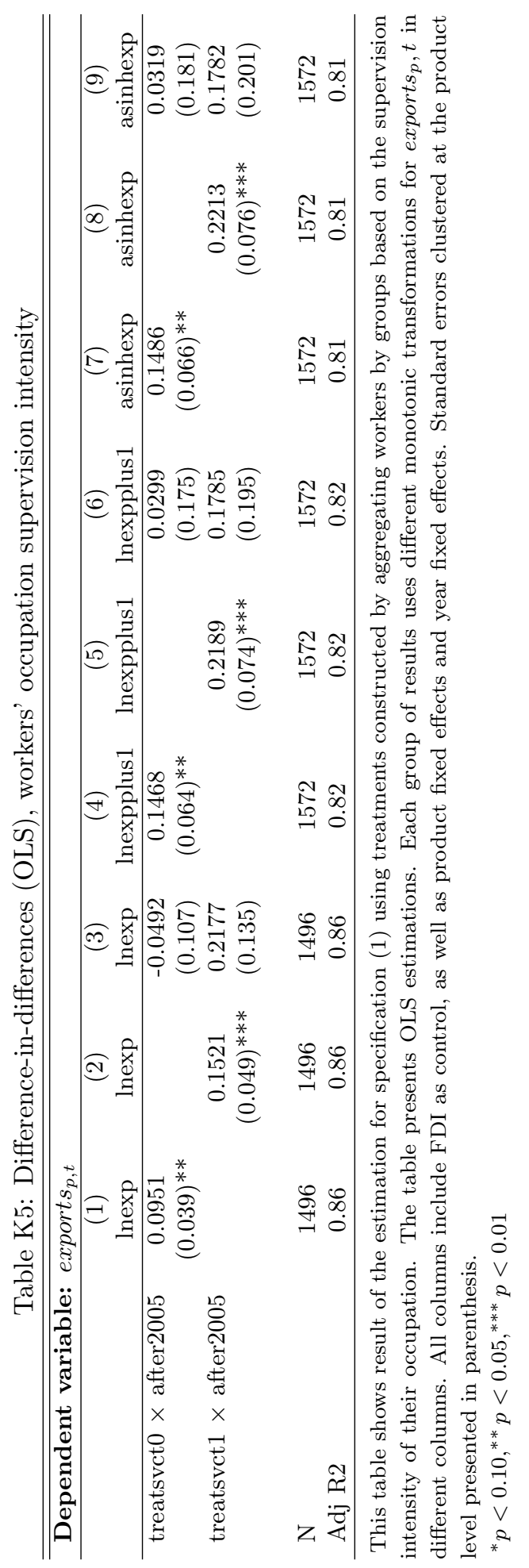




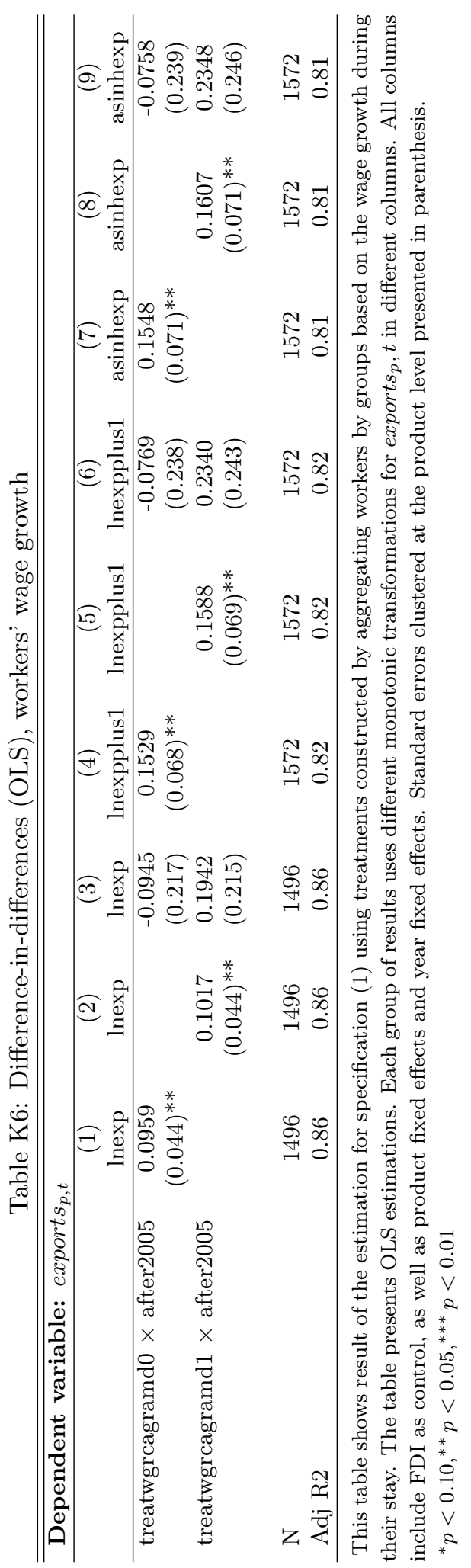




\section{Expanding to all countries: external validation}

After having established the link between migration and comparative advantage, we turn to study the same phenomenon in a multi-country and multi-period setting. In this setting our focus is not on the identification, but rather on externally validating the results, while exploiting a much larger variation allowing us to study differential effects based on the characteristics of the migrants. That is, we expand our difference-in-difference strategy to all countries in the original dataset using as treatment the presence and sizes of their diasporas in Germany working in different 4-digit products.

Our prior for this exercise is that if knowledge diffusion is the mechanisms through which migration explains productivity shifts seen as changes in the comparative advantage of nations, this effect should be stronger among migrants that are skilled and/or work in occupations that are more cognitive and analytical in nature. This is what we explore in this section.

\section{L.1 Empirical strategy and summary statistics}

In this section we adapt our difference-in-difference specification to a multicountry multi-period setting. To do that, we follow Besley and Burgess (2004) and estimate the following specification: ${ }^{50}$

\footnotetext{
${ }^{50}$ Both specifications are equivalent. To see it, suppose the following two specifications, the first one where the treatment is defined as a difference and the second one where the treatment is defined as a level:

$$
\begin{aligned}
& y_{p, t}=\beta_{1} \Delta \text { migrants }_{p} \times \text { after }_{t}+\delta_{t}+\eta_{p}+\varepsilon_{p, t} \\
& y_{p, t}=\beta_{2} \text { migrants }_{p, t}+\delta_{t}+\eta_{p}+\varepsilon_{p, t}
\end{aligned}
$$

Assume there are only two periods, $t=[0,1]$. According to the first functional form, we have:$$
E\left(y_{p, t} \mid t=1\right)=\beta_{1} \Delta \text { migrants }_{p}+\delta_{1}+\eta_{p}+\varepsilon_{p, 1}
$$$$
E\left(y_{p, t} \mid t=0\right)=\delta_{0}+\eta_{p}+\varepsilon_{p, 0}
$$

It is clear that $E\left(y_{p, t} \mid t=1\right)-E\left(y_{p, t} \mid t=0\right)=\beta_{1} \Delta$ migrants $_{p}+\left(\delta_{1}-\delta_{0}\right)+\left(\varepsilon_{p, 1}-\varepsilon_{p, 0}\right)$. According to the second functional form, we have:
} 
exports $_{c, p, t}=\beta^{D I D}$ migrants $_{c, p, t-10}+\beta^{g e}$ globalexports $_{p, t}+\eta_{c, p}+\alpha_{c, t}+\varepsilon_{c, p, t}$

Our dependent variable, exports $s_{c, p, t}$, is defined as total export value of product $p$ during year $t$ from country $c$ to the rest of the world, excluding Germany in order to rule out that our results are driven by lower costs to export due to migrant networks. Similarly to the previous section, we present our results for different monotonic transformations of the dependent variable. Our variable of interest, the treatment, in this case is migrants $_{c, p, t-10}$, which is the stock of migrants from country $c$ at time $t-10$ (e.g., we allow for a 10-year lag for the treatment to "kick in") working in product $p$ in the German labor force. We also include a series of fixed effects, crucial for the estimation. Since we have expanded the dimension of our dataset to include countries our unit of analysis becomes now a country-product pair. Thus, we include $\eta_{c, p}$ which is a countryby-product fixed effects, to allow each country-product to have a different intercept and also, in the difference-in-difference setting, allows us to exploit within country-product variation. We also include $\alpha_{c, t}$, a country-by-year fixed effect, which controls for changes at the country level that could explain changes in exports: income, population, institutions, etc. We also include globalexport $_{p, t}$, which in measures the total export value of product $p$ by all countries during year $t$, to control for total global demand, and as a proxy for the introduction of a technology that explains a global increase in the exports of product $p .^{51}$

$$
\begin{aligned}
& E\left(y_{p, t} \mid t=1\right)=\beta_{2} \text { migrants }_{p, 1}+\delta_{1}+\eta_{p}+\varepsilon_{p, 1} \\
& E\left(y_{p, t} \mid t=0\right)=\beta_{2} \text { migrant }_{p, 0}+\delta_{0}+\eta_{p}+\varepsilon_{p, 0}
\end{aligned}
$$

Thus, in this case, $E\left(y_{p, t} \mid t=1\right)-E\left(y_{p, t} \mid t=0\right)=\beta_{2}$ (migrants $_{p, 1}-$ migrants $\left._{p, 0}\right)+\left(\delta_{1}-\right.$ $\left.\delta_{0}\right)+\left(\varepsilon_{p, 1}-\varepsilon_{p, 0}\right)$. Since $\Delta$ migrants $_{p}=$ migrant $_{p, 1}-$ migrant $_{p, 0}$ it follows that $\beta_{1}=\beta_{2}$.

${ }^{51}$ Ideally, we would introduce a product-by-year fixed effect but turns out doing so eliminates most of the remaining variation. 
All of the continuous right hand side variables are monotonically transformed using the inverse hyperbolic sine. Our estimations cluster standard errors at the country-product level (Besley and Burgess, 2004; Bertrand et al., 2004).

As mentioned earlier, the sample for this estimation includes 124 countries and 786 products across two periods: 1990 to 2000 and 2000 to 2010 . The IAB data allows us to compute the migrant stock by different categories, and we exploit that variation in this setting. Table L1 summarizes the statistics for the main variables used in this analysis. The first three rows summarize the export value averaged across countries, products and years 2000 and 2010, using three different monotonic transformations; note that the number of observations using a simple logarithmic transformation is reduced due to zeros in the sample.

\section{[Table L1 about here.]}

Table L1 shows that the average number of migrant workers in Germany across all countries and 4-digit products for both 1990 and 2000 (e.g., the baseline years) is 8 . The number is surprisingly small, but note that this variable has many zeros (in fact, the median value is zero), and there is a mix of countries from many different sizes. This last fact is reflected in both the large standard deviation and upper bound of the variable which reaches a maximum of over 20 thousand workers.

We start by estimating Specification (L1) using all workers, without distinction, as the independent variable. The results are presented in Table L2. The elasticity parameter is estimated to be between 0.08 and 0.11 , which falls into the lower range of the the results of Section 4. In this case, the point estimate when the dependent variable is a simple logarithmic transformation is lower than in the other columns where the monotonic transformation does include the zeros. This suggests, also consistently with the results from Section 4, that return migration (this time computed as the difference in the stock) is also 
explanatory of the extensive margin (e.g., the emergence of new export sectors).

[Table L2 about here.] 
Table L1: Summary statistics, all sample

\begin{tabular}{lccccc}
\hline \hline Variable & $\mathbf{N}$ & Mean & sd & Min & Max \\
\hline Exports (log) & 136,684 & 14.029 & 3.44 & 6.9 & 25.8 \\
Exports (log +1) & 179,208 & 10.700 & 6.68 & 0.0 & 25.8 \\
Exports (asinh) & 179,208 & 11.229 & 6.95 & 0.0 & 26.5 \\
All Migrants & 179,208 & 8.047 & 127.48 & 0.0 & $22,803.5$ \\
Skilled & 179,208 & 3.769 & 63.15 & 0.0 & $12,501.7$ \\
Unskilled & 179,208 & 4.001 & 67.83 & 0.0 & $11,614.6$ \\
White collars & 179,208 & 0.636 & 7.24 & 0.0 & 798.1 \\
Non-white collars & 179,208 & 7.093 & 121.60 & 0.0 & $22,497.6$ \\
Analytical \& Cognitive tasks & 179,208 & 1.913 & 26.45 & 0.0 & $3,816.8$ \\
Manual tasks & 179,208 & 5.531 & 92.33 & 0.0 & $15,918.0$ \\
High prob solving & 179,208 & 1.480 & 21.36 & 0.0 & $4,193.2$ \\
Low prob solving & 179,208 & 6.273 & 107.56 & 0.0 & $19,721.0$ \\
\hline
\end{tabular}

This table presents the sample summary statistics for the variables used to estimate specification (1). 
Table L2: Difference-in-difference estimation, all sample

\begin{tabular}{|c|c|c|c|}
\hline \multicolumn{4}{|c|}{ Dependent variable: exports $_{p, t}$} \\
\hline & (1) & $(2)$ & $(3)$ \\
\hline & $\ln \exp$ & lnexpplus1 & asinhexp \\
\hline \multirow[t]{2}{*}{ L10.AllMigrants } & 0.0846 & 0.1252 & 0.1232 \\
\hline & $(0.015)^{* * *}$ & $(0.030)^{* * *}$ & $(0.032)^{* * *}$ \\
\hline \multirow[t]{2}{*}{ lntotalexp } & 0.8935 & 0.4403 & 0.4595 \\
\hline & $(0.016)^{* * *}$ & $(0.011)^{* * *}$ & $(0.012)^{* * *}$ \\
\hline $\mathrm{N}$ & 114288 & 165060 & 165060 \\
\hline Adj R2 & 0.94 & 0.91 & 0.90 \\
\hline $\mathrm{cpFE}$ & $\mathrm{Y}$ & Y & Y \\
\hline
\end{tabular}

This table shows result of the estimation for specification (1) using different monotonic transformations for exports $s_{p}, t$ in each column. The estimation uses years 2000 and 2010 for exports and 1990 and 2000 for migration. All columns include country-byproduct fixed effects and country-by-year fixed effects. Standard errors clustered at the country-product level presented in parenthesis.

${ }^{*} p<0.10,{ }^{* *} p<0.05,{ }^{* * *} p<0.01$ 